\title{
Intravenous magnesium sulfate for treating adults with acute asthma in the emergency department (Review)
}

Kew KM, Kirtchuk L, Michell CI

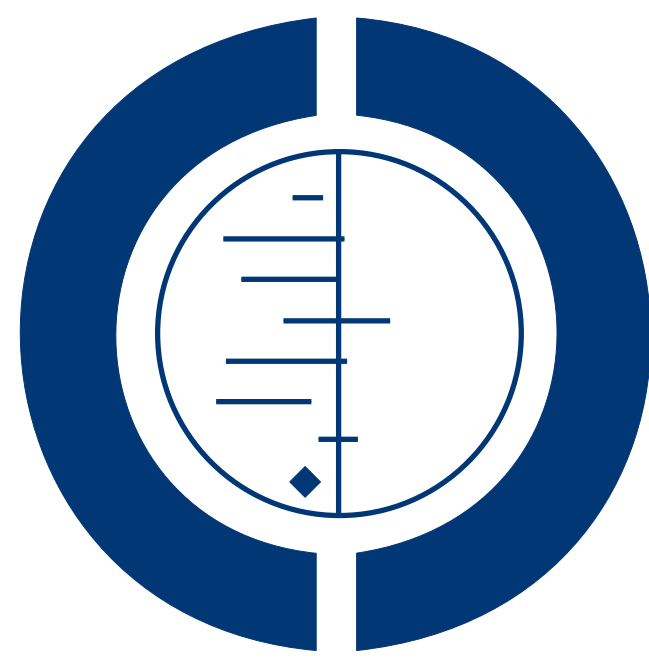

THE COCHRANE COLLABORATION $^{\circledR}$

This is a reprint of a Cochrane review, prepared and maintained by The Cochrane Collaboration and published in The Cochrane Library 2014, Issue 5

http://www.thecochranelibrary.com

\section{WILEY}

Intravenous magnesium sulfate for treating adults with acute asthma in the emergency department (Review)

Copyright $\odot 2014$ The Cochrane Collaboration. Published by John Wiley \& Sons, Ltd. 
TABLE OF CONTENTS

HEADER

ABSTRACT . . . . . . . . . . . . . . . . . . . . . . . . . . . . . . . . . . . . . . .

PLAIN LANGUAGE SUMMARY . . . . . . . . . . . . . . . . . . . . . . . . . . . . . . . . .

SUMMARY OF FINDINGS FOR THE MAIN COMPARISON . . . . . . . . . . . . . . . . . . . . . . . 4

BACKGROUND . . . . . . . . . . . . . . . . . . . . . . . . . . . . . . . . . . . . . . . . 7

OBJECTIVES . . . . . . . . . . . . . . . . . . . . . . . . . . . . . . . . . . . . . . . . . . . . . .

METHODS . . . . . . . . . . . . . . . . . . . . . . . . . . . . . . . . . . . . . . 7

RESULTS . . . . . . . . . . . . . . . . . . . . . . . . . . . . . . . . . . . 10

Figure 1. . . . . . . . . . . . . . . . . . . . . . . . . . . . . . . . . . . . . . 11

Figure 2. . . . . . . . . . . . . . . . . . . . . . . . . . . . . . . . . . . . . 15

Figure 3. . . . . . . . . . . . . . . . . . . . . . . . . . . . . . . . . . . . . . 18

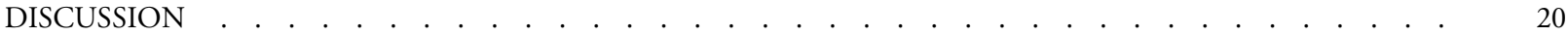

AUTHORS' CONCLUSIONS . . . . . . . . . . . . . . . . . . . . . . . . . . . . . . . . . . . . . .

ACKNOWLEDGEMENTS . . . . . . . . . . . . . . . . . . . . . . . . . . . . . . . . . . . . . . .

REFERENCES . . . . . . . . . . . . . . . . . . . . . . . . . . . . . . . . . . . . . . 24

CHARACTERISTICS OF STUDIES . . . . . . . . . . . . . . . . . . . . . . . . . . . . . . 26

DATA AND ANALYSES . . . . . . . . . . . . . . . . . . . . . . . . . . . . . . . . . . . . . . . . . . . . . . 46

Analysis 1.1. Comparison $1 \mathrm{IV}$ MgSO4 versus placebo, Outcome 1 Hospital admissions. . . . . . . . . . . . . . . . 47

Analysis 1.2. Comparison 1 IV MgSO4 versus placebo, Outcome 2 Intensive care unit (ICU) admissions. . . . . . $\quad$. 48

Analysis 1.3. Comparison 1 IV MgSO4 versus placebo, Outcome 3 High dependency unit (HDU) admissions. . . . 48

Analysis 1.4. Comparison 1 IV MgSO4 versus placebo, Outcome 4 ED treatment duration (minutes). . . . . . . 49

Analysis 1.5. Comparison 1 IV MgSO4 versus placebo, Outcome 5 Length of hospital stay (days). . . . . . . . . 49

Analysis 1.6. Comparison 1 IV MgSO4 versus placebo, Outcome 6 Readmission. . . . . . . . . . . . . . . . . 50

Analysis 1.7. Comparison 1 IV MgSO4 versus placebo, Outcome 7 Heart rate (bpm). . . . . . . . . . . . . . . . . 51

Analysis 1.8. Comparison 1 IV MgSO4 versus placebo, Outcome 8 Respiratory rate (breaths $/ \mathrm{min}) . \quad$. . . . . . . $\quad 52$

Analysis 1.9. Comparison 1 IV MgSO4 versus placebo, Outcome 9 Systolic blood pressure (mmHg). . . . . . . . 53

Analysis 1.10. Comparison 1 IV MgSO4 versus placebo, Outcome 10 FEV1 (\% predicted). . . . . . . . . . . . 54

Analysis 1.11. Comparison 1 IV MgSO4 versus placebo, Outcome 11 PEF (\% predicted). . . . . . . . . . . . . $\quad 55$

Analysis 1.12. Comparison 1 IV MgSO4 versus placebo, Outcome 12 PEF (L/min). . . . . . . . . . . . . . . 56

Analysis 1.13. Comparison 1 IV MgSO4 versus placebo, Outcome 13 Borg Dyspnoea Scale score. . . . . . . . . 57

Analysis 2.1. Comparison 2 IV MgSO4 versus placebo (subgroup and sensitivity analyses), Outcome 1 Hospital admissions

(by severity). . . . . . . . . . . . . . . . . . . . . . . . . . . . . . . . . . . . 58

Analysis 2.2. Comparison 2 IV MgSO4 versus placebo (subgroup and sensitivity analyses), Outcome 2 Hospital admissions (by co-medications).

Analysis 2.3. Comparison 2 IV MgSO4 versus placebo (subgroup and sensitivity analyses), Outcome 3 Hospital admissions (risk of bias sensitivity).

Analysis 2.4. Comparison 2 IV MgSO4 versus placebo (subgroup and sensitivity analyses), Outcome 4 Hospital admissions (unpublished sensitivity).

Analysis 2.5. Comparison 2 IV MgSO4 versus placebo (subgroup and sensitivity analyses), Outcome 5 PEF \% predicted (Goodacre change score sensitivity).

Analysis 2.6. Comparison $2 \mathrm{IV} \mathrm{MgSO} 4$ versus placebo (subgroup and sensitivity analyses), Outcome $6 \mathrm{PEF} \mathrm{L} / \mathrm{min}$ (Goodacre change score sensitivity).

ADDITIONAL TABLES .

CONTRIBUTIONS OF AUTHORS

$\cdot \cdot \cdot \cdot \cdot \cdot \cdot \cdot \cdot \cdot \cdot \cdot \cdot \cdot \cdot \cdot \cdot \cdot \cdot$

DIFFERENCES BETWEEN PROTOCOLAND REVIEW

Intravenous magnesium sulfate for treating adults with acute asthma in the emergency department (Review)

Copyright @ 2014 The Cochrane Collaboration. Published by John Wiley \& Sons, Ltd. 


\title{
[Intervention Review] \\ Intravenous magnesium sulfate for treating adults with acute asthma in the emergency department
}

\author{
Kayleigh M Kew ${ }^{1}$, Liza Kirtchuk ${ }^{1}$, Clare I Michell ${ }^{1}$ \\ ${ }^{1}$ Population Health Research Institute, St George's, University of London, London, UK \\ Contact address: Kayleigh M Kew, Population Health Research Institute, St George's, University of London, Cranmer Terrace, London, \\ SW17 0RE, UK. kkew@sgul.ac.uk.
}

Editorial group: Cochrane Airways Group.

Publication status and date: New, published in Issue 5, 2014.

Review content assessed as up-to-date: 2 May 2014.

Citation: Kew KM, Kirtchuk L, Michell CI. Intravenous magnesium sulfate for treating adults with acute asthma in the emergency department. Cochrane Database of Systematic Reviews 2014, Issue 5. Art. No.: CD010909. DOI: 10.1002/14651858.CD010909.pub2.

Copyright (C) 2014 The Cochrane Collaboration. Published by John Wiley \& Sons, Ltd.

\begin{abstract}
A B S T R A C T
Background

Asthma is a chronic respiratory condition characterised by airways inflammation, constriction of airway smooth muscle and structural alteration of the airways that is at least partially reversible. Exacerbations of asthma can be life threatening and place a significant burden on healthcare services. Various guidelines have been published to inform management personnel in the acute setting; several include the use of a single bolus of intravenous magnesium sulfate ( $\mathrm{IV} \mathrm{MgSO}_{4}$ ) in cases that do not respond to first-line treatment. However, the effectiveness of this approach remains unclear, particularly in less severe cases.
\end{abstract}

Objectives

To assess the safety and efficacy of $\mathrm{IV} \mathrm{MgSO}_{4}$ in adults treated for acute asthma in the emergency department.

\section{Search methods}

We identified trials from the Cochrane Airways Review Group Specialised Register (CAGR) up to 2 May 2014. We also searched www.ClinicalTrials.gov and reference lists of other reviews, and we contacted trial authors to ask for additional information.

\section{Selection criteria}

We included randomised controlled trials (RCTs) of adults treated in the emergency department (ED) for exacerbations of asthma if they compared any dose of $\mathrm{IV} \mathrm{MgSO}_{4}$ with placebo.

\section{Data collection and analysis}

All review authors screened titles and abstracts for inclusion, and at least two review authors independently extracted study characteristics, risk of bias and numerical data. Disagreements were resolved by consensus, and we contacted trial investigators to obtain missing information.

We analysed dichotomous data as odds ratios using study participants as the unit of analysis, and we analysed continuous data as mean differences or standardised mean differences using fixed-effect models. We rated all outcomes using GRADE and presented results in Summary of findings table 1.

We carried out subgroup analyses on the primary outcome for baseline severity of exacerbations and whether or not ipratropium bromide was given as a co-medication. Unpublished data and studies at high risk of bias for blinding were removed from the main analysis in sensitivity analyses.

Intravenous magnesium sulfate for treating adults with acute asthma in the emergency department (Review)

Copyright $\odot 2014$ The Cochrane Collaboration. Published by John Wiley \& Sons, Ltd. 


\section{Main results}

Fourteen studies met the inclusion criteria, randomly assigning 2313 people with acute asthma to the comparisons of interest in this review.

Most studies were double-blinded trials comparing a single infusion of $1.2 \mathrm{~g}$ or $2 \mathrm{~g} \mathrm{IV} \mathrm{MgSO} 4$ over 15 to 30 minutes versus a matching placebo. Eleven were conducted at a single centre, and three were multi-centre trials. Participants in almost all of the studies had already been given at least oxygen, nebulised short-acting beta 2 -agonists and IV corticosteroids in the ED; in some studies, investigators also administered ipratropium bromide. Ten studies included only adults, and four included both adults and children; these were included because the mean age of participants was over 18 years.

Intravenous $\mathrm{MgSO}_{4}$ reduced hospital admissions compared with placebo (odds ratio (OR) 0.75 , $95 \%$ confidence interval (CI) 0.60 to $0.92 ; \mathrm{I}^{2}=28 \%$, P value $0.18 ; \mathrm{n}=972$; high-quality evidence). In absolute terms, this odds ratio translates into a reduction of seven hospital admissions for every 100 adults treated with $\mathrm{IV} \mathrm{MgSO}_{4}(95 \% \mathrm{CI}$ two to 13 fewer). The test for subgroup differences revealed no statistical heterogeneity between the three severity subgroups $\left(\mathrm{I}^{2}=0 \%, \mathrm{P}\right.$ value 0.73$)$ or between the four studies that administered nebulised ipratropium bromide as a co-medication and those that did not $\left(\mathrm{I}^{2}=0 \%\right.$, P value 0.82$)$. Sensitivity analyses in which unpublished data and studies at high risk for blinding were removed from the primary analysis did not change conclusions.

Within the secondary outcomes, high- and moderate-quality evidence across three spirometric indices suggests some improvement in lung function with $\mathrm{IV} \mathrm{MgSO}_{4}$. No difference was found between IV $\mathrm{MgSO}_{4}$ and placebo for most of the non-spirometric secondary outcomes, all of which were rated as low or moderate quality (intensive care admissions, ED treatment duration, length of hospital stay, readmission, respiration rate, systolic blood pressure).

Adverse events were inconsistently reported and were not meta-analysed. The most commonly cited adverse events in the IV $\mathrm{MgSO}_{4}$ groups were flushing, fatigue, nausea and headache and hypotension (low blood pressure).

\section{Authors' conclusions}

This review provides evidence that a single infusion of $1.2 \mathrm{~g}$ or $2 \mathrm{~g} \mathrm{IV} \mathrm{MgSO} 4$ over 15 to 30 minutes reduces hospital admissions and improves lung function in adults with acute asthma who have not responded sufficiently to oxygen, nebulised short-acting beta 2 agonists and IV corticosteroids. Differences in the ways the trials were conducted made it difficult for the review authors to assess whether severity of the exacerbation or additional co-medications altered the treatment effect of $\mathrm{IV} \mathrm{MgSO}_{4}$. Limited evidence was found for other measures of benefit and safety.

Studies conducted in these populations should clearly define baseline severity parameters and systematically record adverse events. Studies recruiting participants with exacerbations of varying severity should consider subgrouping results on the basis of accepted severity classifications.

\section{PLAIN LANGUAGE SUMMARY}

\section{Do magnesium sulfate infusions reduce the need for hospital admission in adults with acute asthma?}

\section{Why is this question important?}

Asthma is a long-term condition that causes coughing, wheezing, shortness of breath and chest tightness. When symptoms significantly worsen, often referred to as an attack or 'exacerbation,' this can be life threatening. Management of exacerbations in the emergency department (ED) varies, and some guidelines recommend the use of intravenous magnesium sulfate ( $\mathrm{IV} \mathrm{MgSO}_{4}$ ) when other treatments

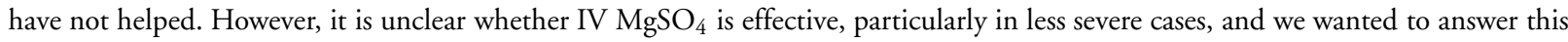
question.

\section{How did we answer the question?}

We looked for trials that compared IV $\mathrm{MgSO}_{4}$ versus placebo in adults attending the ED with an asthma exacerbation. The most recent searches were done on 2 May 2014. We were interested primarily in whether $\mathrm{IV} \mathrm{MgSO}_{4}$ reduced the number of people needing to be admitted to hospital, and we looked at several other measures as well, including time spent in the ED, lung function and symptom scores.

\section{What did we find?}

Intravenous magnesium sulfate for treating adults with acute asthma in the emergency department (Review)

Copyright $\odot 2014$ The Cochrane Collaboration. Published by John Wiley \& Sons, Ltd. 
Fourteen studies met the inclusion criteria, involving a total of 2313 people. These studies varied in terms of how bad exacerbations had to be for people to be included and in terms of what other treatments were provided before $\mathrm{IV} \mathrm{MgSO}_{4}$ was given, but almost all trials gave participants at least oxygen, nebulised short-acting medications and steroid tablets or injection.

Overall, IV $\mathrm{MgSO}_{4}$ reduced the need for hospital admission compared with placebo (seven fewer per 100 treated; $95 \%$ confidence interval two to 13 fewer). Not enough information was available to show whether the reduction in hospital admissions was associated with severity of the asthma exacerbation, or whether it made a difference what other treatments were given. Evidence suggests that IV $\mathrm{MgSO}_{4}$ improved some lung function parameters, but for other measures such as heart rate, variation among study findings reduced our confidence in the results. We did not find a difference between $\mathrm{IV} \mathrm{MgSO}_{4}$ and placebo in most other measures (including time spent in the ED, respiratory rate and blood pressure), and adverse events generally were poorly reported.

\section{Conclusion}

This review showed that $\mathrm{IV} \mathrm{MgSO}_{4}$ reduces hospital admissions and improves lung function in adults with exacerbations of asthma when other first-line medications have not relieved the acute symptoms (i.e. oxygen, inhaled short-acting medications and IV steroids). Evidence for other measures of benefit and safety was limited.

Researchers should clearly define the severity of the asthma condition among people in their studies while carefully recording adverse events.

This plain language summary is current as of May 2014. 


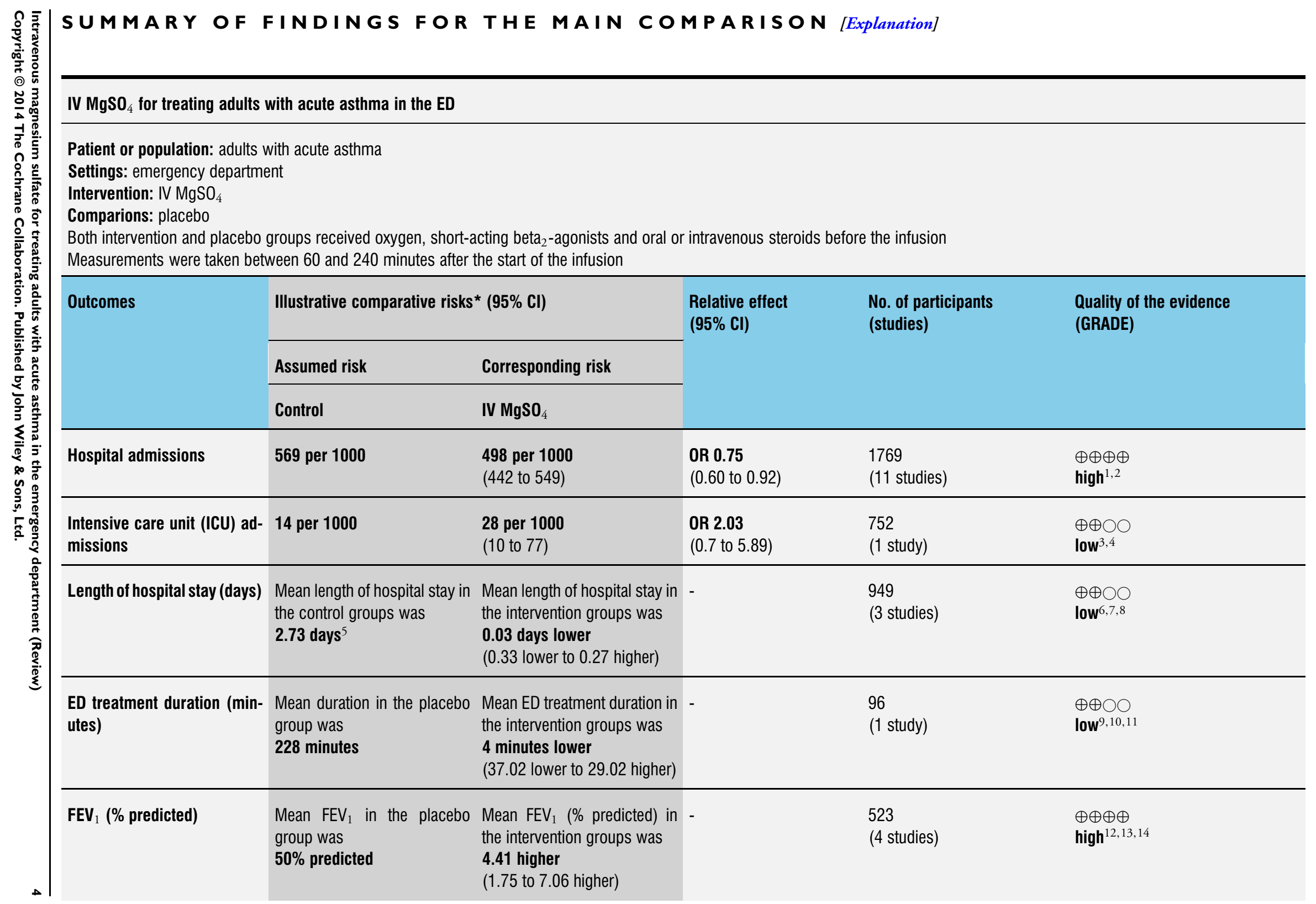




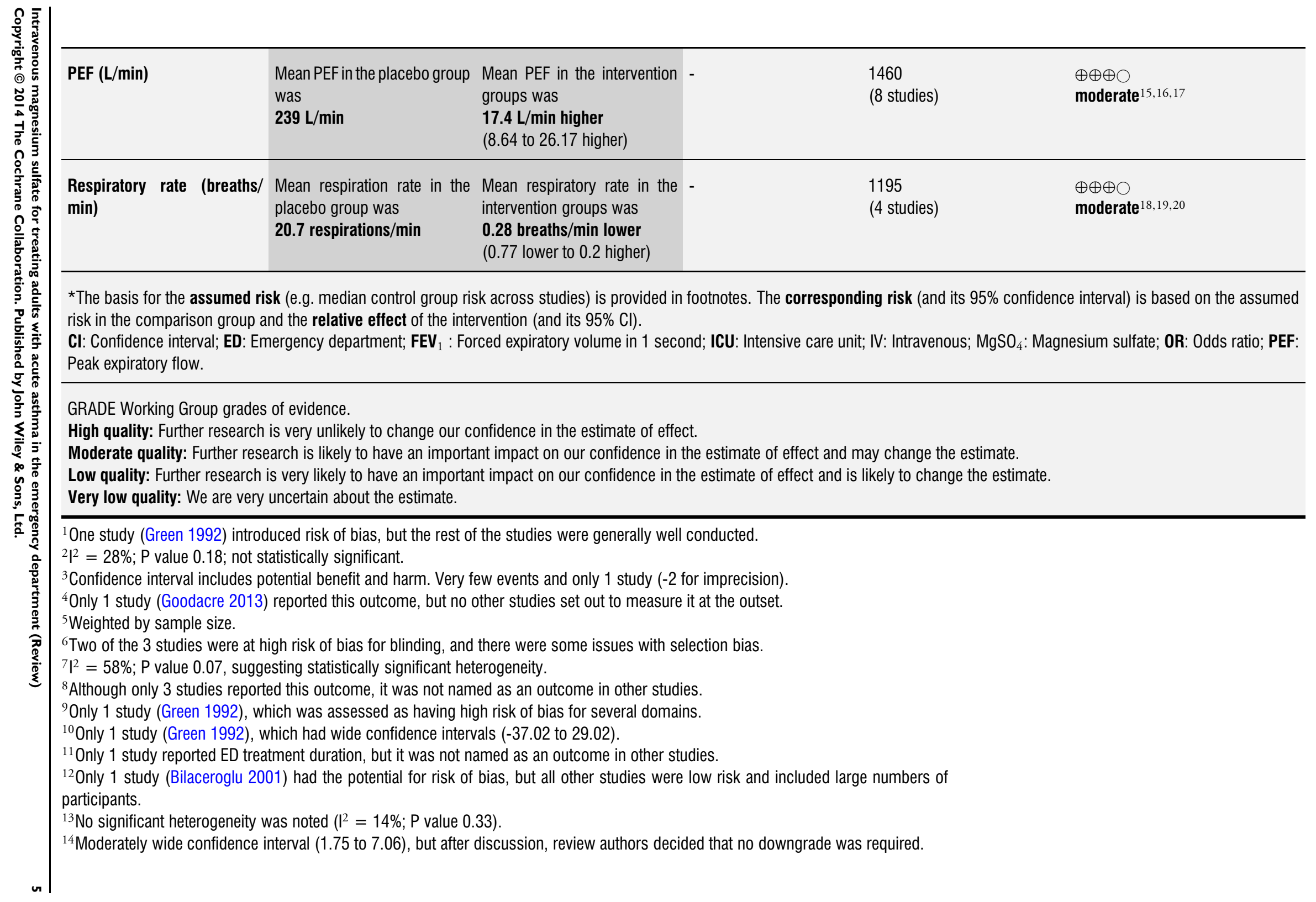



\begin{tabular}{l|l}
${ }^{15}$ Two studies (Green 1992; Matusiewicz 1994) had 'unclear' and 'high' risk of bias, respectively. However, the remaining 6 studies were \\
of low risk and contributed most of the participant numbers.
\end{tabular}

${ }^{16}$ Some heterogeneity between the studies, which was statistically significant $\left(l^{2}=50 \%\right.$; $P$ value 0.05$)$. However, when random effects were applied, conclusions were not changed.

${ }^{17}$ Wide confidence intervals (8.64 to 26.17 ), but does not cross zero

${ }^{18}$ Very little heterogeneity observed between the studies $\left(I^{2}=1 \%\right)$, which was not significant ( $P$ value 0.39$)$.

${ }^{19}$ Confidence interval (-0.77 to 0.20 ) includes significant benefit and potential harm (i.e. crosses the line of no effect).

${ }^{20}$ Only 4 studies reported respiratory rate, but it was not named as an outcome in other studies. 


\section{B A C K G R O U N D}

\section{Description of the condition}

Asthma is a chronic respiratory condition characterised by airway inflammation, constriction of airway smooth muscle and structural alteration of the airways that is at least partially reversible. Common symptoms include cough, wheezing, difficulty breathing, reduced exercise tolerance and chest tightness. Common triggers include allergens, pollutants and viral infections, although endogenous factors have also been identified. The World Health Organization (WHO) recognises the global burden of asthma and estimates a worldwide prevalence of 300 million people of all ages, with 250,000 dying each year. Epidemiological data suggest that prevalence is greatest in the developed world, with prevalence amongst adults at $8.2 \%$ in the USA (CDC) and $9 \%$ to $10 \%$ in the UK (DOH 2012).

Asthma can present with varying degrees of severity, and in the most severe cases, it can cause daily chronic symptoms and frequent exacerbations (defined as acute worsening of asthma symptoms). Overarching principles of treatment focus on controlling daily symptoms and preventing exacerbations through good education and appropriate use of inhalers. Short-acting bronchodilators are given to relieve bronchospasm, and corticosteroids for the underlying inflammation; both are usually delivered via inhalers. Depending on the persistence of symptoms, inhalers can be taken regularly (maintenance therapy) or on an as-needed basis (reliever therapy) (BTS/SIGN 2012; GINA 2011). Treatment guidelines recommend preventative management in the community and prompt interventions during exacerbations to reduce mortality and other negative outcomes (such as intubation and hospital admissions).

\section{Description of the intervention}

In severe exacerbations of asthma, which can be life threatening, most guidelines recommend the use of oxygen, nebulised or intravenous beta 2 -agonists, nebulised antimuscarinics and intravenous or oral corticosteroids as first-line treatment (BTS/SIGN 2012; GINA 2011; NACA 2006; NAEPP 2007). Beta 2 -agonists are recognised as most effective in relieving bronchospasm (Teoh 2012); however, anticholinergic inhalers have also been shown to be effective in the treatment of acute asthma (Griffiths 2013). When patients show poor response to these, or when they present with a severe or life-threatening exacerbation, a single dose of intravenous (IV) or nebulised magnesium sulfate $\left(\mathrm{MgSO}_{4}\right)$ can be considered. Nebulised $\mathrm{MgSO}_{4}$ is the subject of a separate review (Powell 2012). The recommended dosage of $\mathrm{IV} \mathrm{MgSO}_{4}$ in the UK is $1.2 \mathrm{~g}$ to $2 \mathrm{~g}$, delivered by infusion over 20 minutes (BTS/SIGN 2012), but guidelines differ regarding how and when $\mathrm{IV} \mathrm{MgSO}_{4}$ should be administered (Table 1),
National guidelines also vary with respect to definitions of asthma severity and use of additional interventions. Table 1 offers a summary of treatment strategies recommended by some of these guidelines for the management of acute asthma.

\section{How the intervention might work}

Magnesium is an important intracellular and extracellular cation that plays a key role in intracellular enzymatic reactions. Its mechanism of action in the context of an exacerbation of asthma is not fully understood, but several theories have been proposed (Rowe 2013). It is believed to play a role in bronchial smooth muscle relaxation via its ability to prevent calcium ion movement into smooth muscle cells by blocking the voltage-dependent calcium channels (Gourgoulianis 2001; Spivey 1990). Furthermore, some evidence suggests that it may reduce the neutrophilic burst seen with the inflammatory response (Cairns 1996), and that it may be involved in acetylcholine release from cholinergic nerve terminals and histamine release from mast cells (Dominguez 1998). The combination of these properties contributes to relief of airflow obstruction and provides the theoretical basis for the effectiveness of magnesium.

\section{Why it is important to do this review}

Acute asthma presentations represent a significant burden on emergency departments (EDs) and carry a substantial mortality risk, with 1143 deaths from asthma reported in the UK in 2010 (Asthma UK) and an estimated mortality rate of 1.1 deaths per 100,000 in the USA (CDC). In the UK, it is thought that " $75 \%$ of hospital admissions for asthma are avoidable and as many as $90 \%$ of the deaths from asthma are preventable" (Asthma UK). The financial burden is also significant, with a cost to the National Health Service (NHS) of $£ 1$ billion a year, $80 \%$ of which is spent on the $20 \%$ of people with the most severe disease (DOH 2012). Current guidelines advocate the use of $\mathrm{IV} \mathrm{MgSO}_{4}$ in the treatment of acute severe asthma, but evidence in the literature remains inconclusive (Rowe 2009). New evidence from randomised controlled trials published since the last version of this review may alter the conclusions.

\section{O B J E C T I VES}

To assess the safety and efficacy of $\mathrm{IV} \mathrm{MgSO}_{4}$ in adults treated for acute asthma in the emergency department.

METHODS 


\section{Criteria for considering studies for this review}

\section{Types of studies}

We included randomised controlled trials (RCTs) of any followup duration reported as full text, those published as abstract only and unpublished data.

\section{Types of participants}

We included studies of adults (defined as over 18 years of age) treated in the ED for acute asthma. If studies recruited both adults and children, we contacted the study authors to try to obtain separate data from adults.

\section{Types of interventions}

We included trials comparing any dose of $\mathrm{IV} \mathrm{MgSO}_{4}$ versus placebo. People with acute asthma often require multiple medications; therefore we included studies that allowed other treatments (for maintenance, for exacerbation itself or for other co-morbidities), provided they were not part of the randomly assigned treatment.

\section{Types of outcome measures}

\section{Primary outcomes}

- Hospital admissions.

\section{Secondary outcomes}

- ED treatment duration.

- Intensive care unit admissions.

- Vital signs (heart rate, respiratory rate, blood pressure, oxygen saturation).

- Spirometry (peak expiratory flow (PEF), forced expiratory volume within one second $\left.\left(\mathrm{FEV}_{1}\right)\right)$.

- Validated symptom scores.

- Adverse events.

Reporting in the trial of one or more of the outcomes listed here was not an inclusion criterion for the review.

\section{Search methods for identification of studies}

\section{Electronic searches}

We identified trials from the Cochrane Airways Review Group Specialised Register (CAGR), which is maintained by the Trials Search Co-ordinator for the Group. The Register contains trial reports identified through systematic searches of bibliographic databases including the Cochrane Central Register of Controlled Trials (CENTRAL), MEDLINE, EMBASE, CINAHL, AMED and PsycINFO, and by handsearching of respiratory journals and meeting abstracts (see Appendix 1 for further details). We searched all records in the CAGR using the search strategy described in Appendix 2.

We also conducted a search of ClinicalTrials.gov (www.ClinicalTrials.gov) and the WHO trials portal (www.who.int/ictrp/en/). We searched all databases from their inception to the present, and we imposed no restriction on language of publication.

\section{Searching other resources}

We checked reference lists of all relevant primary studies and review articles for additional references. We also searched for errata or retractions from included studies published in full text on PubMed (www.ncbi.nlm.nih.gov/pubmed) and reported within the review the date this was done.

\section{Data collection and analysis}

\section{Selection of studies}

Three review authors (KK, LK, CM) independently screened titles and abstracts for inclusion of all citations identified by the search and coded them as 'retrieve' (eligible or potentially eligible/ unclear) or 'do not retrieve.' We retrieved the full-text study reports/publications, and the review authors independently screened the full-text documents and identified studies for inclusion. We identified and recorded reasons for exclusion of ineligible studies. We resolved disagreements through discussion, or, if required, we consulted a fourth person. We identified and excluded duplicates and collated multiple reports of the same study, so that each study rather than each report was the unit of interest in the review. We recorded the selection process in sufficient detail to complete a PRISMA flow diagram and a Characteristics of excluded studies table.

\section{Data extraction and management}

To record study characteristics and outcome data, we used a data collection form that had been piloted on at least one study in the review. All review authors (KK, LK, CM) extracted study characteristics from included studies, and all review authors independently extracted outcome data. We extracted the following study characteristics.

- Methods: study design, duration of observation and followup, details of any 'run-in' period, number of study centres and locations, withdrawals, dates of study. 
- Participants: N, mean age, age range, gender, asthma severity* diagnostic criteria, co-morbidities, co-medications, baseline lung function, inclusion and exclusion criteria.

- Interventions: intervention, dose, comparison, concomitant and failed treatments, excluded medications.

- Outcomes: primary and secondary outcomes specified and collected, time points reported.

- Notes: funding for trial, notable conflicts of interest of trial authors.

We noted in the Characteristics of included studies table if outcome data were not reported in a usable way. We resolved disagreements by reaching consensus or by involving a fourth person. One review author transferred data into the Review Manager (RevMan) (version 5.2) file. We double-checked that data were entered correctly by comparing data presented in the systematic review versus data provided in the study reports. A second review author (LK or CM) spot-checked study characteristics for accuracy against the trial report.

\section{Assessment of risk of bias in included studies}

All review authors independently assessed risk of bias for each study using the criteria outlined in the Cochrane Handbook for Systematic Reviews of Interventions (Higgins 2011), resolving disagreements by discussion. We assessed the risk of bias according to the following domains.

- Random sequence generation.

- Allocation concealment.

- Blinding of participants and personnel.

- Blinding of outcome assessment.

- Incomplete outcome data.

- Selective outcome reporting.

- Other bias.

We graded each potential source of bias as high, low or unclear and provided a quote from the study report together with a justification for our judgement in the Risk of bias in included studies table. We summarised risk of bias judgements across different studies for each of the domains listed. We considered blinding separately for different key outcomes when necessary (e.g. for unblinded outcome assessment, risk of bias for hospital admission may be very different than for a patient-reported scale). When information on risk of bias was related to unpublished data or correspondence with a trial author, we noted this in the Risk of bias in included studies table.

When considering treatment effects, we took into account the risk of bias for all studies that contributed to that outcome.

\section{Assessment of bias in conducting the systematic review}

We conducted the review according to this published protocol and reported deviations from it in the Differences between protocol and review section of the systematic review.

\section{Measures of treatment effect}

We analysed dichotomous data as odds ratios (ORs) and continuous data as mean differences (MDs) or standardised mean differences (SMDs) with 95\% confidence intervals (CIs). If studies reported several validated symptom measures, or if different scales were reported across studies, we analysed the data as SMDs in one analysis to reduce measurement error and to increase precision. We entered data presented as a scale with a consistent direction of effect. We narratively described skewed data reported as medians and interquartile ranges.

We undertook meta-analyses only when this was meaningful (i.e. when treatments, participants and the underlying clinical question were similar enough for pooling to make sense).

When multiple trial arms were reported in a single trial, we included only the relevant arms. When two relevant comparisons from a single study were combined in the same meta-analysis, we halved the control group to avoid double-counting.

\section{Unit of analysis issues}

For dichotomous outcomes, we used participants rather than events as the unit of analysis (i.e. number of adults admitted to hospital rather than number of admissions per adult).

\section{Dealing with missing data}

We contacted investigators or study sponsors to verify key study characteristics and to obtain missing numerical outcome data when possible (e.g. when a study was identified as abstract only). When this was not possible, and when missing data were thought to introduce serious bias, we conducted a sensitivity analysis to explore the impact of including such studies in the overall assessment of results.

\section{Assessment of heterogeneity}

We used the $\mathrm{I}^{2}$ statistic to measure heterogeneity among the trials in each analysis. When substantial heterogeneity was identified, we explored possible causes by conducting prespecified subgroup analyses.

\section{Assessment of reporting biases}

We created and examined a funnel plot to explore possible smallstudy and publication biases. We considered the impact of unpublished trials in the GRADE ratings for each outcome.

\section{Data synthesis}

We used a fixed-effect model and performed a sensitivity analysis with random effects when significant heterogeneity was observed $\left(\mathrm{I}^{2}>30 \%\right)$. 


\section{Summary of findings table}

We created Summary of findings for the main comparison for seven of the prespecified outcomes. We used the five GRADE considerations (study limitations, consistency of effect, imprecision, indirectness and publication bias) to assess the quality of a body of evidence as it relates to the studies that contributed data to meta-analyses for the prespecified outcomes (http: //www.gradeworkinggroup.org/). We applied methods and recommendations described in Section 8.5 and Chapter 12 of the Cochrane Handbook for Systematic Reviews of Interventions (Higgins 2011) using GRADEpro software. We justified all decisions to downgrade or upgrade the quality of studies by using footnotes, and we made comments to aid readers' understanding of the review when necessary.

\section{Subgroup analysis and investigation of heterogeneity}

We carried out the following subgroup analyses for the primary outcome, using the formal test for subgroup differences in Review Manager (version 5.2) (Review Manager (RevMan)).

- Baseline severity (moderate, severe and life-threatening exacerbations*).

- Mean age ( $\leq$ and $>65$ years).

- Co-medications (with or without ipratropium bromide**).

* Since there is no single accepted metric for assessment of asthma severity, we extracted baseline data relevant to the severity criteria, as stated in the British Thoracic Society (BTS) guidelines (BTS/ SIGN 2012), that is,

- Clinical features (e.g. ability to complete sentences, respiratory effort, conscious level, signs of exhaustion);

- Previous intensive care unit admissions;

- Pulse;

- Blood pressure;

- Respiratory rate;

- Pulse oximetry;

- Pulsed expiratory flow (PEF); and

- Arterial blood gas.

Exacerbations of the study populations were labelled as moderate, severe or life threatening on the basis of available data, as judged by an independent assessor who was not involved in the review process and had no other details or results of the trials. Consistent with British Thoracic Society (BTS)/Scottish Intercollegiate Guidelines Network (SIGN) criteria (BTS/SIGN 2012), for which the percentage predicted PEF was available, mean values less than 33\% were judged to be life threatening, 33\% to $50 \%$ severe and over $50 \%$ moderate. When this measure was not available, or when the value was close to a cutoff, other criteria were consulted, and the value was then standardised across trials using studies reporting several indices. The decision to perform a subgroup analysis by severity was informed by conclusions drawn in the previous Cochrane review (Rowe 2009) that the intervention may be more effective in cases of severe or life-threatening asthma.

${ }^{* *}$ For co-medications, we grouped studies by whether investigators gave ipratropium bromide in addition to other treatments (i.e. short-acting beta 2 -agonists (SABAs) via a nebuliser or spacer, oral or intravenous corticosteroids). Ipratropium bromide is included in most guidelines, but it is unclear whether this treatment is adopted in all EDs. Griffiths 2013 has demonstrated that it is an effective adjunct to SABAs in children with asthma exacerbation in the acute setting.

\section{Sensitivity analysis}

We plan to carry out the following sensitivity analyses.

- Studies at high risk of bias for blinding.

- Unpublished data.

\section{Reaching conclusions}

We have based our conclusions only on findings from the quantitative or narrative synthesis of included studies for this review. We have avoided making recommendations for practice, and our implications for research suggest priorities for future research and outline remaining uncertainties in this area.

\section{RES U L T S}

\section{Description of studies}

Full details of the conduct and characteristics of each included study can be found in Characteristics of included studies, and reasons for exclusion when full texts had to be viewed are given in Characteristics of excluded studies.

\section{Results of the search}

119 references were identified by electronic searches, and 27 additional records were identified by a search of clinicaltrials.gov. Most were excluded upon screening of titles and abstracts $(n=117)$. Full texts were consulted for the remaining 29 references, and 10 were excluded at this stage, primarily because the study was not conducted in an emergency setting $(\mathrm{n}=7)$. Other reasons for exclusion at this stage were 'study population did not have asthma' $(\mathrm{n}=2)$ and 'no placebo comparison' $(\mathrm{n}=1)$. Several unsuccessful efforts were made to find a trial publication for one additional study (Abd El Kader 1997), which is awaiting classification. The remaining 18 citations related to 14 studies, which were included in this review. Trial flow is presented in Figure 1. 
Figure I. Study flow diagram.

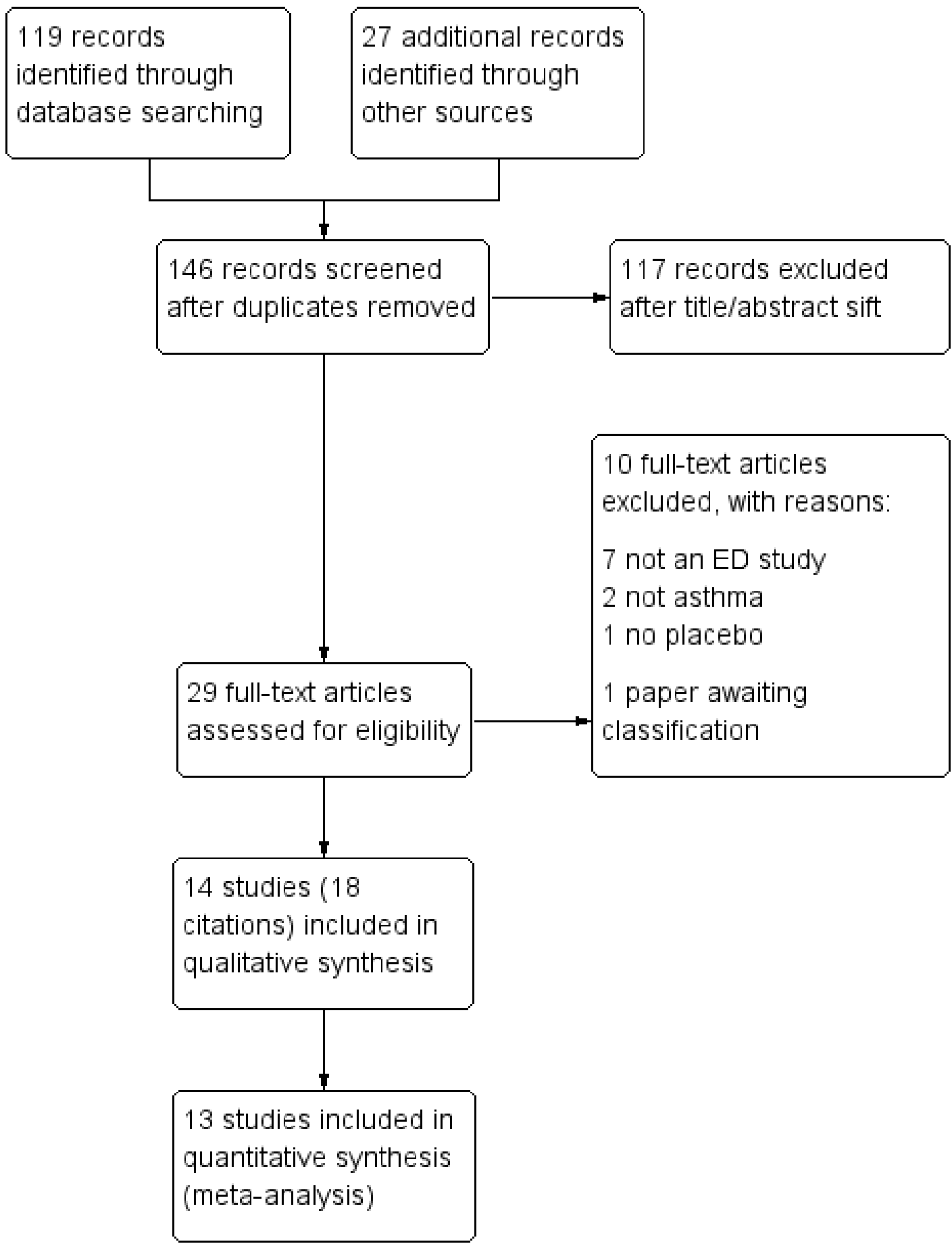




\section{Included studies}

Fourteen studies met the inclusion criteria, randomly assigning 2313 people with acute asthma to the comparisons of interest in this review. Goodacre 2013 contributed the largest sample size to the analyses, with 1109 participants randomly assigned to the two intervention groups; in contrast, Del Castillo Rueda 1991 had the smallest sample size, with 16 participants randomly assigned to the intervention groups. Mean sample size across the included studies was 165 . Summary characteristics of the included trials are presented in Table 2, and full details of each included study are given in Characteristics of included studies.

\section{Design and duration}

Most of the studies included in this review were randomised, double-blinded, placebo-controlled trials. Of those that were not, two were randomised, single-blinded, placebo-controlled trials (Bilaceroglu 2001; Singh 2008), one was unblinded with the control group receiving no placebo (Green 1992) and for two trials, the study design was unclear from the information provided (Del Castillo Rueda 1991; Matusiewicz 1994). For these two studies, the former commented on randomisation but not blinding, and the latter commented on neither randomisation nor blinding, although both studies appeared to include treatment and control groups.

The duration of the studies ranged from 45 minutes (Skobeloff 1989) to 260 minutes (Tiffany 1993). Most trials reported outcome data at the end of study treatment periods, but further follow-up provided in five studies ranged from six hours to one month (Bijani 2001; Bilaceroglu 2001; Bloch 1995; Goodacre 2013; Silverman 2002). Most trials were conducted at a single centre, occurring within one ED, except for Bloch 1995, which was done across two EDs in the USA; Goodacre 2013, which took place across 34 EDs in the UK and Silverman 2002, which was completed across eight EDs in the USA.

\section{Participant inclusion and exclusion criteria}

All studies included participants with an exacerbation of asthma. However differences between studies included the measures used to define an exacerbation, with some using PEF and others using $\mathrm{FEV}_{1}$, as well as the time at which these measurements were taken (e.g. on arrival, after initial treatment).

PEF was used in seven studies (Bijani 2001; Bilaceroglu 2001; Bradshaw 2007; Goodacre 2013; Matusiewicz 1994; Porter 2001; Skobeloff 1989). Two studies (Bijani 2001; Skobeloff 1989) used $\mathrm{PEF}<200 \mathrm{~L} / \mathrm{min}$, Porter 2001 used $\mathrm{PEF}<100$ or $<25 \%$ predicted and Matusiewicz 1994 specified PEF < $250 \mathrm{~L} / \mathrm{min}$ or $<50 \%$ predicted as the cutoff to indicate an exacerbation. Both Bilaceroglu
2001 and Goodacre 2013 specified PEF < 50\% predicted as a cutoff. $\mathrm{FEV}_{1}$ was used as a criterion for inclusion in four studies (Bilaceroglu 2001; Bloch 1995; Silverman 2002; Singh 2008), with the cutoff being $\mathrm{FEV}_{1}<75 \%$ predicted (Bilaceroglu 2001; Bloch 1995) or $\mathrm{FEV}_{1}<30 \%$ (Silverman 2002; Skobeloff 1989). Boonyavorakul 2000 used a severity score $>4$ (Fischl Index, which is a composite of vital signs, PEF and clinical features). Three studies (Del Castillo Rueda 1991; Green 1992; Tiffany 1993) did not define the criteria used for an exacerbation.

Three studies did not define any exclusion criteria (Bijani 2001; Del Castillo Rueda 1991; Matusiewicz 1994). For the remaining studies $(n=11)$, exclusion criteria were quite consistent and included diabetes mellitus, congestive cardiac disease, hypertension, chronic renal failure, temperature $>38^{\circ} \mathrm{C}$, pneumonia, pregnancy, participants requiring ventilation and those who did not provide consent.

\section{Baseline characteristics of participants}

The most common age range used across studies was 18 to 60 years (Silverman 2002; Singh 2008; Tiffany 1993). Bloch 1995 and Green 1992 used a range of 18 to 65 years, Porter 200118 to 55 years and Skobeloff 198918 to 60 years. Two studies (Bradshaw 2007; Goodacre 2013) included participants 16 years of age and older, whilst Boonyavorakul 2000 included participants aged 15 to 65 years. Two studies included children and reported age ranges of 12 to 85 years (Bijani 2001) and six to 65 years (Bilaceroglu 2001). From the studies for which we have only the abstract, Del Castillo Rueda 1991 did not specify the age of participants, and Matusiewicz 1994 described participants as 'adults.'

Most of the studies were well matched between control and intervention with respect to sex (other than Porter 2001, in which the IV $\mathrm{MgSO}_{4}$ arm consisted of $50 \%$ men compared with $25 \%$ in the placebo arm).

Only four studies reported ethnicity data (Bilaceroglu 2001; Goodacre 2013; Green 1992; Silverman 2002). The percentage classified as 'white' ranged from $59 \%$ to $100 \%$ in three of these (Bilaceroglu 2001; Goodacre 2013; Green 1992), whereas Silverman 2002 had a greater preponderance of black and Hispanic participants, with only $11 \%$ to $14 \%$ of participants classified as 'white.'

Five studies distinguished smokers (Bilaceroglu 2001; Bloch 1995; Goodacre 2013; Silverman 2002; Singh 2008), and in all cases the placebo and intervention arms were well matched. The percentage of current smokers within these studies ranged from $7 \%$ to $10 \%$ in Singh 2008 , to $30 \%$ to $35 \%$ in Goodacre 2013 and Silverman 2002. The remainder of the studies (Bilaceroglu 2001; Bloch 1995) combined current smokers and ex-smokers, and their proportions ranged from $29 \%$ to $50 \%$. 
Three studies further stratified participants by severity of asthma using American (Bilaceroglu 2001; Bloch 1995) and British (Bradshaw 2007) Thoracic Society Guidelines.

As stated in the protocol, we categorised study populations on the basis of average severity to conduct a subgroup analysis. Judgements of severity were based on baseline severity characteristics presented in the trials, which are summarised in Table 3. The justification for each judgement is given in each study's characteristics table.

\section{Characteristics of the interventions}

\section{IV $\mathrm{MgSO}_{4}$}

In nine studies a dose of $2 \mathrm{~g}$ IV was used, usually in 50 to $100 \mathrm{~mL}$ (250 mL in Singh 2008) of $0.9 \%$ normal saline or $5 \%$ dextrose solution, and was infused over periods ranging from 15 to 30 minutes.

Bradshaw 2007, Del Castillo Rueda 1991, Matusiewicz 1994 and Skobeloff 1989 used a dose of $1.2 \mathrm{~g} \mathrm{IV} \mathrm{MgSO}_{4}$ in solutions akin to those mentioned above. Bijani 2001 used doses calculated by weight of $25 \mathrm{mg} / \mathrm{kg}$; this reflects the broader age range of the participants.

\section{Placebo group}

All studies had a placebo arm except Green 1992, in which no placebo was administered to the control group. In all other cases, the same solution that was used to infuse $\mathrm{IV} \mathrm{MgSO}_{4}$ to the treatment group was used as the control solution, in equal volume and over the same time period. Boonyavorakul 2000 added $2 \mathrm{~mL}$ sterile water to the control solution, and Silverman 2002 does not comment on the specific solution used for control but describes it as 'like appearing solution' of equal volume.

\section{Co-medications}

A number of other drugs commonly used in acute asthma were co-administered, and there was a degree of variation in the way this was done. In all trials participants received nebulised SABA (salbutamol and, in one case, metaproterenol sulfate), and most also described the use of oxygen $(\mathrm{n}=10)$ and IV corticosteroids

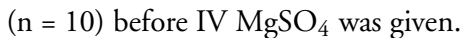

Goodacre 2013 administered oral prednisolone rather than IV corticosteroids, and the form of corticosteroid administered was unclear in Bijani 2001, Del Castillo Rueda 1991 and Bilaceroglu 2001. In the latter, the decision to administer was based on the severity category to which the participant had been assigned.

Use of oxygen was described in 10 studies, although some study authors commented that this was the case only if clinically indicated (Bilaceroglu 2001; Boonyavorakul 2000). Some authors did not describe the use of oxygen, although they may not have considered this to be a drug treatment requiring mention in the treatment protocol (Bloch 1995; Del Castillo Rueda 1991; Skobeloff 1989; Tiffany 1993).

Three studies administered aminophylline or theophylline (Bijani 2001; Skobeloff 1989; Tiffany 1993), and in Skobeloff 1989, this was guided by serum theophylline levels.

Nebulised ipratropium bromide was administered in four studies (Bradshaw 2007; Goodacre 2013; Matusiewicz 1994; Singh 2008). Goodacre 2013 and Green 1992 commented that other interventions were permitted at the discretion of the treating physician, although they did not specify which ones were permitted.

\section{Outcomes and analysis structure}

Most studies reported the number of participants who required hospitalisation after treatment $(\mathrm{n}=11)$, but secondary outcomes were inconsistently reported. Three studies reported length of hospital stay for those hospitalised, and only one study at high risk of bias reported the duration of ED treatment (Green 1992). Readmission was reported in Bloch 1995 and Goodacre 2013 after a week and a month, respectively.

Lung function was reported in most of the studies, although this was done in different ways (primarily percentage predicted $\mathrm{FEV}_{1}$ and PEF, and PEF in litres per minute). Absolute values or changes in $\mathrm{FEV}_{1}(\mathrm{~L})$ were not consistently reported. Bloch 1995 did not report standard deviation for $\mathrm{FEV}_{1}$, but the study was included on the basis of variance derived from the $\mathrm{P}$ value reported in the paper. This resulted in an unusually large standard deviation but did not significantly change the final results.

In the PEF analysis, we combined three studies reporting mean change from baseline (Bijani 2001; Skobeloff 1989; Tiffany 1993) with five reporting absolute endpoint scores (Goodacre 2013; Green 1992; Matusiewicz 1994; Porter 2001; Silverman 2002).

Four studies reported heart rate, respiratory rate and systolic blood pressure (Bloch 1995; Goodacre 2013; Silverman 2002; Singh 2008). Bijani 2001 reported respiratory rate, but the data could not be included because no measure of variance was provided. Goodacre 2013 reported oxygen saturation for participants on and off oxygen separately, but because no other studies reported data, we did not perform a meta-analysis. Partial pressure was reported in one study (Bilaceroglu 2001), but again this was not formally analysed. These results are summarised narratively.

Validated symptom scales generally were not reported in the studies, but four studies reported scores on the Borg Dyspnoea Scale (Bloch 1995; Porter 2001; Silverman 2002; Singh 2008). One additional study (Goodacre 2013) measured breathlessness using a visual analogue scale (VAS), which we chose not to analyse, as it was not validated. Boonyavorakul 2000 used the Fischl Index, which is a composite of vital signs, PEF and clinical features. As individual measures were not available, the data were not analysed. A large degree of disparity was noted in the reporting of adverse 
events; this precluded pooling of data in the meta-analysis. Five studies reported no information on adverse events (Bijani 2001; Del Castillo Rueda 1991; Matusiewicz 1994; Silverman 2002; Tiffany 1993), although Silverman 2002 noted that no major adverse events were reported. Boonyavorakul 2000 and Green 1992 described minor adverse events such as flushing and fatigue, but these were not quantified. Other studies quantified adverse events for the duration of the treatment period, which ranged from 60 to 240 minutes. As such, we summarised information across studies narratively in the results.

\section{Subgroup and sensitivity analyses}

We conducted subgroup analyses on the primary outcome (hospital admissions) for baseline severity and co-medications. For severity, 15 groups were identified across the 11 studies reporting the outcome: two moderate, six severe and seven life threatening.

We performed the analysis based on whether ipratropium bromide was administered as described in the protocol. Bradshaw 2007, Goodacre 2013, Matusiewicz 1994 and Singh 2008 were the only studies in which ipratropium bromide was given; three of these are UK studies. However, as information about co-medications was inconsistently reported (summarised above and in Table 2), and it was often unclear when infusions or nebulisers were given, we were conservative in interpretation and have summarised the limitations of the analysis in the discussion. We could not carry out a subgroup analysis based on mean age ( $\leq$ and $>65$ years), as no trials solely recruited older adults.

We also conducted two sensitivity analyses excluding trials at high risk of bias for blinding and those that contributed only unpublished data. Bilaceroglu 2001, Green 1992 and Matusiewicz 1994 were removed from the prior, and only Matusiewicz 1994 from the latter. No full paper was available for Del Castillo Rueda 1991, but this study did not report hospital admissions, and although only an abstract was available in English for Bilaceroglu 2001, the full paper had been published in Turkish, from which we were able to obtain further information. None of the studies provided additional unpublished data for the primary outcome.

We added a post-hoc sensitivity analysis using change from baseline instead of endpoint means from Goodacre 2013, as baseline imbalances were noted in this study.

\section{Excluded studies}

Studies that took place outside of an acute setting were excluded, as were those concerned with the effects of nebulised magnesium sulfate (the subject of another review (Powell 2012)).

We excluded trials that were exclusively concerned with children, defined as those younger than 18 years of age. These studies will be dealt with in a separate Cochrane review (Griffiths 2014). We included studies in which participants were both older and younger than 18. Bradshaw 2007 and Goodacre 2013 included participants 16 years of age and older, and we believe that these data are applicable to adults, as we would not expect significant physiological differences between the ages of 16 and 18. Bijani 2001, Boonyavorakul 2000 and Bilaceroglu 2001 included participants 12 to 85 years and 15 to 65 years of age, respectively; we endeavoured to obtain data for adults only but were ultimately unsuccessful. Age ranges were unclear in three studies, although the implication was that participants were adults (Bilaceroglu 2001; Del Castillo Rueda 1991; Matusiewicz 1994).

\section{Risk of bias in included studies}

For details of the risk of bias rating for each study and the reasons for each rating, see Characteristics of included studies. A summary of risk of bias judgements by study and domain (allocation generation, allocation concealment, blinding and incomplete data) can be found in Figure 2. 
Figure 2. Risk of bias summary: review authors' judgements about each risk of bias item for each included study.

\begin{tabular}{|c|c|c|c|c|c|c|}
\hline & 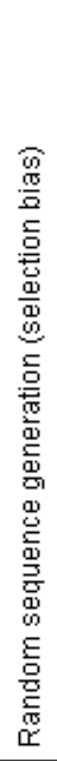 & 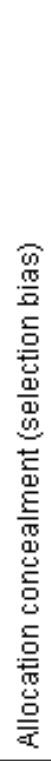 & 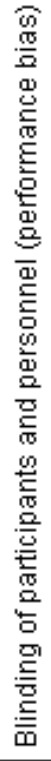 & 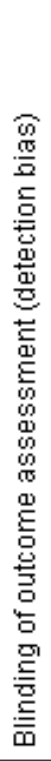 & 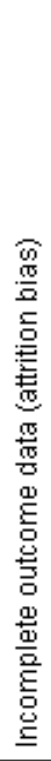 & 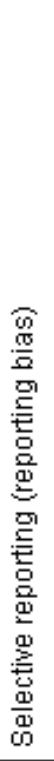 \\
\hline Bijani 2001 & $?$ & $?$ & + & $?$ & $?$ & + \\
\hline Bilaceroglu 2001 & $?$ & $?$ & - & & + & $?$ \\
\hline Bloch 1995 & + & + & + & + & + & \\
\hline Boonyavorakul 2000 & + & $?$ & + & + & + & \\
\hline Bradshaw 2007 & + & + & + & + & + & \\
\hline Del Castillo Rueda 1991 & ? & $?$ & $?$ & $?$ & ? & ? \\
\hline Goodacre 2013 & + & + & + & + & + & \\
\hline Green 1992 & & & - & & ? & ? \\
\hline Matusiewicz 1994 & ? & $?$ & ? & ? & ? & ? \\
\hline Porter 2001 & + & + & + & + & $?$ & $?$ \\
\hline Silverman 2002 & + & + & + & + & $?$ & + \\
\hline Singh 2008 & + & + & ? & + & + & \\
\hline Skobeloff 1989 & $?$ & + & + & + & + & \\
\hline Tiffany 1993 & + & $?$ & + & + & ? & \\
\hline
\end{tabular}




\section{Allocation}

We assessed six studies to be at low risk of bias for random sequence generation and seven for allocation concealment. Both Bloch 1995 and Bradshaw 2007 used random number generation by pharmacy, with blinding of physicians to the allocation. Goodacre 2013 used telephone- or Internet-generated randomisation sequencing, whilst Porter 2001 used a random number generator producing a code, and in both studies, numbered treatment packs were prepared in pharmacy before they were used by physicians. Silverman 2002 used 1:1 randomisation tables, and the pharmacy prepared vials of placebo or $\mathrm{IV} \mathrm{MgSO}_{4}$ with identical appearances and labelled with study IDs. Singh 2008 used 1:1 randomisation tables, and study numbers were concealed in envelopes until allocation was completed.

Skobeloff 1989 did not provide sufficient details of random sequence allocation to warrant a low risk bias judgement but adequately described allocation concealment.

Two studies (Boonyavorakul 2000; Tiffany 1993) detailed adequate randomisation processes (computer-generated lists); in Tiffany 1993, this was managed by pharmacy, but no information about allocation concealment was provided, and hence this study was assessed to be at unclear risk in this domain.

Bilaceroglu 2001, Del Castillo Rueda 1991 and Bijani 2001 commented on randomisation, although no further details were provided and no comment on allocation concealment was made; hence these studies were assessed as unclear in both areas. The same assessment was made with Matusiewicz 1994, for which no information about randomisation or allocation concealment was provided.

We considered Green 1992 to be at high risk of bias in these domains, as participants were allocated to control or treatment group according to the day of presentation to the department.

\section{Blinding}

In the domains of both performance and detection bias, we considered most $(\mathrm{n}=8)$ of the included studies to be at low risk of bias (Bloch 1995; Boonyavorakul 2000; Bradshaw 2007; Goodacre 2013; Porter 2001; Silverman 2002; Skobeloff 1989; Tiffany 1993). These were described as double-blinded placebo-controlled trials, and investigators provided adequate detail about who was blinded and commented that their primary outcomes were nonsubjective assessor-rated outcomes.

Singh 2008 described this study as single-blinded; however through correspondence with the study author, we were able to ascertain that participants and assessors of spirometric and clinical outcomes were blinded, as was the chief resident who made the decision about admission. The individual administering the medication was unblinded; therefore we rated performance bias as 'unclear' and detection bias as 'low risk.'

We believe that although Bijani 2001 performed a double-blinded study with decoding done at completion of the study, limited detail was provided about who the blinded parties were, and we considered this to be unclear.

We have no information for these domains from Del Castillo Rueda 1991 and Matusiewicz 1994 and have graded them as also having unclear risk of bias.

We assessed that both Bilaceroglu 2001 and Green 1992 are at high risk of bias in these domains. The former study was singleblinded, and further correspondence with the study author confirmed that only participants were blinded to treatment, allowing for bias in assessment of outcome measures. In Green 1992, the physicians were unblinded to randomisation, and although neither participants nor respiratory therapists carrying out PEF measures were aware that a study was being conducted, they may have been aware of the treatment received.

\section{Incomplete outcome data}

We considered that in half of the included studies $(n=7)$, the risk of attrition bias was low, and in the other half, the risk was unclear. In studies for which we considered the risk to be low (Bilaceroglu 2001; Bloch 1995; Boonyavorakul 2000; Bradshaw 2007; Goodacre 2013; Singh 2008; Skobeloff 1989), withdrawal rates were clearly documented and numbers were low, with similar rates reported in placebo and control groups.

In four studies (Bijani 2001; Del Castillo Rueda 1991; Matusiewicz 1994; Tiffany 1993), no information was provided about withdrawal rates, hence the reason for considering the risk to be unclear.

In Green 1992, 97 of 217 participants were excluded from analysis, with 80 participants repeat attenders (no comment on the groups to which they had been randomly assigned) and the medical records of 17 participants misplaced. No comment was made about whether there was intention to treat any of the participants who withdrew, although at the point of analysis, numbers in all groups were similar.

Porter 2001 reports that where repeat attendance to the department was documented, data from only the first presentation were used, but no further commentary was made about withdrawals. Silverman 2002 provides a very detailed report of participants with protocol violations who were retained in the intention-to-treat data set and gives reasons for these inclusions. However, attrition rates were quite high and were not provided for each arm. As such it was unclear whether attrition was balanced between groups, and the study was rated as 'unclear.' 


\section{Selective reporting}

We considered that only five studies demonstrated low risk of bias in reporting of outcome data: Bijani 2001; Bloch 1995; Goodacre 2013; Silverman 2002; and Singh 2008. Although Bijani 2001 did not report on arterial blood gas (ABG) results as was planned, other data were well reported, and we believe that the ABG measure was not critical to the study. Both Goodacre 2013 and Singh 2008 provided further raw data when directly contacted by the review authors, and this completed the outcomes planned for assessment. The published report of Bloch 1995 provided data at only one of the prespecified time points and $\mathrm{FEV}_{1}$ was provided graphically, but the study author provided additional data to the review authors upon request.

We considered the following studies to be unclear for risk of reporting bias: Bilaceroglu 2001; Del Castillo Rueda 1991; Green 1992; Matusiewicz 1994; and Porter 2001. We have only the abstract for both Del Castillo Rueda 1991 and Matusiewicz 1994; The former provided no outcome data, just a written description of investigator conclusions, and the latter provided outcomes at only one of the recorded time points. Bilaceroglu 2001 did provide further raw data to the review authors on request, but this still did not include all time points laid out in the methodology. Green 1992 provided outcome data, but the methodology did not indicate the primary outcome measures selected when the study was designed. Porter 2001 provided all primary outcome data at the prespecified time point; however data were also collected at other time points, and this was not reported.

We considered that four studies demonstrated high risk of reporting bias. Boonyavorakul 2000 provided only raw admission data, and severity scores were provided only in terms of 'variance.'
Bradshaw 2007, Skobeloff 1989 and Tiffany 1993 provided raw data for only a subset of outcomes or time points, with remaining results presented graphically or without variance and with no reporting of raw data.

\section{Other potential sources of bias}

No additional sources of bias were identified.

\section{Effects of interventions}

See: Summary of findings for the main comparison $\mathrm{IV} \mathrm{MgSO}_{4}$ for treating adults with acute asthma in the emergency department

\section{Primary outcomes}

\section{Hospital admissions}

Combining 11 studies $(\mathrm{n}=972)$ revealed a significant reduction in hospital admissions compared with placebo (OR 0.75, 95\% CI 0.60 to 0.92 ; high-quality evidence; Analysis 1.1 ). Some heterogeneity that was not statistically significant was observed $\left(\mathrm{I}^{2}=\right.$ $28 \%$; P value 0.18 ). In absolute terms, this odds ratio translates to a reduction of seven hospital admissions for every 100 adults (95\% $\mathrm{CI}$ two to 13 fewer) treated with $\mathrm{IV} \mathrm{MgSO}_{4}$ (Figure 3). There was no reason to downgrade for any of the five domains in GRADE (risk of bias, inconsistency, indirectness, imprecision, publication bias). Specifically, risk of bias was generally low or unclear across trials, heterogeneity was not significant, trials matched the research question well, confidence intervals were relatively narrow and almost all studies contributed data to the analysis. 
Figure 3. In the control group, 57 of 100 people were admitted to hospital, compared with 50 (95\% Cl 45 to 55) of 100 for the IV MgSO4 group.

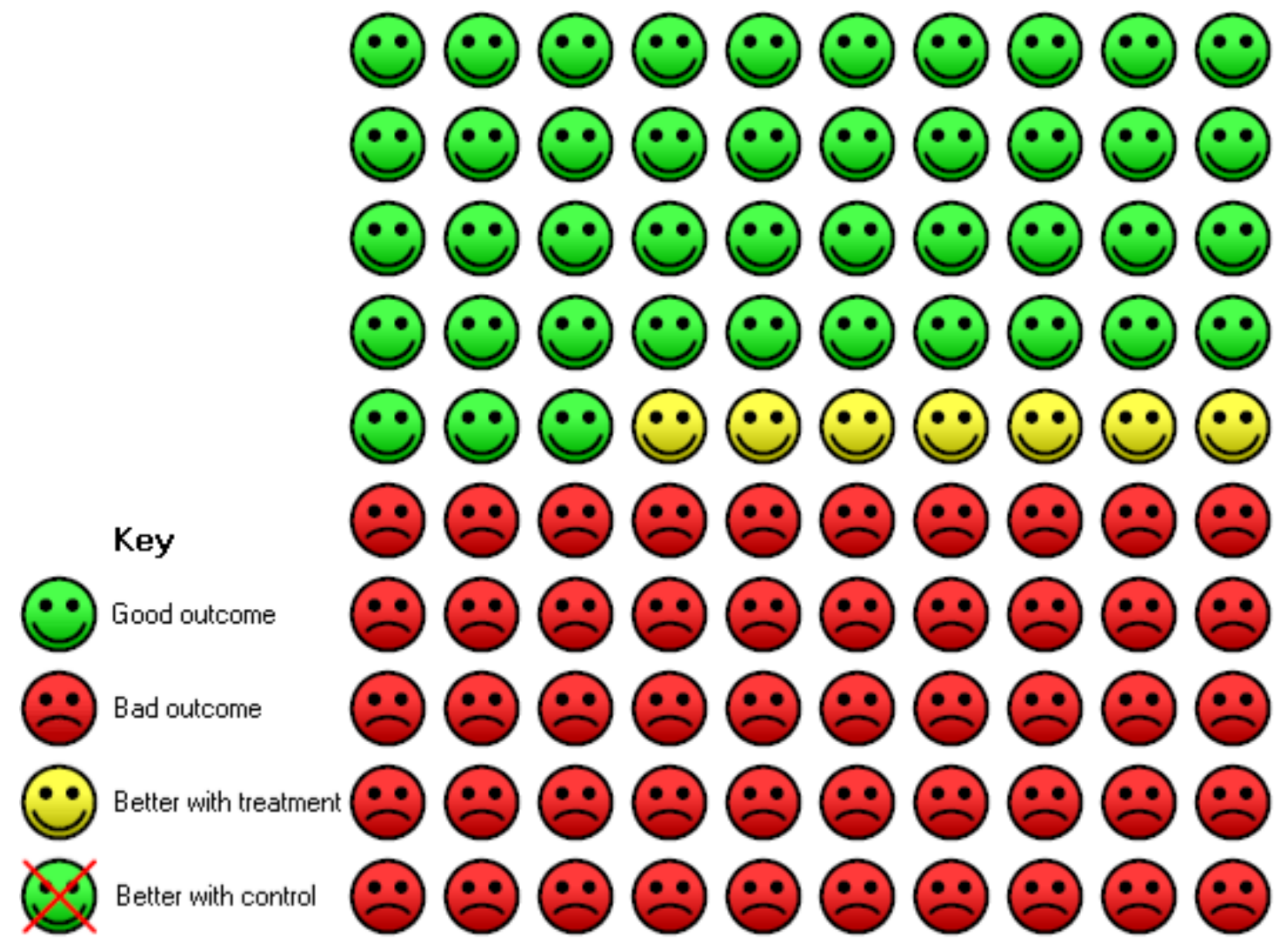

\section{Secondary outcomes}

\section{Intensive care admissions}

Evidence from one study (Goodacre 2013; $\mathrm{n}=752$ ) showed no significant difference in admission rates between $\mathrm{IV} \mathrm{MgSO}_{4}$ and placebo (OR 2.03, 95\% CI 0.70 to 5.89; moderate-quality evidence; Analysis 1.2). The same study reported the number of participants admitted to the high dependency unit and showed no significant difference between the two arms (OR 1.05, 95\% CI 0.57 to 1.94 ; moderate-quality evidence; Analysis 1.3 ). Both outcomes contained few events from only one study, so they were downgraded twice for imprecision, and the quality of evidence was rated as 'low.'
Only one study (Green 1992; $\mathrm{n}=452$ ) reported ED treatment duration and found no significant difference between $\mathrm{IV} \mathrm{MgSO}_{4}$ and placebo (MD -4.00, 95\% CI -37.02 to 29.02; low-quality evidence; Analysis 1.4). The outcome was downgraded for risk of bias and imprecision.

\section{Length of hospital stay (days)}

Combining three studies reporting the outcome $(n=949)$ revealed no significant difference in time spent in hospital between the IV $\mathrm{MgSO}_{4}$ and placebo groups (MD - $0.03,95 \%$ CI -0.33 to 0.27 ; low-quality evidence; Analysis 1.5). The evidence was downgraded for risk of bias and inconsistency $\left(\mathrm{I}^{2}=53 \%\right.$; $\mathrm{P}$ value 0.10$)$. As $\mathrm{I}^{2}$ was over the $30 \%$ defined in the protocol, we performed a sensitivity analysis using random effects, which did not change the conclusions (MD -0.16, 95\% CI -0.68 to 0.37). 
Too few events were described in only two studies to indicate whether $\mathrm{IV} \mathrm{MgSO}_{4}$ had an effect on readmission to hospital compared with placebo (OR 2.30, 95\% CI 0.66 to 7.99; moderatequality evidence; Analysis 1.6). No statistical heterogeneity was noted between the studies $\left(\mathrm{I}^{2}=0 \%\right.$; $\mathrm{P}$ value 0.34$)$, but the outcome was downgraded for imprecision.

\section{Vital signs}

\section{Heart rate}

Combining four studies $(\mathrm{n}=1195)$ showed a small significant reduction in heart rate with $\mathrm{IV}_{\mathrm{MgSO}}$ compared with placebo (MD -2.37, 95\% CI -4.13 to -0.61 ; moderate-quality evidence; Analysis 1.7). However a high degree of heterogeneity was observed, which was statistically significant and warranted downgrading $\left(\mathrm{I}^{2}=78 \%\right.$; $\mathrm{P}$ value 0.004$)$. A sensitivity analysis using random effects decreased precision significantly, with confidence intervals including both significant benefit and potential harm of IV $\mathrm{MgSO}_{4}$ (MD -2.61, 95\% CI -6.58 to 1.35 ).

\section{Respiratory rate}

When five studies were combined ( $\mathrm{n}=1276), \mathrm{IV} \mathrm{MgSO}_{4}$ did not show a significant reduction in respiratory rate compared with placebo (MD $-0.28,95 \%$ CI -0.77 to 0.20 ; moderate-quality evidence; Analysis 1.8). Heterogeneity was not significant $\left(\mathrm{I}^{2}=1 \%\right.$; $P$ value 0.39 ), but the evidence was downgraded for imprecision because confidence intervals included significant benefit and potential harm of the treatment.

\section{Systolic blood pressure}

Four studies (Bloch 1995; Bradshaw 2007; Goodacre 2013; Silverman 2002; $\mathrm{n}=1264)$ reporting systolic blood pressure showed no difference between $\mathrm{IV} \mathrm{MgSO}_{4}$ and placebo (MD 0.08, 95\% CI -1.89 to 2.05; moderate-quality evidence; Analysis 1.9). Heterogeneity was high, and although it was not statistically significant, authors considered it large enough to warrant downgrading for inconsistency $\left(\mathrm{I}^{2}=51 \%\right.$; P value 0.11$)$. A sensitivity analysis using random effects did not change the conclusions (MD $0.73,95 \%$ CI -4.13 to 2.67 ).

\section{Oxygen saturations}

One study reported outcomes separately for those receiving and those not receiving oxygen (Goodacre 2013). This outcome was not reported in other studies; therefore we were unable to metaanalyse the data.

\section{Spirometry}

\section{$\mathrm{FEV}_{1}$ (\% predicted)}

When four studies were combined (Bilaceroglu 2001; Bloch 1995; Silverman 2002; Singh 2008) ( $\mathrm{n}=523)$, significant improvement in percentage predicted $\mathrm{FEV}_{1}$ was seen in the IV $\mathrm{MgSO}_{4}$ group compared with the placebo group (MD 4.41, 95\% CI 1.75 to 7.06; high-quality evidence; Analysis 1.10). No significant heterogeneity was noted among studies $\left(\mathrm{I}^{2}=14 \%\right.$; $\mathrm{P}$ value 0.33$)$.

During data analysis, reported standard deviations in Bilaceroglu 2001 were outliers and appeared to be more consistent with standard error values; the author confirmed that this was the case. In addition, Bloch 1995 reported no standard deviations; therefore the standard error of the mean was calculated from the graphs.

\section{PEF (\% predicted)}

Three studies (Bradshaw 2007; Goodacre 2013; Silverman 2002; $\mathrm{n}=1129$ ) reported PEF (\% predicted) and showed a statistically significant improvement in PEF with $\mathrm{IV} \mathrm{MgSO}_{4}$ compared with placebo (MD 4.78, 95\% CI 2.14 to 7.43 ; high-quality evidence; Analysis 1.11). Heterogeneity between studies was high but was not statistically significant $\left(\mathrm{I}^{2}=45 \%\right.$; P value 0.16$)$, so the evidence was not downgraded. A sensitivity analysis with random effects did not change our conclusions (MD 5.17, 95\% CI 1.15 to 9.19). On the basis of observed baseline imbalances in the largest study (Goodacre 2013), a second sensitivity analysis using change from baseline instead of endpoint means substantially reduced the effect (MD 1.57, 95\% CI -0.55 to 3.69; $\mathrm{I}^{2}=79 \%, \mathrm{P}=0.009$; Analysis 2.5).

\section{PEF (L/min)}

Combining eight studies $(\mathrm{n}=1460)$ revealed that $\mathrm{IV} \mathrm{MgSO}_{4}$ improved PEF compared with placebo (MD 17.40, 95\% CI 8.64 to 26.17; moderate-quality evidence; Analysis 1.12). However statistically significant heterogeneity between the studies $\left(\mathrm{I}^{2}=50 \%\right.$; $P$ value 0.05 ) warranted downgrading. A sensitivity analysis with random effects did not change our conclusions (MD 18.35, 95\% CI 4.12 to 32.58). As with the percentage PEF predicted analysis, a second sensitivity analysis using Goodacre 2013 change from baseline substantially reduced the magnitude of effect (MD 9.44, 95\% CI 2.07 to $16.81 ; \mathrm{I}^{2}=68 \%, \mathrm{P}=0.003$; Analysis 2.6).

\section{Validated symptom scores}

Five studies used symptom scales, all measuring breathlessness $(\mathrm{n}=$ 1237). The Borg Dyspnoea Scale was used by four studies (Bloch 1995; Porter 2001; Silverman 2002; Singh 2008), and Goodacre 2013 used a VAS for breathlessness. Data for the Borg Dyspnoea Scale revealed no significant change with $\mathrm{IV}_{\mathrm{MgSO}_{4}}$ compared 
with placebo (MD $-0.22,95 \% \mathrm{CI}-0.55$ to 0.12 ; high-quality evidence; Analysis 1.13), and no significant heterogeneity between studies was noted $\left(\mathrm{I}^{2}=0 \%\right.$; P value 0.82$)$.

Similarly, Goodacre 2013 reported no significant change in VAS score with IV $\mathrm{MgSO}_{4}$ compared with placebo (MD -3.00, 95\% CI -7.09 to 1.09$)$.

\section{Adverse events}

The most commonly cited adverse events were flushing, fatigue, nausea and headache; some study authors also commented on hypotension.

Bilaceroglu 2001 reported flushing in $42 \%$ of those receiving IV $\mathrm{MgSO}_{4}$ versus no flushing in the placebo group. Although paraesthesia, vertigo and hypotension were also reported, no marked differences between treatment and placebo arms were observed.

Bloch 1995 reported that $58 \%$ of those receiving $\mathrm{IV} \mathrm{MgSO}_{4}$ reported adverse events, including the sensation of flushing, fatigue and burning at the IV site, with one participant experiencing transient urticaria in the upper extremities.

Bradshaw 2007 reported minor adverse events in $8 \%$ of those receiving $\mathrm{IV} \mathrm{MgSO}_{4}$ (headache, flushing, dizziness), with only one participant in the placebo arm reporting flushing (1.5\%).

Goodacre 2013 reported the rate of adverse events (death, arrhythmia, cardiac arrest, non-invasive ventilation, intubation, other) as $13 \%$ in the treatment group compared with $10 \%$ in the placebo group, although these rates fall almost entirely in the 'other' category. One death of an unspecified cause (1\%) was reported in the IV $\mathrm{MgSO}_{4}$ group compared with none in the placebo group. No other trials reported deaths. Goodacre 2013 reported commonly cited adverse events as a separate category and revealed a statistically significant increase in adverse events in the IV $\mathrm{MgSO}_{4}$ group (OR 1.68, 95\% CI 1.07 to 2.63 ; P value 0.025 ).

Both Porter 2001 and Singh 2008 reported that the difference between rates of adverse events (including deep tendon reflexes) among participants given IV $\mathrm{MgSO}_{4}$ versus placebo was not statistically significant.

Skobeloff 1989 reported higher rates of fatigue (32\% vs $11 \%$ ), warmth $(26 \%)$ and lightheadedness $(5 \%)$ in the IV $\mathrm{MgSO}_{4}$ group, but the numbers in this study were small.

With respect to blood pressure, Bilaceroglu 2001 reported hypotension in $5 \%$ versus $3 \%$ of participants in the treatment versus placebo groups, whilst Goodacre 2013 reported 8\% versus 6\%, respectively. Bradshaw 2007 reported a non-significant trend for decreasing blood pressure at 60 minutes, and Singh 2008 reported no hypotension.

\section{Subgroup analyses}

Baseline severity (moderate, severe and life-threatening exacerbations)
The test for subgroup differences revealed no statistical heterogeneity between the three severity subgroups $\left(\mathrm{I}^{2}=0 \%\right.$; $\mathrm{P}$ value $0.73)$, and between-trial heterogeneity was significant within all three subgroups $\left(\mathrm{I}^{2}=50 \%\right.$; $\mathrm{P}$ value 0.01$)$.

\section{Mean age ( $\leq$ and $>65$ years)}

Most studies included participants over age 65 , but all population mean ages were much lower than the cutoff. As we did not have access to individual participant data within the trials, we were unable to draw any conclusions regarding potential differential effects of $\mathrm{IV} \mathrm{MgSO}_{4}$ due to age.

\section{Co-medications (with and without nebulised ipratropium bromide)}

The test for subgroup differences showed no significant differences between the four studies that administered nebulised ipratropium bromide as a co-medication and those that did not $\left(\mathrm{I}^{2}=0 \%\right.$; value 0.82 ). Between-trial heterogeneity was not statistically significant within either of the two subgroups $\left(\mathrm{I}^{2}=28 \%\right.$; $\mathrm{P}$ value $0.18)$.

\section{Sensitivity analysis}

\section{Studies at high risk of bias for blinding}

When three studies that were given a 'high' or 'unclear' rating for blinding were removed (Bilaceroglu 2001; Green 1992; Matusiewicz 1994), the pooled effect for hospital admissions was slightly larger in favour of $\mathrm{IV} \mathrm{MgSO}_{4}$ (OR $0.72,95 \% \mathrm{CI} 0.57$ to 0.91; Analysis 2.3). Heterogeneity was slightly larger than in the main analysis, but this difference was not statistically significant $\left(\mathrm{I}^{2}=35 \%\right.$; P value 0.15$)$.

\section{Unpublished data}

Of the two studies for which only a conference abstract was available, one reported hospital admissions (Matusiewicz 1994). When this study was removed from the primary outcome, the magnitude of the effect in favour of IV $\mathrm{MgSO}_{4}$ was slightly increased (OR $0.73,95 \%$ CI 0.58 to 0.91 ), but this did not change the conclusions. Some heterogeneity that was not significant was reported (I $2=32 \%$; P value 0.15$)$. 
Fourteen studies met the inclusion criteria, randomly assigning 2313 people with acute asthma to the comparisons of interest in this review. A recent large study (Goodacre 2013) accounted for a large proportion of the total number of participants $(n=752)$.

The included studies were mostly randomised, double-blinded trials comparing $1.2 \mathrm{~g}$ or $2 \mathrm{~g} \mathrm{IV} \mathrm{MgSO}_{4}$ versus a matching placebo infusion. All of these studies included participants who had an exacerbation of asthma, although definitions and inclusion criteria varied. Ten studies included only adults; four included adults and children and were included because the mean age was over 18 years. Inclusion criteria varied, and studies assigned a level of severity to participants, which we then verified against BTS/SIGN 2012 criteria, confirming that all studies included exacerbations of at least moderate severity.

Eleven studies could be included in the primary analysis and showed that IV $\mathrm{MgSO}_{4}$ reduced hospital admissions compared with placebo (OR $0.75,95 \%$ CI 0.60 to $0.92 ; \mathrm{I}^{2}=28 \%$; P value $0.18 ; n=972$; high-quality evidence). In absolute terms, this odds ratio translates into a reduction of seven hospital admissions for every 100 adults ( $95 \%$ CI two to 13 fewer) treated with $\mathrm{IV} \mathrm{MgSO}_{4}$ (Figure 3). The test for subgroup differences did not reveal statistical heterogeneity between the three severity subgroups $\left(\mathrm{I}^{2}=\right.$ $0 \%$; P value 0.73 ), or between the four studies that administered nebulised ipratropium bromide as a co-medication and those that did not $\left(\mathrm{I}^{2}=0 \% ; \mathrm{P}\right.$ value 0.82$)$. Sensitivity analyses removing unpublished data and studies at high risk for blinding from the primary analysis did not change conclusions; this increased our confidence in the effect.

Within the secondary outcomes, evidence of high and moderate quality across three spirometric indices suggested some improvement in lung function with $\mathrm{IV} \mathrm{MgSO}_{4}$; however the clinical significance of the size of these effects is uncertain, and baseline imbalances in the largest study reduced our confidence in some of the findings. Although close, the mean difference in PEF (L/min) found in this meta-analysis did not reach the minimal clinically important difference (MCID) defined by Santanello 1999 (18.79 $\mathrm{L} / \mathrm{min}$ ). There are no accepted MCIDs for the percentage predicted measures reported in most of the trials. Mean $\mathrm{FEV}_{1}$ in litres, for which an MCID does exist, was reported in only two of the 14 trials.

No difference between $\mathrm{IV} \mathrm{MgSO}_{4}$ and placebo was found for most of the non-spirometric secondary outcomes, all of which were rated of low or moderate quality (intensive care admissions, ED treatment duration, length of hospital stay, readmission, respiration rate, systolic blood pressure).

Adverse events were inconsistently reported and were not metaanalysed. The most commonly cited adverse events in the IV $\mathrm{MgSO}_{4}$ groups were flushing, fatigue, nausea and headache and hypotension. However we found no significant difference in blood pressure between the $\mathrm{IV} \mathrm{MgSO}_{4}$ and placebo groups.

\section{Overall completeness and applicability of evidence}

A large degree of variation between prescribing procedures was evident in the trials, but doses used in the included studies are in accord with current BTS/SIGN 2012, GINA 2011 and NACA 2006 guidelines. However, the treatment protocols differed as to when the decision to administer $\mathrm{IV} \mathrm{MgSO}_{4}$ was made; the dosage, frequency and form of co-medications and the order in which the medications were administered in relation to one another. We suspect that differences between individual EDs both within and among countries were significant, and insufficient reporting in the trials themselves further complicated interpretation of the subgroup analysis for co-medications. As such, although no evidence suggested a difference in the efficacy of IV $\mathrm{MgSO}_{4}$ delivered in settings where ipratropium bromide was prescribed, we cannot exclude the possibility that other combinations of co-medications may significantly alter the effectiveness of $\mathrm{IV} \mathrm{MgSO}_{4}$. Moreover, as almost all of the studies administered short-acting beta 2 -agonists, oxygen and IV corticosteroids before $\mathrm{MgSO}_{4}$, the evidence is suitably applied to situations for which these medications have already been prescribed. Doses of magnesium used and method and rate of delivery were relatively consistent across studies $(1.2 \mathrm{~g}$ to $2 \mathrm{~g}$ via 15 to 30 -minute infusion), so it is not clear whether the same effect would be observed with alternative administrations (e.g. higher dose, bolus).

The definition of hospital admission may have varied between the healthcare settings in which these studies were carried out, and this was not clearly defined in the studies. We accept that variation exists in the broader health and economic environments and in health infrastructures, such as the use of clinical decision making or observation wards, and that this is likely to have influenced the decision to admit. This variation is likely to have introduced heterogeneity in the primary outcome.

The previous version of this review (Rowe 2009) suggested the possibility of greater efficacy of treatment in more severe exacerbations; this partially informed our decision to perform a subgroup analysis based on severity. We did not find a statistically significant difference between the three severity subgroups; however, the method that we used to allocate baseline severity had limitations. We based this classification on BTS/SIGN 2012 criteria, but reporting of baseline metrics on which this guidance is based was insufficient in several studies. In studies that subdivided the population on the basis of severity (Bilaceroglu 2001; Bloch 1995; Bradshaw 2007), subgroups with a more severe condition gained greater benefit with respect to hospital admission. This suggests that within-study subgroups may serve as a more reliable way of assessing severity as an effect modifier by controlling for differences in other variables that may exist between study protocols. We were unable to draw conclusions regarding the potential effects of age on study outcomes, as none of the studies recruited older adults. It is possible that diagnosis in this age group would be complicated by important co-morbidities (e.g. chronic obstructive 
pulmonary disease (COPD)), and that these might also affect the safety and effectiveness of IV $\mathrm{MgSO}_{4}$. As such, it is likely that the conclusions of this review are not applicable to this population, or to children younger than the age of 12 .

Several outcomes showed significant statistical heterogeneity among studies that was not accounted for by subgrouping results by severity of exacerbations (heart rate (HR), systolic blood pressure (BP), PEF in L/min, length of hospital stay). For HR, systolic $\mathrm{BP}$ and $\mathrm{PEF}$ in $\mathrm{L} / \mathrm{min}$, variation may be explained in part by when and how the measurement was taken, measurement error and the influence of co-medications. Length of hospital stay is highly dependent on local hospital guidelines and procedures.

We were unable to meta-analyse data related to adverse events and therefore could not draw conclusions about the safety of IV $\mathrm{MgSO}_{4}$ in asthma. Some commonly cited adverse events were consistently reported among the studies; however, the methods of recording adverse events appeared unsystematic.

\section{Quality of the evidence}

We used GRADEpro software to assess the quality of all outcomes; this assessment is summarised in the text and in the Summary of findings for the main comparison. Most outcomes were not downgraded for risk of bias, and in the two cases in which this was done, the decision was related primarily to insufficient blinding. It is unclear how this may have affected results for the primary outcome (i.e. decision to admit), but a sensitivity analysis excluding studies in which blinding was insufficient or unclear showed that this bias is unlikely to have significantly affected the pooled estimate.

Several outcomes were downgraded for inconsistency, that is, statistical heterogeneity, between studies. In these cases we performed sensitivity analyses using a random-effects model, which did not alter conclusions. The clinical source of the statistical heterogeneity remains unclear in most cases, as planned subgroup analyses were performed only on the primary outcome. Most of the secondary outcomes for which heterogeneity was observed contained a small number of studies; therefore it is unlikely that subgrouping of results would have allowed a meaningful distinction between severity or co-medication subgroups.

Studies included in this review were directly relevant to our review question with respect to participants recruited, interventions and comparisons provided, healthcare setting selected, and outcome measures used, so none of the evidence was downgraded for indirectness.

Four outcomes were downgraded for imprecision on the basis of their wide confidence intervals (intensive care unit (ICU) admission, ED treatment duration, $\mathrm{PEF}$ in $\mathrm{L} / \mathrm{min}$, respiratory rate $(\mathrm{RR})$ ). In each case the review authors made a clinical judgement regarding the minimal clinically important difference in relation to the confidence intervals. Moreover, with the exception of ED treatment duration, evidence from related outcomes (e.g. other spirometric measures) helped us draw conclusions when imprecision was due to a small number of participants or events.

No outcomes were downgraded for publication bias, although several of the secondary outcomes included a small number of studies. No incidences were identified in which studies stated outcomes and failed to report them, but this was generally a result of insufficient reporting of intended outcomes and the fact that the studies could not be linked to trial registrations. Most studies were conducted before adherence to trial registration or reporting standards was common practice, so in most cases we were unable to definitively judge whether the evidence was compromised as a result of deliberate or inadvertent selective reporting.

To resolve uncertainties related to risk of bias and missing data, we made an effort to contact all study authors. We received additional data from four of these authors (Bilaceroglu 2001; Bloch 1995; Goodacre 2013; Singh 2008), were unable to obtain current contact details for two (Matusiewicz 1994; Porter 2001) and received no response from the remaining eight.

\section{Potential biases in the review process}

We made every effort to adhere to Cochrane methods during the review process. All study characteristics and numerical data were extracted by at least two review authors, and discrepancies were resolved through discussion. The same was true for risk of bias ratings, and none of the review authors have conflicting interests. We performed relatively broad searches that were screened by at least two review authors independently, and we included studies regardless of language of publication. As a result, It is unlikely that any published studies were missed during study selection. In addition, review authors attempted to contact all study authors to clarify study methodology or to obtain additional data when details were not included in the published reports. We received detailed replies and additional data from four study authors, but in most cases, it was unclear whether study authors had failed to receive the request or were simply unable to provide the information required. The subgroup analysis based on exacerbation severity introduced the potential for internal bias, despite efforts to remove bias by consultation with an independent fourth party. Although we were transparent in the method of classification, an element of subjectivity due to reporting standards was noted in some trials; this reduced our confidence in the subgroup findings.

\section{Agreements and disagreements with other studies or reviews}

Our literature search identified five systematic reviews with metaanalyses comparing use of $\mathrm{IV} \mathrm{MgSO}_{4}$ versus placebo in adults with acute asthma (Alter 2000; Mohammed 2007; Rodrigo 2000; Rowe 2009; Shan 2013). One of these, Rowe 2009, was a previous Cochrane review, and Shan 2013, the most recent research 
synthesis, included the greatest number of trials $(n=16), 10$ of which are included in this review.

The main outcomes analysed were hospital admissions and spirometric data. None of the existing reviews found a statistically significant reduction in hospital admissions across all severity subgroups. However Rowe 2009 found a significant reduction in hospital admissions within the more severe group (OR 0.10, 95\% CI 0.04 to 0.27 ) and suggested that $\mathrm{IV} \mathrm{MgSO}_{4}$ might play a role in these more severe exacerbations. Hospital admission data for Shan 2013 were on the border of statistical significance (P value 0.06). Alter 2000 and Shan 2013 reported significant improvement in pooled spirometric measures for those receiving $\mathrm{IV} \mathrm{MgSO}_{4}$, whilst Mohammed 2007 reported weak evidence to support this (SMD 0.25 , 95\% CI -0.01 to 0.51 ; P value 0.05 ). Pooled analyses in Rodrigo 2000 and Rowe 2009 showed no significant improvement

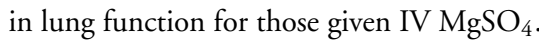

In keeping with these reviews, we found evidence that $\mathrm{IV} \mathrm{MgSO}_{4}$ improves lung function on a variety of spirometric measures. However, our findings differ in that when all data regardless of severity criteria were pooled, a statistically significant reduction in hospital admissions was seen among those treated with $\mathrm{IV} \mathrm{MgSO}_{4}$. We did not draw firm conclusions regarding the extent to which severity of exacerbation affects the efficacy of IV $\mathrm{MgSO}_{4}$ because differences in the ways the studies were conducted made it difficult to assess the effect of exacerbation severity independent of other effect moderators.

Several reasons may account for the discrepancies between our conclusions and those of previous evidence syntheses. Unlike some previous systematic reviews (Alter 2000; Mohammed 2007; Rowe 2009; Shan 2013), our inclusion criteria did not include paediatric trials. Several additional trials have been published since the previous version of this review, and this warranted synthesising of data for adults separately from data for children (Bijani 2001; Bilaceroglu 2001; Boonyavorakul 2000; Bradshaw 2007; Del Castillo Rueda 1991; Goodacre 2013; Matusiewicz 1994; Porter 2001; Singh 2008). One of these trials, Goodacre 2013, is a recent randomised controlled trial with a large sample size; it accounted for a significant proportion of the total weight in several of our analyses. Evidence for the use of $\mathrm{IV} \mathrm{MgSO}_{4}$ in the paediatric population will be analysed in a separate Cochrane review, which is currently in production. Some previous syntheses have included trials of nebulised magnesium sulfate (Mohammed 2007; Rodrigo 2000; Shan 2013), which we did not include, as this is the subject of an existing Cochrane review (Powell 2012).

\section{AUTHORS' CONCLUSIONS}

\section{Implications for practice}

This review provides evidence that a single infusion of $1.2 \mathrm{~g}$ or $2 \mathrm{~g}$ IV $\mathrm{MgSO}_{4}$ over 15 to 30 minutes reduces hospital admissions and improves lung function in adults with acute asthma who have not responded sufficiently to oxygen, nebulised short-acting beta 2 -agonists and IV corticosteroids. Differences in the ways the trials were conducted made it difficult to assess whether the severity of the exacerbation, or additional co-medications, altered the treatment effect of $\mathrm{IV} \mathrm{MgSO}_{4}$. Evidence for other measures of benefit and safety was limited.

\section{Implications for research}

Studies conducted in these populations should clearly define baseline severity parameters and systematically record adverse events. Studies recruiting participants with exacerbations of varying severity should consider subgrouping results on the basis of accepted severity classifications.

\section{ACKNOWLEDGEMENTS}

We acknowledge Chris Cates for assistance in classifying the baseline severity of study populations and contributions to clinical interpretation of study findings.

Brian Rowe was the Editor for this review and commented critically on the review.

We are grateful to study authors who provided additional data and clarifications (Bilaceroglu 2001; Bloch 1995; Goodacre 2013; Singh 2008).

CRG Funding Acknowledgement: The National Institute for Health Research (NIHR) is the largest single funder of the Cochrane Airways Group.

Disclaimer: The views and opinions expressed herein are those of the review authors and do not necessarily reflect those of the NIHR, the NHS or the Department of Health. 


\section{R E F E R E N C E S}

\section{References to studies included in this review}

Bijani 2001 \{published and unpublished data\}

Bijani K, Moghadamnia AA, Islami Khalli E. Intravenous magnesium sulfate as an adjunct in the treatment of severe asthmatic patients non-responding to conventional therapy. http://ispub.com/IJAAI/2/1/12115 (accessed 7 March 2013).

Bijani KH, Moghadamnia AA, Islami Khalili E. Intravenous magnesium sulfate as an adjunct in the treatment of severe asthmatic patients non-responding to conventional therapy. Acta Medica Iranica 2001;39(4):219-21.

Bilaceroglu 2001 \{published and unpublished data\} Bilaceroglu S, Akpinar M, Tiras A, Celikten E, Kalenci D, Perim K. Intravenous magnesium sulphate in acute asthma. American Thoracic Society 97th International Conference; May 18-23; San Francisco. 2001.

Bloch 1995 \{published and unpublished data\}

Bloch H, Silverman R, Mancherje N, Grant S, Jagminas L, Scharf SM. Intravenous magnesium sulfate as an adjunct in the treatment of acute asthma. Chest 1995;107(6): 1576-81.

Boonyavorakul 2000 \{published and unpublished data\} Boonyavorakul C, Thakkinstian A, Charoenpan P. Intravenous magnesium sulfate in acute severe asthma. Respirology 2000;5(3):221-5.

Bradshaw 2007 \{published and unpublished data\} Bradshaw TA, Matusiewicz SP, Crompton GK, Alastair Innes J, Greening AP. Intravenous magnesium sulphate provides no additive benefit to standard management in acute asthma. Respiratory Medicine 2008;102(1):143-9.

Del Castillo Rueda 1991 \{published and unpublished data\} del Castillo Rueda A, Recarte García-Andrade C, Torres Segovia FJ. Magnesium, the 4th drug in asthma treatment?. Revista Clinica Espanola 1991;189(5):250.

Goodacre 2013 \{published and unpublished data\} Goodacre $\mathrm{S}$. The $3 \mathrm{Mg}$ study: a randomised trial of intravenous or nebulised magnesium sulphate versus placebo for acute severe asthma. http://www.controlledtrials.com/ISRCTN04417063 (accessed 10 March 2014). Goodacre S, Cohen J, Bradburn M, Gray A, Benger J, Coats $\mathrm{T}$. Intravenous or nebulised magnesium sulphate versus standard therapy for severe acute asthma (3Mg trial): a double-blind, randomised controlled trial. The Lancet Respiratory Medicine 2013;1(4):293-300.

Goodacre S, Cohen J, Bradburn M, Stevens J, Gray A, Benger J, Coats $\mathrm{T}$. The $3 \mathrm{Mg}$ trial: a randomised controlled trial of intravenous or nebulised magnesium sulphate versus placebo in adults with acute severe asthma. Health Technology Assessment 2013;18(22):1-168.

Green 1992 \{published and unpublished data\}

Green SM, Rothrock SG. Intravenous magnesium for acute asthma: failure to decrease emergency treatment duration or need for hospitalization. Annals of Emergency Medicine 1992;21(3):260-5.

Pugh G. Intravenous magnesium for acute asthma. Annals of Emergency Medicine 1993;22(3):617.

Matusiewicz 1994 \{published and unpublished data\} Matusiewicz SP, Cusack S, Greening AP, Crompton GK. A double blind placebo controlled parallel group study of intravenous magnesium sulphate in acute severe asthma [abstract]. European Respiratory Journal 1994;7(Suppl 18): $14 \mathrm{~s}$.

Porter 2001 \{published and unpublished data\} Porter RS, Nester N, Braitman LE, Geary U, Dalsey WC, Nester BA, et al.Intravenous magnesium is ineffective in adult asthma, a randomized trial. European Journal of Emergency Medicine 2001;8(1):9-15.

Silverman 2002 \{published and unpublished data\} Silverman RA, Osborn H, Runge J, Gallagher EJ, Chiang W, Feldman J, et al.IV magnesium sulfate in the treatment of acute severe asthma: a multicenter randomized controlled trial. Chest 2002;122(2):489-97. [: 0012-3692]

Singh 2008 \{published and unpublished data\}

Singh AK, Gaur S, Kumar R. A randomized controlled trial of intravenous magnesium sulphate as an adjunct to standard therapy in acute severe asthma. Iranian Journal of Allergy, Asthma, and Immunology 2008;7(4):221-9.

Singh AK, Gaur SN, Kumar R. Comparison of efficacy of intravenous and inhaled magnesium sulphate as an adjunct to standard therapy in acute severe asthma [Abstract]. European Respiratory Society 18th Annual Congress; Oct 3-7; Berlin. 2008:[P3620].

Skobeloff 1989 \{published and unpublished data\} Skobeloff EM, Spivey WH, McNamara RM, Greenspoon L. Intravenous magnesium sulfate for the treatment of acute asthma in the emergency department. JAMA 1989;262(9): 1210-3.

Tiffany 1993 \{published and unpublished data\} * Tiffany BR, Berk WA, Todd IK, White SR. Magnesium bolus or infusion fails to improve expiratory flow in acute asthma exacerbations. Chest 1993;104(3):831-4.

\section{References to studies excluded from this review}

Abreu-Gonzalez 2002 \{published data only\} Abreu-Gonzalez J, Rodríguez-Díaz CY. Magnesium and bronchodilator effect of beta-adrenergic. American Journal of Respiratory and Critical Care Medicine 2002;165(Suppl 8):A185.

Brunner 1985 \{published data only\} Brunner EH, Delabroise AM, Haddad ZH. Effect of parenteral magnesium on pulmonary function, plasma cAMP, and histamine in bronchial asthma. Journal of Asthma 1985;22(1):3-11. 
Cairns 1996a \{published data only\}

Cairns CB, Kraft M. Magnesium attenuates the neutrophil respiratory burst in adult asthmatic patients. Academic Emergency Medicine 1996;3(12):1093-7.

Harmanci 1996 \{published data only\} Harmanci E, Ekici M, Erginel S, Ozdemir N, Ozkan G. Comparison of effects of nebulized to intravenous magnesium sulfate on bronchial hyperreactivity and expiratory flow rate in asthmatic patients. European Respiratory Journal 1996;9 Suppl 23:34s.

Hill 1996 \{published data only\}

Hill JM, Britton J. Effect of intravenous magnesium sulphate on airway calibre and airway reactivity to histamine in asthmatic subjects. British Journal of Clinical Pharmacology 1996;42(5):629-31.

Liang 1998 \{published data only\}

Liang XG. Analysis of the effect of magnesium sulfate in the treatment of asthmatoid disease. Chinese Journal of Modern Medicine 1998;8(2):29.

Okayama 1987 \{published data only\}

Okayama H, Aikawa T, Okayama M, Sasaki H, Mue $\mathrm{S}$, Takishima T. Bronchodilating effect of intravenous magnesium sulfate in bronchial asthma. Journal of American Medical Association 1987;257(8):1076-8.

Rolla 1988 \{published data only\}

Rolla G, Bucca C, Caria E, Arossa W, Bugiani M, Cesano $\mathrm{L}$, et al.Acute effect of intravenous magnesium sulfate on airway obstruction of asthmatic patients. Annals of Allergy 1988;61(5):388-91.

Rolla 1994 \{published data only\}

Rolla G, Bucca C, Brussino L, Colagrande P. Effect of intravenous magnesium infusion on salbutamol-induced bronchodilatation in patients with asthma. Magnesium Research 1994;7(2):129-33.

Schenk 2001 \{published data only\}

Schenk P, Vonbank K, Schnack B, Haber P, Lehr S, Smetana R. Intravenous magnesium sulfate for bronchial hyperreactivity: a randomized, controlled, double-blind study. Clinical Pharmacology and Therapeutics 2001;69(5): $365-71$.

\section{References to studies awaiting assessment}

\section{Abd El Kader 1997 \{published data only\}}

Abd El Kader F. Ventilatory, cardiovascular and metabolic responses to salbutamol, ipratropium bromide and magnesium sulfate in bronchial asthma: comparative study. Alexandria Medical Journal [The] 1997;39(1):43-64.

\section{Additional references}

\section{Alter 2000}

Alter HJ, Koepsell TD, Hilty WM. Intravenous magnesium as an adjuvant in acute bronchospasm: a meta-analysis. Annals of Emergency Medicine 2000;36(3):191-7.

\section{Asthma UK}

Asthma UK. Asthma Facts and FAQs. http:// www.asthma.org.uk/asthma-facts-and-statistics (accessed 8 October 2013)

\section{BTS/SIGN 2012}

British Thoracic Society/Scottish Intercollegiate Guidelines Network (BTS/SIGN). British Guideline on the Management of Asthma. http://www.brit-thoracic.org.uk/ guidelines/asthma-guidelines.aspx (accessed 8 October 2013).

\section{Cairns 1996}

Cairns CB, Krafi M. Magnesium attenuates the neutrophil respiratory burst in adult asthmatic patients. Academic Emergency Medicine 1996;3(12):1093-7.

CDC

Centers for Disease Control and Prevention. Asthma Surveillance Data. http://www.cdc.gov/asthma/ (accessed 25 November 2013).

\section{DOH 2012}

Department of Health. An Outcomes Strategy for COPD and Asthma: NHS Companion Document. www.dh.gov.uk/publications (accessed 3 December 2013).

Dominguez 1998

Dominguez LJ, Barbagallo M, Di Lorenzo G, Drago A, Scola S, Morici G, et al.Bronchial reactivity and intracellular magnesium: a possible mechanism for the bronchodilating effects of magnesium in asthma. Clinical Science 1998;95: $137-42$.

GINA 2011

Global Initiative for Asthma (GINA). Global Strategy for Asthma Management and Prevention. http:// www.ginasthma.org/ (accessed 20 October 2013).

Gourgoulianis 2001

Gourgoulianis KI, Chatziparasidis G, Chatziefthimiou A, Molyvdas PA. Magnesium as a relaxing factor of airway smooth muscles. Journal of Aerosol Medicine 2001;14(3): 301-7. [PUBMED: 11693841]

Griffiths 2013

Griffiths B, Ducharme FM. Combined inhaled anticholinergics and short-acting beta2-agonists for initial treatment of acute asthma in children. Cochrane Database of Systematic Reviews 2013, Issue 9. [DOI: 10.1002/ 14651858.CD000060.pub2]

Griffiths 2014

Griffiths B, Kew Kayleigh M, Michell Clare I, Kirtchuk L. Intravenous magnesium sulfate for treating children with acute asthma in the emergency department. Cochrane Database of Systematic Reviews 2014, Issue 4. [DOI: 10.1002/14651858.CD011050; : CD011050]

\section{Higgins 2011}

Higgins JPT, Green S (editors). Cochrane Handbook for Systematic Reviews of Interventions Version 5.1 [updated March 2011]. The Cochrane Collaboration. www.cochrane-handbook.org 2011. 


\section{Mohammed 2007}

Mohammed S, Goodacre S. Intravenous and nebulised magnesium sulphate for acute asthma: systematic review and meta-analysis. Emergency Medicine Journal 2007;24: 823-30.

\section{NACA 2006}

National Asthma Council Australia. Asthma Management Handbook. http://www.nationalasthma.org.au/handbook (accessed 25 November 2013).

\section{NAEPP 2007}

National Asthma Education and Prevention Program. Guidelines for the Diagnosis and Management of Asthma. www.nhlbi.nih.gov/guidelines/asthma/asthgdln.pdf (accessed 25 November 2013).

Powell 2012

Powell C, Dwan K, Milan SJ, Beasley R, Hughes R, Knopp-Sihota JA, et al.Inhaled magnesium sulfate in the treatment of acute asthma. Cochrane Database of Systematic Reviews 2012, Issue 12. [DOI: 10.1002/ 14651858.CD003898.pub5]

\section{Review Manager (RevMan)}

The Nordic Cochrane Centre, The Cochrane Collaboration. Review Manager (RevMan). 5.2. Copenhagen: The Nordic Cochrane Centre, The Cochrane Collaboration, 2012.

\section{Rodrigo 2000}

Rodrigo G, Rodrigo C, Burschtin O. Efficacy of magnesium sulfate in acute adult asthma: a meta- analysis of randomized trials. American Journal of Emergency Medicine 2000;18(2): 216-21.

Rowe 2013

Rowe $\mathrm{BH}$. Intravenous and inhaled $\mathrm{MgSO} 4$ for acute asthma. The Lancet Respiratory Medicine 2013;1(4):276-7. [DOI: 10.1016/S2213-2600(13)70097-3]

\section{Santanello 1999}

Santanello NC, Zhang J, Seidenberg B, Reiss TF, Barber BL. What are minimal important changes for asthma measures in a clinical trial?. European Respiratory Journal 1999;14(1): 23-7.

Shan 2013

Shan Z, Rong Y, Yang W, Wang D, Yao P, Xie J, Liu L. Intravenous and nebulized magnesium sulfate for treating acute asthma in adults and children: a systematic review and meta-analysis. Respiratory Medicine 2013;107(3):321-30.

\section{Spivey 1990}

Spivey WH, Skobeloff EM, Levin RM. Effect of magnesium chloride on rabbit bronchial smooth muscle. Annals of Emergency Medicine 1990;19(10):1107-12.

Teoh 2012

Teoh L, Cates C, Hurwitz M, Acworth JP, Van Asperen P, Chang AB. Anticholinergic therapy for acute asthma in children. Cochrane Database of Systematic Reviews 2012, Issue 4. [DOI: 10.1002/14651858.CD003797.pub2]

\section{References to other published versions of this review}

\section{Kew 2014}

Kew KM, Kirtchuk L, Michell CI, Griffiths B. Intravenous magnesium sulfate for treating adults with acute asthma in the emergency department. Cochrane Database of Systematic Reviews 2014, Issue 1. [DOI: 10.1002/ 14651858.CD010909]

\section{Rowe 2009}

Rowe BH, Bretzlaff J, Bourdon C, Bota G, Blitz S, Camargo CA. Magnesium sulfate for treating exacerbations of acute asthma in the emergency department. Cochrane Database of Systematic Reviews 2009, Issue 3. [DOI: 10.1002/ 14651858.CD001490]

* Indicates the major publication for the study 


\title{
CHARACTERISTICS OF STUDIES
}

\section{Characteristics of included studies [ordered by study ID]}

\author{
Bijani 2001
}

Methods

Design: randomised, double-blind, placebo-controlled study based in Iran. No information provided regarding location of trial or dates when it was carried out

Final measurement of outcomes performed at 180 minutes with participants followed for 6 hours

Participants

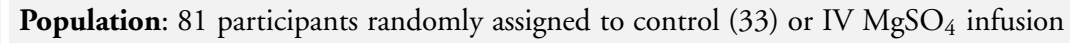
(48)

Inclusion criteria: asthmatic individuals aged 12 to 85 years with an exacerbation of asthma and a peak expiratory flow $(\mathrm{PEF})<200 \mathrm{~L} / \mathrm{min}$ who had taken bronchodilators and corticosteroids and required assisted ventilation. All participants who did not respond to treatment during the next 6 hours selected for investigation

Exclusion criteria: not reported
Control group: $100 \mathrm{~mL}$ normal saline infused over 30 to 45 minutes after 6 hours of no response to standard treatment

IV MgSO$_{4}$ group: $25 \mathrm{mg} / \mathrm{kg}$ in $100 \mathrm{~mL}$ normal saline infused over 30 to 45 minutes after 6 hours of no response to standard treatment

Co-interventions: All participants received oxygen, nebulised oxygen, nebulised salbutamol, IV aminophylline and corticosteroids
Outcomes

Notes
PEF; breathing rate; cyanosis; diaphoresis; use of respiratory muscles; ABGs all measured at baseline

Baseline severity of population: life threatening (based on $31 \%$ predicted PEF, respiration rate 35 breaths per minute)

\section{Risk of bias}

\begin{tabular}{|c|c|c|}
\hline Bias & Authors' judgement & Support for judgement \\
\hline $\begin{array}{l}\text { Random sequence generation (selection } \\
\text { bias) }\end{array}$ & Unclear risk & $\begin{array}{l}\text { 'Randomised' but no information provided } \\
\text { as to how this was done }\end{array}$ \\
\hline Allocation concealment (selection bias) & Unclear risk & No information provided \\
\hline $\begin{array}{l}\text { Blinding of participants and personnel } \\
\text { (performance bias) } \\
\text { All outcomes }\end{array}$ & Low risk & $\begin{array}{l}\text { 'Double-blind' study; } \mathrm{IV} \mathrm{MgSO}_{4} \text { and nor- } \\
\text { mal saline in 'identical containers' }\end{array}$ \\
\hline $\begin{array}{l}\text { Blinding of outcome assessment (detection } \\
\text { bias) } \\
\text { All outcomes }\end{array}$ & Unclear risk & $\begin{array}{l}\text { 'Double-blind' study; investigators report } \\
\text { that 'decoding was done at the completion } \\
\text { of the study.' However the study authors do } \\
\text { not specifically report who was measuring } \\
\text { outcomes }\end{array}$ \\
\hline
\end{tabular}

Intravenous magnesium sulfate for treating adults with acute asthma in the emergency department (Review) 
Bijani 2001 (Continued)

\begin{tabular}{l|l|l}
$\begin{array}{l}\text { Incomplete outcome data (attrition bias) } \\
\text { All outcomes }\end{array}$ & Unclear risk & No withdrawal rates provided \\
\hline Selective reporting (reporting bias) & Low risk & $\begin{array}{l}\text { Everything reported except ABG (but this } \\
\text { is not a primary outcome) No protocol } \\
\text { available. Otherwise all outcomes well re- } \\
\text { ported }\end{array}$ \\
\hline
\end{tabular}

Bilaceroglu 2001

Methods

Design: Randomised, single-blind trial based in Turkey. Trial was carried out in a specialist respiratory hospital in Turkey between December 1995 and December 1996

Final measurement of outcomes performed at 210 minutes, and participants followed up for 1 week afterward

Participants

Population: 81 participants randomly assigned to Group 1-moderate asthma (PEF > $40 \%)(\mathrm{n}=50)$ or Group 2-severe asthma (PEF < 40\%) $(\mathrm{n}=31)$ Within Group 1, participants randomly assigned to placebo (salbutamol + placebo $)(n=27)$ or intervention (salbutamol + magnesium) $(\mathrm{n}=23)$. Within Group 2, participants randomly assigned to placebo (salbutamol + corticosteroid + placebo) $(n=14)$ or intervention (salbutamol + corticosteroid + magnesium $)(\mathrm{n}=17)$

Inclusion criteria: Asthmatic participants (defined by American Thoracic Society Criteria) aged 6 to 65 years (average age 35 years) with PEF increasing by $<50 \%$ and/or $\mathrm{FEV}_{1}<75 \%$ after a single salbutamol nebuliser $(2.5 \mathrm{mg}$ salbutamol in $2.5 \mathrm{~mL}$ saline)

Exclusion criteria: diabetes mellitus, congestive heart failure, hypertension, chronic renal failure,

fever $>38^{\circ} \mathrm{C}$, pneumonia, under mechanical ventilation and/or having suspicion of pregnancy. Furthermore, participants with $>50 \%$ increase in PEF after beta-agonist inhalation, or with $\mathrm{FEV}_{1}$ higher than $75 \%$ of predicted value at presentation or after inhaled beta-agonist (response to treatment)

Interventions

Control group: Group 1 given salbutamol + placebo (100 cc of 5\% dextrose solution). Group 2 given salbutamol (2.5 mg nebulised) + corticosteroid (125 mg prednisolone) + placebo (100 cc of $5 \%$ dextrose solution). In both groups, these were given at the 30 th minute of the participant's arrival

IV $\mathrm{MgSO}_{4}$ group: Group 1 given salbutamol $+2 \mathrm{mg} \mathrm{IV} \mathrm{MgSO}_{4}$ in $100 \mathrm{cc}$ dextrose solution. Group 2 given salbutamol $(2.5 \mathrm{mg}$ nebulised) + corticosteroid (125 mg prednisolone) $+2 \mathrm{mg} \mathrm{MgSO}_{4}$ in $100 \mathrm{cc}$ dextrose solution. Both groups given treatment at the 30 th minute of their arrival

Co-interventions: All participants received oxygen if $\mathrm{PaO}_{2}<60 \mathrm{mmHg}$

Outcomes

PEF, $\mathrm{FEV}_{1}$ and hospitalisation, length of hospital stay; change in systolic arterial pressure; change in respiration rate; dyspnoea; blood gases; serum $\mathrm{Mg}$; calcium; specific adverse events

Notes

Baseline severity of population: Moderate and severe groups in the trial reclassified as severe and life threatening, respectively, for consistency with other study classifications and BTS guidelines (BTS/SIGN 2012)

Intravenous magnesium sulfate for treating adults with acute asthma in the emergency department (Review)

Copyright @ 2014 The Cochrane Collaboration. Published by John Wiley \& Sons, Ltd. 
Bilaceroglu 2001 (Continued)

\section{Risk of bias}

\begin{tabular}{|c|c|c|}
\hline Bias & Authors' judgement & Support for judgement \\
\hline $\begin{array}{l}\text { Random sequence generation (selection } \\
\text { bias) }\end{array}$ & Unclear risk & $\begin{array}{l}\text { 'Randomised' study using } 1: 1 \text { tables but no } \\
\text { other information provided regarding se- } \\
\text { quence generation }\end{array}$ \\
\hline Allocation concealment (selection bias) & Unclear risk & No information provided \\
\hline $\begin{array}{l}\text { Blinding of participants and personnel } \\
\text { (performance bias) } \\
\text { All outcomes }\end{array}$ & High risk & $\begin{array}{l}\text { 'Single-blind' study. Only participants } \\
\text { blinded to the intervention }\end{array}$ \\
\hline $\begin{array}{l}\text { Blinding of outcome assessment (detection } \\
\text { bias) } \\
\text { All outcomes }\end{array}$ & High risk & $\begin{array}{l}\text { 'Single-blind' study. Only participants } \\
\text { blinded to the intervention }\end{array}$ \\
\hline $\begin{array}{l}\text { Incomplete outcome data (attrition bias) } \\
\text { All outcomes }\end{array}$ & Low risk & $\begin{array}{l}\text { Clear withdrawal rates provided. No with- } \\
\text { drawals described after suitable participants } \\
(\mathrm{n}=81) \text { were identified for randomisation. } \\
\text { (Data from all excluded participants ( } \mathrm{n}= \\
218 \text { ) before randomisation not used in the } \\
\text { analysis) }\end{array}$ \\
\hline Selective reporting (reporting bias) & Unclear risk & $\begin{array}{l}\text { Results given for stated outcomes, but some } \\
\text { data given only in graph format. Raw data } \\
\text { not provided }\end{array}$ \\
\hline
\end{tabular}

Bloch 1995

Methods

Design: randomised, double-blind, placebo-controlled study based in the USA. Trial carried out in 2 EDs of a voluntary and a university hospital in the USA between August 1990 and December 1991

Final measurement of outcomes performed at 240 minutes and participants followed up for 7 days

Participants

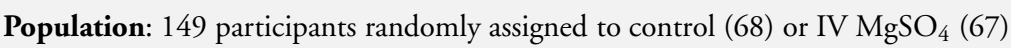
Inclusion criteria: asthmatic participants aged 18 to 65 years, with an exacerbation defined as $\mathrm{FEV}_{1}<75 \%$ predicted before and after a single dose of salbutamol

Exclusion criteria: past medical history of congestive cardiac failure, diabetes mellitus, angina or chronic kidney disease; temperature $>38^{\circ} \mathrm{C}$; pregnancy; pneumonia; requiring intubation; unable to perform spirometry; unable to consent; $\mathrm{FEV}_{1}>75 \%$ before or after single dose of salbutamol

Interventions

Control group: $50 \mathrm{~mL}$ of $0.9 \%$ normal saline given 30 minutes after entry and infused over 20 minutes

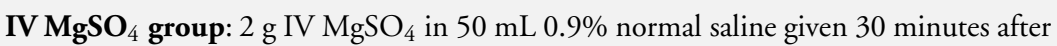




\begin{tabular}{|c|c|c|}
\hline & \multicolumn{2}{|c|}{$\begin{array}{l}\text { entry and infused over } 20 \text { minutes } \\
\text { Co-interventions: All participants received Inhaled albuterol }(2.5 \mathrm{mg} \text { in } 2.5 \mathrm{~mL} \text { normal } \\
\text { saline) on arrival. If } \mathrm{FEV}_{1}<40 \% \text { predicted, or if participants had received oral corticos- } \\
\text { teroids within the past } 6 \text { months, they received } 125 \mathrm{mg} \mathrm{IV} \text { methylprednisolone within } \\
30 \text { minutes of presentation. Some participants were already taking theophylline before } \\
\text { the time of presentation }\end{array}$} \\
\hline Outcomes & \multicolumn{2}{|c|}{$\begin{array}{l}\text { Hospitalisation rate; } \mathrm{FEV}_{1} \text { at } 2 \text { hours after baseline; repeat hospitalisations; respiratory } \\
\text { rate; heart rate; systolic blood pressure; Borg score; wheeze score; adverse events }\end{array}$} \\
\hline Notes & \multicolumn{2}{|c|}{$\begin{array}{l}\text { Funded by the Nina Weisman Pulmonary Research Fund } \\
\text { Baseline severity of population: moderate and severe groups in the trial reclassified as } \\
\text { severe and life threatening, respectively, for consistency with other study classifications } \\
\text { and BTS guidelines (BTS/SIGN 2012) }\end{array}$} \\
\hline \multicolumn{3}{|l|}{ Risk of bias } \\
\hline Bias & Authors' judgement & Support for judgement \\
\hline $\begin{array}{l}\text { Random sequence generation (selection } \\
\text { bias) }\end{array}$ & Low risk & $\begin{array}{l}\text { Randomly assigned by the pharmacy using } \\
\text { 'computer-generated tables' }\end{array}$ \\
\hline Allocation concealment (selection bias) & Low risk & $\begin{array}{l}\text { 'All physicians were blinded to the ran- } \\
\text { domisation that was done by the pharmacy' }\end{array}$ \\
\hline $\begin{array}{l}\text { Blinding of participants and personnel } \\
\text { (performance bias) } \\
\text { All outcomes }\end{array}$ & Low risk & $\begin{array}{l}\text { 'Double -blind' but no description of how } \\
\text { interventions were disguised }\end{array}$ \\
\hline $\begin{array}{l}\text { Blinding of outcome assessment (detection } \\
\text { bias) } \\
\text { All outcomes }\end{array}$ & Low risk & $\begin{array}{l}\text { No subjective assessor-rated outcomes, and } \\
\text { the investigators remained blind }\end{array}$ \\
\hline $\begin{array}{l}\text { Incomplete outcome data (attrition bias) } \\
\text { All outcomes }\end{array}$ & Low risk & $\begin{array}{l}\text { Attrition rates reported: 'Fourteen patients } \\
\text { were excluded after randomisation.' 'Four } \\
\text { patients were included as an intention to } \\
\text { treat because the protocol was violated...' } \\
\text { 'In six patients their baseline FEV1 was un- } \\
\text { available and these were included in the } \\
\text { analysis as a whole and excluded from sub- } \\
\text { group analysis' } \\
\text { Overall small attrition numbers }\end{array}$ \\
\hline Selective reporting (reporting bias) & Low risk & $\begin{array}{l}\text { Published report provided data only at one } \\
\text { of the prespecified time points; FEV1 was } \\
\text { provided graphically, but the study author } \\
\text { provided additional data upon request }\end{array}$ \\
\hline
\end{tabular}


Design: randomised, double-blind, placebo-controlled study based in Thailand. Trial carried out in a single ED between March and November 1997

Final measurement of outcomes performed at 240 minutes with no further follow-up of participants

Participants

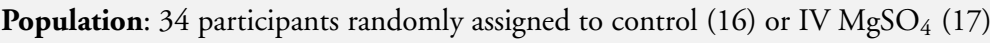

Inclusion criteria: asthmatic individuals aged 15 to 65 years with acute severe asthma, defined as having a severity score $>4$, who consented to enter the trial

Exclusion criteria: co-morbidities including ischaemic heart disease, hypertension, diabetes mellitus, chronic kidney disease, infection or pregnancy; or a FISCHL Index < 4

$\begin{array}{ll}\text { Interventions } & \text { Control group: } 2 \mathrm{~mL} \text { of sterile water in } 50 \mathrm{~mL} 0.9 \% \text { normal saline } \\ & \text { IV MgSO}_{4} \text { group: } 2 \mathrm{~g} \text { of } \mathrm{Mg} \mathrm{SO}_{4} \text { in } 50 \mathrm{~mL} 0.9 \% \text { normal saline } \\ \text { Co-interventions: All participants received } 5 \mathrm{mg} \text { intravenous dexamethasone, } 2.5 \mathrm{mg} \\ \text { nebulised salbutamol at } 0,20,40,60 \text { minutes and oxygen via mask if necessary }\end{array}$

Outcomes

Hospitalisation rate; severity score FISCHL Index at 0, 60, 120, 180, 240 minutes (comprising pulse rate, respiratory rate, PEF, dyspnoea, accessory muscle use and wheeze)

Notes

Baseline severity of population: life threatening (based on comparison of vital stats [HR $125 \mathrm{bpm}$, respiration rate 33] with other studies with multiple baseline measurements)

\section{Risk of bias}

\begin{tabular}{l|l|l} 
Bias & Authors' judgement & Support for judgement \\
\hline $\begin{array}{l}\text { Random sequence generation (selection } \\
\text { bias) }\end{array}$ & Low risk & $\begin{array}{l}\text { Randomly assigned using a 'computer gen- } \\
\text { erated random list' }\end{array}$ \\
\hline $\begin{array}{l}\text { Allocation concealment (selection bias) } \\
\text { Blinding of participants and personnel } \\
\text { (performance bias) } \\
\text { All outcomes }\end{array}$ & Low risk & Not reported \\
\hline
\end{tabular}

Blinding of outcome assessment (detection Low risk bias)

All outcomes
'Only 2 physicians took responsibility for caring for patients in ED. They measured all clinical data and made the decision regarding admission. They were blinded and the protocol was not violated during the study'

Incomplete outcome data (attrition bias) Low risk All outcomes
'One patient in the placebo group didn't consent and so was removed from the group.' Equal numbers of withdrawals from both groups (17 magnesium and 16 placebo) 
Boonyavorakul 2000 (Continued)

Selective reporting (reporting bias) High risk

Incomplete reporting: only the admission data given. Severity scores given only in terms of 'variance' and no raw data provided

Bradshaw 2007

Methods

Design: randomised, double-blind, placebo-controlled study based in Edinburgh. Trial carried out in a teaching hospital. No information provided regarding the dates of the study

Final measurement of outcomes performed at 60 minutes and no follow-up of participants reported

Participants

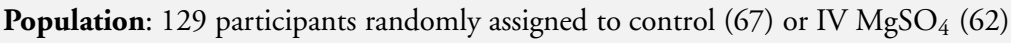

Inclusion criteria: asthmatic individuals aged 16 years and older, with asthma exacerbation defined as PEF $<75 \%$

Exclusion criteria: co-morbidities including chronic obstructive pulmonary disease, pneumonia, congestive cardiac failure, coronary artery disease, chronic kidney disease, hypertension or pregnancy; participants who are unable to carry out peak flow measurements

Interventions

Control group: $50 \mathrm{~mL} 0.9 \%$ normal saline infused over 15 minutes

IV $\mathrm{MgSO}_{4}$ group: $1.2 \mathrm{~g} \mathrm{IV} \mathrm{MgSO}_{4}$ in $50 \mathrm{~mL} 0.9 \%$ normal saline infused over 15 minutes

Co-interventions: All participants received $35 \%$ oxygen, $5 \mathrm{mg}$ nebulised salbutamol, $500 \mathrm{mcg}$ nebulised ipratropium bromide, $200 \mathrm{mg}$ IV hydrocortisone

Outcomes

$\%$ predicted PEF at 60 minutes (repeated at 15, 30, 45 and 60 minutes), hospital admission rates (decision made at 60 minutes), blood pressure and pulse at 60 minutes

Notes

Baseline severity of population: Moderate, severe and life-threatening classifications within the trial were not changed

Risk of bias

\begin{tabular}{|c|c|c|}
\hline Bias & Authors' judgement & Support for judgement \\
\hline $\begin{array}{l}\text { Random sequence generation (selection } \\
\text { bias) }\end{array}$ & Low risk & $\begin{array}{l}\text { 'Randomised using random number gen- } \\
\text { eration under the control of hospital phar- } \\
\text { macy' }\end{array}$ \\
\hline Allocation concealment (selection bias) & Low risk & $\begin{array}{l}\text { Randomisation done by pharmacy and } \\
\text { physicians remained blinded }\end{array}$ \\
\hline
\end{tabular}

Blinding of participants and personnel Low risk (performance bias)

'Double blind, placebo controlled study'. All outcomes IV $\mathrm{MgSO}_{4}$ and placebo 'identical in appearance' 
Bradshaw 2007 (Continued)

\begin{tabular}{|c|c|c|}
\hline $\begin{array}{l}\text { Blinding of outcome assessment (detection } \\
\text { bias) } \\
\text { All outcomes }\end{array}$ & Low risk & $\begin{array}{l}\text { No subjective assessor-rated outcomes }(3 \times \\
\text { PEF), and the investigators remained blind. } \\
\text { The 'decision to admit/discharge was made } \\
\text { by the attending physician' }\end{array}$ \\
\hline $\begin{array}{l}\text { Incomplete outcome data (attrition bias) } \\
\text { All outcomes }\end{array}$ & Low risk & $\begin{array}{l}\text { Well reported. } 21 \text { participants excluded } \\
\text { prior to randomisation. None after that }\end{array}$ \\
\hline Selective reporting (reporting bias) & High risk & $\begin{array}{l}\text { Incomplete reporting- primary and sec- } \\
\text { ondary outcomes given at } 60 \text { minutes but } \\
\text { not at other intervals (data given in graph } \\
\text { format but no raw data available, making } \\
\text { analysis difficult) }\end{array}$ \\
\hline
\end{tabular}

\section{Del Castillo Rueda 1991}

Methods

Design: randomised, no information on blinding, placebo-controlled study based in Spain. Trial carried out in one hospital in Madrid

Information regarding duration of the trial and follow-up of participants not provided

Participants

Population: 16 participants randomly assigned to control (6) and $\mathrm{IV}_{\mathrm{MgSO}_{4}}$ (10)

Inclusion criteria: participants with acute asthma. No details provided regarding age or how acute asthma was defined

Exclusion criteria: not reported

Interventions

Control group: not reported

IV $\mathrm{MgSO}_{4}$ Group: $1.2 \mathrm{~g}$ of $\mathrm{IV} \mathrm{MgSO}_{4}$ in physiological fluid infused over 20 minutes

Co-interventions: All participants received corticosteroids and beta- 2 agonists

Outcomes

PEF; ABG; hospitalisation rate; length of stay; adverse events

Notes Abstract only

Baseline severity of population: unknown, but did not contribute data to the primary analysis

\section{Risk of bias}

Bias Authors' judgement

Random sequence generation (selection Unclear risk bias)

Allocation concealment (selection bias) Unclear risk

\section{Support for judgement}

Authors describe the study as 'randomised, double blind,' but no details given about the blinding process. Difficult to comment based on the abstract alone

No information provided. Difficult to comment based on the abstract alone 


\section{Del Castillo Rueda 1991 (Continued)}

\begin{tabular}{|c|c|c|}
\hline $\begin{array}{l}\text { Blinding of participants and personnel } \\
\text { (performance bias) } \\
\text { All outcomes }\end{array}$ & Unclear risk & $\begin{array}{l}\text { No information provided. Difficult to } \\
\text { comment based on the abstract alone }\end{array}$ \\
\hline $\begin{array}{l}\text { Blinding of outcome assessment (detection } \\
\text { bias) } \\
\text { All outcomes }\end{array}$ & Unclear risk & $\begin{array}{l}\text { No information provided. Difficult to } \\
\text { comment based on the abstract alone }\end{array}$ \\
\hline $\begin{array}{l}\text { Incomplete outcome data (attrition bias) } \\
\text { All outcomes }\end{array}$ & Unclear risk & $\begin{array}{l}\text { No information provided. Difficult to } \\
\text { comment based on the abstract alone }\end{array}$ \\
\hline Selective reporting (reporting bias) & Unclear risk & $\begin{array}{l}\text { No information provided. Difficult to } \\
\text { comment based on the abstract alone }\end{array}$ \\
\hline
\end{tabular}

Goodacre 2013

Methods

Design: randomised, double-blind, placebo-controlled study based in the UK. Trial carried out in the EDs of 34 hospitals across the UK between 30 July 2008 and 30 June 2012

Final measurement of outcomes performed at 120 minutes; however decision to admit made at 240 minutes and participants followed up for 1 month

Participants

Population: 1109 participants randomly assigned to control (364) and $\mathrm{IV} \mathrm{MgSO}_{4}(406)$ and one other group that was not relevant to our study (nebulised magnesium; $n=339$ )

Inclusion criteria: asthmatic individuals aged 16 years and older with severe acute asthma (defined as $\mathrm{PEF}<50 \%$, respiratory rate $>25$ breaths $/ \mathrm{min}$, heart rate $>110 \mathrm{bpm}$, unable to complete sentences)

Exclusion criteria: life-threatening exacerbations, contraindications to study drugs (e. g. pregnancy, chronic kidney disease, liver failure, heart block, high serum magnesium levels), participants who are unable to consent, previous participants in the $3 \mathrm{Mg}$ trial, those who had received magnesium in the previous 24 hours

Interventions Control group: $100 \mathrm{~mL} \mathrm{0.9 \%} \mathrm{normal} \mathrm{saline} \mathrm{infused} \mathrm{over} 20$ minutes

IV $\mathrm{MgSO}_{4}$ group: $2 \mathrm{~g} \mathrm{MgSO}_{4}$ in $100 \mathrm{~mL} 0.9 \%$ normal saline infused over 20 minutes Co-interventions: All participants received oxygen, $5 \mathrm{mg}$ nebulised salbutamol, $500 \mathrm{mcg}$ nebulised ipratropium bromide and oral prednisolone during recruitment, followed by 5 mg salbutamol added to each trial nebuliser. Other treatments allowed at the discretion of the clinician

Outcomes

Hospital admissions (after ED treatment or within the next 7 days); participant breathlessness (VAS score), mortality; adverse events; use of ventilation or respiratory support

Notes

Funded by the UK National Institute for Health Research Health Technology Assessment Programme

Baseline severity of population: We classified baseline severity as moderate, based on $\mathrm{PEF}$ of $433 \mathrm{~L} / \mathrm{min}$ and PEF percentage predicted of $52 \%$

\section{Risk of bias}


Goodacre 2013 (Continued)

\begin{tabular}{|c|c|c|}
\hline Bias & Authors' judgement & Support for judgement \\
\hline $\begin{array}{l}\text { Random sequence generation (selection } \\
\text { bias) }\end{array}$ & Low risk & $\begin{array}{l}\text { Randomly assigned using telephone or In- } \\
\text { ternet randomisation system managed by } \\
\text { Sheffield Clinical Trials Research Unit }\end{array}$ \\
\hline Allocation concealment (selection bias) & Low risk & $\begin{array}{l}\text { 'Participants were allocated to numbered } \\
\text { treatment packs kept in the ED' }\end{array}$ \\
\hline $\begin{array}{l}\text { Blinding of participants and personnel } \\
\text { (performance bias) } \\
\text { All outcomes }\end{array}$ & Low risk & $\begin{array}{l}\text { 'Double blind placebo controlled study.' } \\
\text { Numbered treatment packs used. Not clear } \\
\text { whether these were identical in appearance }\end{array}$ \\
\hline $\begin{array}{l}\text { Blinding of outcome assessment (detection } \\
\text { bias) } \\
\text { All outcomes }\end{array}$ & Low risk & $\begin{array}{l}\text { 'Participants, hospital staff and research } \\
\text { staff were masked to allocated treatment' }\end{array}$ \\
\hline $\begin{array}{l}\text { Incomplete outcome data (attrition bias) } \\
\text { All outcomes }\end{array}$ & Low risk & $\begin{array}{l}\text { Well documented: '25 withdrew without } \\
\text { starting trial drug, were recruited in error or } \\
\text { could not be allocated to a treatment pack' }\end{array}$ \\
\hline Selective reporting (reporting bias) & Low risk & $\begin{array}{l}\text { Primary outcomes well reported in the pub- } \\
\text { lished paper, but no information provided } \\
\text { regarding clinical data (e.g. BP, RR, HR) } \\
\text { or participant satisfaction/QOL data (po- } \\
\text { tentially reported elsewhere). However the } \\
\text { author did supply all of this information on } \\
\text { request }\end{array}$ \\
\hline
\end{tabular}

Green 1992

Methods

Design: prospective unblinded trial (no placebo and unclear whether randomised) based in California, USA. Trial carried out in a single ED of an urban teaching hospital between 29 March 1990 and 21 March 1991

Final measurement of outcomes time point unclear

Participants

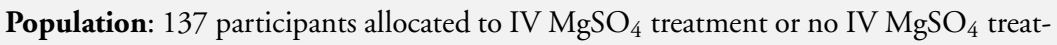
ment on alternate days of the week

Inclusion criteria: asthmatic individuals aged 18 to 65 years with an exacerbation of asthma (no further definition)

Exclusion criteria: co-morbidities including ischaemic heart disease, hypertension, angina, congestive cardiac failure, heart block, chest pain, metastatic cancer, chronic kidney disease, temperature $>38.3^{\circ} \mathrm{C}$, blood pressure $<120$ systolic, pregnancy, pneumonia or requiring intubation

Interventions

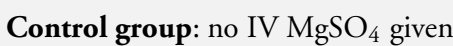

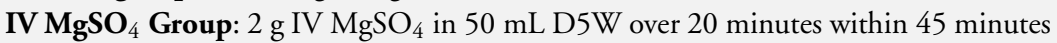
of treatment initiation

Intravenous magnesium sulfate for treating adults with acute asthma in the emergency department (Review)

Copyright @ 2014 The Cochrane Collaboration. Published by John Wiley \& Sons, Ltd. 
Co-interventions: All participants received oxygen, $2.5 \mathrm{mg}$ inhaled albuterol, $125 \mathrm{mg}$ IV methylprednisolone. Other medications (e.g. theophylline, injectable beta-agonists, epinephrine) were allowed at the discretion of the attending physician

Outcomes

Hospitalisation rate; ED treatment time (for those discharged); adverse events; relapse rate; PEF change from baseline; length of hospital stay

Notes

Baseline severity of population: severe (based on low PEF L/min 143 and high vital stats, HR 108 and respiration rate 29)

\section{Risk of bias}

\begin{tabular}{|c|c|c|}
\hline Bias & Authors' judgement & Support for judgement \\
\hline $\begin{array}{l}\text { Random sequence generation (selection } \\
\text { bias) }\end{array}$ & High risk & $\begin{array}{l}\text { 'Patients presenting on odd days were given } \\
\text { magnesium and those on even days did not } \\
\text { receive magnesium' }\end{array}$ \\
\hline Allocation concealment (selection bias) & High risk & $\begin{array}{l}\text { Allocation dependent on the days they pre- } \\
\text { sented. Unblinded and not randomised }\end{array}$ \\
\hline $\begin{array}{l}\text { Blinding of participants and personnel } \\
\text { (performance bias) } \\
\text { All outcomes }\end{array}$ & High risk & $\begin{array}{l}\text { 'Physicians were not blinded to patient ran- } \\
\text { domisation; however, patients and respira- } \\
\text { tory therapists were unaware that a study } \\
\text { was being performed' }\end{array}$ \\
\hline $\begin{array}{l}\text { Blinding of outcome assessment (detection } \\
\text { bias) } \\
\text { All outcomes }\end{array}$ & High risk & $\begin{array}{l}\text { Respiratory therapists (who were measur- } \\
\text { ing the PEF) 'were unaware that a study } \\
\text { was going on,' but no formal blinding at all }\end{array}$ \\
\hline $\begin{array}{l}\text { Incomplete outcome data (attrition bias) } \\
\text { All outcomes }\end{array}$ & Unclear risk & $\begin{array}{l}\text { Reported as follows: } 217 \text { participants in to- } \\
\text { tal. } 80 \text { were repeats and so were excluded } \\
\text { (although it is unclear from which groups } \\
\text { these came), and } 17 \text { others were removed } \\
\text { from data analysis because of misplaced } \\
\text { records (total } 97 / 217 \text { ). No evidence of ITT. } \\
\text { Final group sizes of quite equal size: } 58 \text { and } \\
62\end{array}$ \\
\hline Selective reporting (reporting bias) & Unclear risk & $\begin{array}{l}\text { All outcome data given but not clearly de- } \\
\text { scribed as primary or secondary outcomes } \\
\text { in the initial methodology }\end{array}$ \\
\hline
\end{tabular}


Methods

Participants

Design: unclear. Based in Scotland but unclear as to location where the trial was carried out and during what dates

Final measurement of outcomes performed at 60 minutes and information about followup of participants not provided

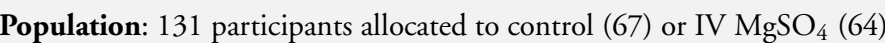

Inclusion criteria: Adults (age not specified) with acute severe asthma (defined as PEF $<250$ or $50 \%$ of best previous PEF)

Exclusion criteria: not reported
Control group: $50 \mathrm{~mL} \mathrm{0.9 \%} \mathrm{normal} \mathrm{saline} \mathrm{infused} \mathrm{over} 15$ minutes

IV $\mathrm{MgSO}_{4}$ group: $1.2 \mathrm{mg} \mathrm{IV} \mathrm{MgSO}_{4}$ in $50 \mathrm{~mL} 0.9 \%$ normal saline infused over 15 minutes

Co-interventions: All participants received $5 \mathrm{mg}$ nebulised salbutamol, $500 \mathrm{mcg}$ nebulised ipratropium bromide, oxygen, $200 \mathrm{mg}$ IV hydrocortisone. Aminophylline was given at the discretion of the attending physician

Outcomes

PEF at 15, 30, 45, 60 minutes; hospitalisation rate

Notes

Baseline severity of population: We have classified this population as severe based on inclusion criteria of $\mathrm{PEF}<250 \mathrm{~L} / \mathrm{min}$ and $<50 \%$ predicted

\section{Risk of bias}

\begin{tabular}{|c|c|c|}
\hline Bias & Authors' judgement & Support for judgement \\
\hline $\begin{array}{l}\text { Random sequence generation (selection } \\
\text { bias) }\end{array}$ & Unclear risk & $\begin{array}{l}\text { No information provided. Difficult to } \\
\text { comment based on the abstract alone }\end{array}$ \\
\hline Allocation concealment (selection bias) & Unclear risk & $\begin{array}{l}\text { No information provided. Difficult to } \\
\text { comment based on the abstract alone }\end{array}$ \\
\hline $\begin{array}{l}\text { Blinding of participants and personnel } \\
\text { (performance bias) } \\
\text { All outcomes }\end{array}$ & Unclear risk & $\begin{array}{l}\text { 'Double blind placebo controlled parallel } \\
\text { group study.' No mention of randomisa- } \\
\text { tion nor details of blinding. Difficult to } \\
\text { comment based on the abstract alone }\end{array}$ \\
\hline $\begin{array}{l}\text { Blinding of outcome assessment (detection } \\
\text { bias) } \\
\text { All outcomes }\end{array}$ & Unclear risk & $\begin{array}{l}\text { No information provided. Difficult to } \\
\text { comment based on the abstract alone }\end{array}$ \\
\hline $\begin{array}{l}\text { Incomplete outcome data (attrition bias) } \\
\text { All outcomes }\end{array}$ & Unclear risk & $\begin{array}{l}\text { No information provided. Difficult to } \\
\text { comment based on the abstract alone }\end{array}$ \\
\hline Selective reporting (reporting bias) & Unclear risk & $\begin{array}{l}\text { No information provided. Difficult to } \\
\text { comment based on the abstract alone }\end{array}$ \\
\hline
\end{tabular}




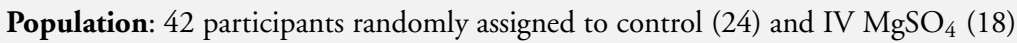

Inclusion criteria: asthmatic individuals aged 18 to 55 years with an exacerbation (defined as PEF $<100$ or $<25 \%$ predicted) and able to consent

Exclusion criteria: co-morbidities including pneumonia, chronic kidney disease, congestive cardiac failure, previous myocardial infarction, hypertension, pregnancy or possibly requiring intubation

Interventions

Control group: $50 \mathrm{~mL} \mathrm{0.9 \%} \mathrm{normal} \mathrm{saline} \mathrm{given} \mathrm{immediately}$

IV $\mathrm{MgSO}_{4}$ group: $2 \mathrm{~g} \mathrm{MgSO}_{4}$ in $50 \mathrm{~mL} 0.9 \%$ normal saline given immediately

Co-interventions: All participants received $2.5 \mathrm{mg}$ nebulised albuterol sulfate, $125 \mathrm{mg}$

IV methylprednisolone, oxygen and repeated albuterol every 20, 40 and 60 minutes

Outcomes

PEF (at 60 minutes), hospitalisation rate; Borg score; adverse effects of hypotension and hyporeflexia

Notes

Baseline severity of population: life threatening (based on PEF $88.5 \mathrm{~L} / \mathrm{min}$ and high vital stats HR 110 and respiration rate 31)

Risk of bias

\begin{tabular}{|c|c|c|}
\hline Bias & Authors' judgement & Support for judgement \\
\hline $\begin{array}{l}\text { Random sequence generation (selection } \\
\text { bias) }\end{array}$ & Low risk & $\begin{array}{l}\text { 'Randomised using a random number gen- } \\
\text { erator which assigned the code' }\end{array}$ \\
\hline
\end{tabular}

Allocation concealment (selection bias) Low risk

'Enrolment packs containing data recording sheets and study solutions in random order were prepared by the Pharmacy.' Saline and magnesium identical in appearance

Blinding of participants and personnel Low risk (performance bias)

All outcomes

Blinding of outcome assessment (detection Low risk bias)

All outcomes

Incomplete outcome data (attrition bias) Unclear risk All outcomes
'Double blind' study. 'Investigators, other caretakers and patients were unaware of contents of the study solution'

'Investigators, other caretakers and patients were unaware of contents of the study solution'

No attrition data specifically reported. Comment that the same participant presenting more than once was not used, indicating that investigators always used the first presentation for analysis 
Porter 2001 (Continued)

Selective reporting (reporting bias) Unclear risk

Primary outcomes reported as stated at $\mathrm{T}$ $=60$. However incomplete reporting for other time points

Silverman 2002

Methods

Design: randomised, double-blind, placebo-controlled study based in the United States of America (USA). Trial carried out in the EDs of eight hospitals in the USA, but dates during which this occurred not reported

Final measurement of outcomes performed at 240 minutes and participants followed up for seven days

Participants

Population: 248 participants randomly assigned to control (126) and $\mathrm{IV} \mathrm{MgSO}_{4}$ (122) Inclusion criteria: asthmatic individuals aged 18 to 60 years with an exacerbation (defined as $\mathrm{FEV}_{1}<30 \%$ ) who were able to stay for 4 hours and consented to being involved in the trial

Exclusion criteria: co-morbidities such as chronic obstructive pulmonary disease or other chronic lung disease, pneumonia, temperature $>38.9^{\circ} \mathrm{C}$, congestive cardiac failure, coronary artery disease, diabetes mellitus, chronic kidney disease, hypertension, pregnancy, requiring intubation or unable to do spirometry

Interventions

Control group: $50 \mathrm{~mL}$ 'like appearing solution' infused over 10 to 15 minutes and given at 30 minutes

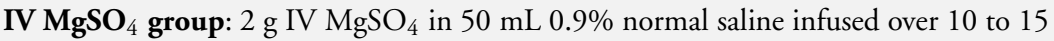
minutes and given at 30 minutes

Co-interventions: All participants received $2.5 \mathrm{mg}$ nebulised $0.5 \%$ albuterol with $100 \%$ oxygen, $125 \mathrm{mg}$ IV methylprednisolone. Albuterol subsequently given at 30, 60, 120 and 180 minutes

Outcomes

$\mathrm{FEV}_{1}$ (at 240 minutes), hospitalisation rate; relapse rate; vital signs; Borg scale; PEF (all at 30 and 240 minutes)

Notes

Funded in part by the Max and Victoria Dreyfus Foundation

Baseline severity of population: life threatening (based on PEF $27 \%$ predicted, $\mathrm{FEV}_{1}$ $23 \%$ predicted)

\section{Risk of bias}

\begin{tabular}{lll} 
Bias & Authors' judgement & Support for judgement \\
\hline $\begin{array}{l}\text { Random sequence generation (selection } \\
\text { bias) }\end{array}$ & Low risk & $\begin{array}{l}\text { Randomly assigned using a 1:1 ratio ran- } \\
\text { domisation table unique for each centre }\end{array}$ \\
\hline Allocation concealment (selection bias) & Low risk & 'Study pharmacists placed drug or placebo \\
in identically appearing vials, with only the \\
study ID on the label'
\end{tabular}

Intravenous magnesium sulfate for treating adults with acute asthma in the emergency department (Review) 
Silverman 2002 (Continued)

Blinding of participants and personnel Low risk (performance bias)

All outcomes

Blinding of outcome assessment (detection Low risk bias)

All outcomes

Incomplete outcome data (attrition bias) Unclear risk

All outcomes

Selective reporting (reporting bias)

Low risk
'Double blind, placebo-controlled'

Investigators blinded (' $\mathrm{FEV}_{1}$ results were reviewed blindly by the 2 investigators')

Singh 2008

Methods

Design: randomised, single-blinded, placebo-controlled trial based in Delhi, India. Trial carried out in a single ED at the Chest Institute

Final measurement of outcomes performed at 180 minutes with no further participant follow-up

Participants

Population: 70 participants of South Asian origin randomly assigned to control (30) and $\mathrm{IV} \mathrm{MgSO}_{4}(30)$

Inclusion criteria: asthmatic individuals aged 18 to 60 years with a severe exacerbation (as defined by GINA) and an FEV $<30 \%$ predicted on presentation, who were able to remain in the department for 3 hours

Exclusion criteria: co-morbidities such as chronic obstructive pulmonary disorder (COPD) or other chronic lung disease, cardiac, renal or hepatic dysfunction, pregnancy or lactating or requiring intubation or unable to do spirometry

Interventions

Control group: $250 \mathrm{~mL} 0.9 \%$ normal saline infused over 20 minutes at 30 minutes

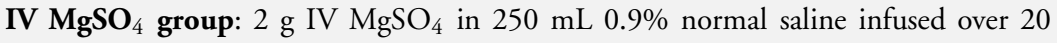
minutes at 30 minutes

Co-interventions: All participants received $100 \mathrm{mg}$ IV hydrocortisone on arrival (0 minutes). They then received a nebulising solution consisting of: $2.5 \mathrm{mg}$ nebulised salbutamol, $1.5 \mathrm{~mL}$ ipratropium bromide and $2.5 \mathrm{~mL}$ normal saline with $100 \%$ oxygen at 0,20 and 40 minutes

Outcomes

Change in $\mathrm{FEV}_{1}$ \% predicted, hospitalisation rate; cyanosis; stats; vital signs; Borg score

Notes

Trial done as part of an MD dissertation project funded by a grant from University of Delhi, India

Baseline severity of population: life threatening (based on PEF $22 \%$ predicted, $\mathrm{FEV}_{1}$ $38 \%$ predicted, and high HR $127 \mathrm{bpm}$ )

\section{Risk of bias}


Singh 2008 (Continued)

\begin{tabular}{|c|c|c|}
\hline Bias & Authors' judgement & Support for judgement \\
\hline $\begin{array}{l}\text { Random sequence generation (selection } \\
\text { bias) }\end{array}$ & Low risk & $\begin{array}{l}\text { Randomly assigned using a } 1: 1 \text { ration ran- } \\
\text { domisation table }\end{array}$ \\
\hline Allocation concealment (selection bias) & Low risk & $\begin{array}{l}\text { Random number tables used. 'Individual } \\
\text { random numbers were kept in separate en- } \\
\text { velopes so the concealment could be main- } \\
\text { tained until the patient was included in the } \\
\text { assigned group.' Placebo described only as } \\
\text { 'like appearing placebo' }\end{array}$ \\
\hline $\begin{array}{l}\text { Blinding of participants and personnel } \\
\text { (performance bias) } \\
\text { All outcomes }\end{array}$ & Unclear risk & $\begin{array}{l}\text { Described as a 'single blind study.' However } \\
\text { further information from the study author } \\
\text { confirmed that participants and assessors } \\
\text { of spirometric and clinical outcomes were } \\
\text { blinded to the treatment given, and the de- } \\
\text { cision to admit was made by chief residents } \\
\text { blinded to type of treatment given }\end{array}$ \\
\hline $\begin{array}{l}\text { Blinding of outcome assessment (detection } \\
\text { bias) } \\
\text { All outcomes }\end{array}$ & Low risk & $\begin{array}{l}\text { Study authors do not specify in the pub- } \\
\text { lished paper who does the spirometry and } \\
\text { clinical examination of the respiratory sys- } \\
\text { tem at each time interval, but further in- } \\
\text { formation from the study authors confirms } \\
\text { that participants and assessors of spiromet- } \\
\text { ric and clinical outcomes were blinded to } \\
\text { the treatment given } \\
\text { Decision to hospitalise or discharge was } \\
\text { made by ED staff blinded to group alloca- } \\
\text { tion }\end{array}$ \\
\hline $\begin{array}{l}\text { Incomplete outcome data (attrition bias) } \\
\text { All outcomes }\end{array}$ & Low risk & $\begin{array}{l}\text { This is clearly given for both groups ( } 5 \text { in } \\
\text { each group), so it is equal, and total with- } \\
\text { drawal percentage is low at } 14 \%\end{array}$ \\
\hline Selective reporting (reporting bias) & Low risk & $\begin{array}{l}\text { Good reporting of primary outcomes at all } \\
\text { time points for FEV1 and at } 120 \text { minutes } \\
\text { for Borg scale and clinical indicators }\end{array}$ \\
\hline
\end{tabular}

Intravenous magnesium sulfate for treating adults with acute asthma in the emergency department (Review) 
Methods

Participants
Design: randomised, double-blind, placebo-controlled study based in Philadelphia, USA. Trial carried out in a single ED between August 1987 and February 1988

Final measurement of outcomes performed at 45 minutes, with the decision to admit at 240 minutes and no reported follow-up of participants

\begin{tabular}{|c|c|}
\hline Participants & $\begin{array}{l}\text { Population: } 38 \text { participants randomly assigned to control (19) and } \mathrm{IV} \mathrm{MgSO}_{4}(19) \\
\text { Inclusion criteria: asthmatic individuals aged } 18 \text { to } 70 \text { years with an exacerbation (initial } \\
\mathrm{PEF}<200 \mathrm{~L} / \mathrm{min} \text { ) and defined as poor responders to initial treatment } \\
\text { Exclusion criteria: initial } \mathrm{PEF}>200 \mathrm{~L} / \mathrm{min} \text {, rectal temperature }>38^{\circ} \mathrm{C} \text {, systolic blood } \\
\text { pressure }<120 \text {, history of kidney disease, pregnancy, purulent sputum or infiltrate on } \\
\text { chest }\end{array}$ \\
\hline Interventions & 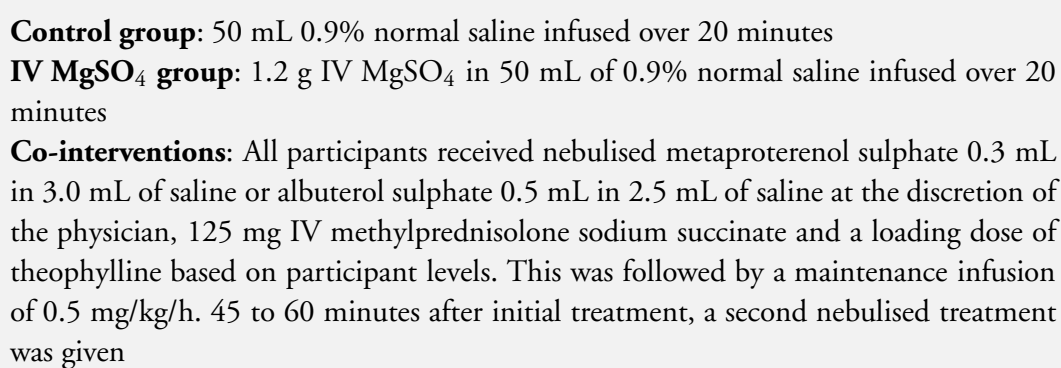 \\
\hline
\end{tabular}
graphs (HR - $100 \mathrm{bpm}, \mathrm{RR}-28 \mathrm{rpm}, \mathrm{PEF}-150 \mathrm{~L} / \mathrm{min})$

\section{Risk of bias}

\begin{tabular}{l|l|l}
\hline Bias & Authors' judgement & Support for judgement \\
\hline $\begin{array}{l}\text { Random sequence generation (selection } \\
\text { bias) }\end{array}$ & Unclear risk & 'Coded from a randomised list' \\
\hline $\begin{array}{l}\text { Allocation concealment (selection bias) } \\
\text { Llinding of participants and personnel } \\
\text { (performance bias) } \\
\text { All outcomes }\end{array}$ & Low risk & $\begin{array}{l}\text { Placebo/magnesium solutions prepackaged } \\
\text { in identical vials by the pharmacy and } \\
\text { coded from a randomised list }\end{array}$ \\
\hline
\end{tabular}

Blinding of outcome assessment (detection Low risk bias)

All outcomes

Incomplete outcome data (attrition bias) Low risk All outcomes
Double-blinded. 'The decision to admit or discharge was made by the physician caring for the patient and not influenced by the investigator'

Withdrawals few and well commented on (2/14 excluded) 
Skobeloff 1989 (Continued)

\begin{tabular}{|c|c|c|}
\hline Selective reporting (reporting bias) & High risk & $\begin{array}{l}\text { All predetermined outcomes reported (ex- } \\
\text { cept deep tendon reflexes, but the relevance } \\
\text { of this is uncertain). However raw data not } \\
\text { provided. Only graphs for some outcomes }\end{array}$ \\
\hline
\end{tabular}

Tiffany 1993

Methods

Design: randomised, double-blind, placebo-controlled based in Detroit, USA. Trial carried out in a single ED, the dates of which are not provided

Final measurement of outcomes performed at 260 minutes with no reported follow-up of participants

Participants

Population: 48 participants randomly assigned to control (21) and $\mathrm{IV}_{\mathrm{MgSO}_{4}}$ (15), and one other group that was not relevant to this review (continuous IV $\mathrm{MgSO}_{4}$ infusion $\mathrm{n}$ $=12$ )

Inclusion criteria: asthmatic individuals aged 18 to 60 years with an exacerbation who have consented to being involved in the trial

Exclusion criteria: first episode of wheeze, history of chronic lung disease, temperature $>38.2^{\circ} \mathrm{C}$, chronic kidney disease, congestive cardiac failure, requiring intubation and initial $\mathrm{PEF}>200 \mathrm{~L} / \mathrm{min}$

Interventions

Control group: $2 \mathrm{~g}$ stat of $0.9 \%$ normal saline over 20 minutes followed by a placebo infusion over 4 hours

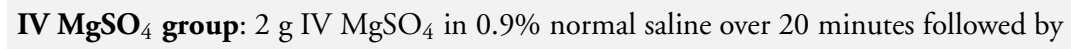
placebo infusion over 4 hours

Co-interventions: All participants received $2.5 \mathrm{mg}$ nebulised albuterol 30 minutes apart, $125 \mathrm{mg}$ IV methylprednisolone, followed by a third albuterol aerosol treatment and an aminophylline loading dose and infusion to keep levels at $15 \mathrm{mg} / \mathrm{L}$

\begin{tabular}{ll}
\hline Outcomes & PEF and $\mathrm{FEV}_{1}$ \\
\hline Notes & Baseline severity of population: life threatening (based on PEF L/min 115, and FEV \\
& $0.95 \mathrm{~L})$
\end{tabular}

\section{Risk of bias}

\begin{tabular}{l|ll}
\hline Bias & Authors' judgement & Support for judgement \\
\hline $\begin{array}{l}\text { Random sequence generation (selection } \\
\text { bias) }\end{array}$ & Low risk & $\begin{array}{l}\text { Randomly assigned using a 'computerised } \\
\text { random number generation under the con- } \\
\text { trol of the hospital pharmacy' }\end{array}$ \\
\hline $\begin{array}{l}\text { Allocation concealment (selection bias) } \\
\text { Blinding of participants and personnel } \\
\text { (performance bias) } \\
\text { All outcomes }\end{array}$ & Low risk & No information provided \\
\hline
\end{tabular}

Intravenous magnesium sulfate for treating adults with acute asthma in the emergency department (Review) 
Tiffany 1993 (Continued)

\begin{tabular}{l|l|l}
$\begin{array}{l}\text { Blinding of outcome assessment (detection } \\
\text { bias) } \\
\text { All outcomes }\end{array}$ & Low risk & $\begin{array}{l}\text { Best of } 3 \text { PEF and FEV1 values measured } \\
\text { (objective measurements). 'Clinical deci- } \\
\text { sion making (i.e. decision to admit) was left } \\
\text { to attending physicians' }\end{array}$ \\
\hline $\begin{array}{l}\text { Incomplete outcome data (attrition bias) } \\
\text { All outcomes }\end{array}$ & Unclear risk & No information provided \\
\hline $\begin{array}{l}\text { Selective reporting (reporting bias) } \\
\text { High risk }\end{array}$ & Hignete and no raw data reported. Re-
\end{tabular}

ABGs: Arterial blood gases; BP: Blood pressure; BTS: British Thoracic Society; COPD: Chronic obstructive pulmonary disease; ED: Emergency department; $\mathrm{FEV}_{1}$ : Forced expiratory volume in 1 second; GINA: Global Initiative for Asthma; HR: Heart rate; ITT: Intent-to-treat; IV: Intravenous; $\mathrm{Mg}$ : Magnesium; $\mathrm{MgSO}_{4}$ : Magnesium sulfate; $\mathrm{PaO}_{2}$ : Partial pressure of oxygen in arterial blood; PEF: Peak expiratory flow; RR: Respiratory rate; VAS: Visual analogue scale.

\section{Characteristics of excluded studies [ordered by study ID]}

\begin{tabular}{|c|c|}
\hline Study & Reason for exclusion \\
\hline Abreu-Gonzalez 2002 & Not an ED study. Design did not match inclusion criteria, laboratory study \\
\hline Brunner 1985 & $\begin{array}{l}\text { Not an ED study. Design did not match inclusion criteria, laboratory study ('each subject serving as his own } \\
\text { control') }\end{array}$ \\
\hline Cairns 1996a & Not an ED study. Design did not match inclusion criteria, laboratory study \\
\hline Harmanci 1996 & Nebulised versus IV $\mathrm{MgSO}_{4}$. Does not appear to have a placebo arm \\
\hline Hill 1996 & Not an ED study. Design did not match inclusion criteria, laboratory study \\
\hline Liang 1998 & No diagnosis of asthma. Child study \\
\hline Okayama 1987 & Not an ED study. Portion of the sample inpatients \\
\hline Rolla 1988 & Not an ED study. Design did not match inclusion criteria and non-emergency patients \\
\hline Rolla 1994 & Not an ED study \\
\hline Schenk 2001 & No diagnosis of asthma \\
\hline
\end{tabular}

Intravenous magnesium sulfate for treating adults with acute asthma in the emergency department (Review) 
Characteristics of studies awaiting assessment [ordered by study ID]

\section{Abd El Kader 1997}

\begin{tabular}{ll}
\hline Methods & 'Comparative study' \\
\hline Participants & Patients with bronchial asthma \\
\hline Interventions & Salbutamol, ipratropium bromide and magnesium sulfate \\
\hline Outcomes & Ventilatory, cardiovascular and metabolic responses \\
\hline Notes & Numerous attempts made to locate the paper, but no library holdings found \\
\hline
\end{tabular}


DATA ANDANALYSES

Comparison 1. IV $\mathrm{MgSO}_{4}$ versus placebo

\begin{tabular}{|c|c|c|c|c|}
\hline Outcome or subgroup title & $\begin{array}{l}\text { No. of } \\
\text { studies }\end{array}$ & $\begin{array}{c}\text { No. of } \\
\text { participants }\end{array}$ & Statistical method & Effect size \\
\hline 1 Hospital admissions & 11 & 1769 & Odds Ratio (M-H, Fixed, 95\% CI) & $0.75[0.60,0.92]$ \\
\hline $\begin{array}{l}2 \text { Intensive care unit (ICU) } \\
\text { admissions }\end{array}$ & 1 & & Odds Ratio (M-H, Fixed, 95\% CI) & Totals not selected \\
\hline $\begin{array}{l}3 \text { High dependency unit (HDU) } \\
\text { admissions }\end{array}$ & 1 & & Odds Ratio (M-H, Fixed, 95\% CI) & Totals not selected \\
\hline $\begin{array}{l}4 \text { ED treatment duration } \\
\text { (minutes) }\end{array}$ & 1 & & Mean Difference (IV, Fixed, 95\% CI) & Totals not selected \\
\hline 5 Length of hospital stay (days) & 3 & 949 & Mean Difference (IV, Fixed, 95\% CI) & $-0.03[-0.33,0.27]$ \\
\hline 6 Readmission & 2 & 887 & Odds Ratio (M-H, Fixed, 95\% CI) & $2.30[0.66,7.99]$ \\
\hline 7 Heart rate (bpm) & 4 & 1195 & Mean Difference (IV, Fixed, 95\% CI) & $-2.37[-4.13,-0.61]$ \\
\hline 8 Respiratory rate (breaths/min) & 4 & 1195 & Mean Difference (IV, Fixed, 95\% CI) & $-0.28[-0.77,0.20]$ \\
\hline 9 Systolic blood pressure $(\mathrm{mmHg})$ & 4 & 1264 & Mean Difference (IV, Fixed, 95\% CI) & $0.08[-1.89,2.05]$ \\
\hline $10 \mathrm{FEV}_{1}$ (\% predicted) & 4 & 523 & Mean Difference (IV, Fixed, 95\% CI) & $4.41[1.75,7.06]$ \\
\hline $11 \mathrm{PEF}$ (\% predicted) & 3 & 1129 & Mean Difference (IV, Fixed, 95\% CI) & $4.78[2.14,7.43]$ \\
\hline $12 \mathrm{PEF}(\mathrm{L} / \mathrm{min})$ & 8 & 1460 & Mean Difference (IV, Fixed, 95\% CI) & $17.40[8.64,26.17]$ \\
\hline 13 Borg Dyspnoea Scale score & 4 & & Mean Difference (IV, Fixed, 95\% CI) & Subtotals only \\
\hline
\end{tabular}

\section{Comparison 2. IV $\mathrm{MgSO}_{4}$ versus placebo (subgroup and sensitivity analyses)}

\begin{tabular}{|c|c|c|c|c|}
\hline Outcome or subgroup title & $\begin{array}{l}\text { No. of } \\
\text { studies }\end{array}$ & $\begin{array}{c}\text { No. of } \\
\text { participants }\end{array}$ & Statistical method & Effect size \\
\hline 1 Hospital admissions (by severity) & 11 & 1743 & Odds Ratio (M-H, Fixed, 95\% CI) & $0.76[0.62,0.95]$ \\
\hline 1.1 Moderate & 2 & 791 & Odds Ratio (M-H, Fixed, 95\% CI) & $0.76[0.55,1.04]$ \\
\hline 1.2 Severe & 6 & 474 & Odds Ratio (M-H, Fixed, 95\% CI) & $0.87[0.58,1.31]$ \\
\hline 1.3 Life threatening & 7 & 478 & Odds Ratio (M-H, Fixed, 95\% CI) & $0.69[0.46,1.03]$ \\
\hline $\begin{array}{l}2 \text { Hospital admissions (by } \\
\text { co-medications) }\end{array}$ & 11 & 1769 & Odds Ratio (M-H, Fixed, 95\% CI) & $0.75[0.60,0.92]$ \\
\hline $\begin{array}{l}2.1 \text { Nebulised ipratropium } \\
\text { bromide }\end{array}$ & 4 & 1072 & Odds Ratio (M-H, Fixed, 95\% CI) & $0.73[0.55,0.96]$ \\
\hline $\begin{array}{l}2.2 \text { No nebulised ipratropium } \\
\text { bromide }\end{array}$ & 7 & 697 & Odds Ratio (M-H, Fixed, 95\% CI) & $0.77[0.55,1.06]$ \\
\hline $\begin{array}{l}3 \text { Hospital admissions (risk of bias } \\
\text { sensitivity) }\end{array}$ & 8 & 1437 & Odds Ratio (M-H, Fixed, 95\% CI) & $0.72[0.57,0.91]$ \\
\hline $\begin{array}{l}4 \text { Hospital admissions } \\
\quad \text { (unpublished sensitivity) }\end{array}$ & 10 & 1638 & Odds Ratio (M-H, Fixed, 95\% CI) & $0.73[0.58,0.91]$ \\
\hline $\begin{array}{l}5 \text { PEF \% predicted (Goodacre } \\
\text { change score sensitivity) }\end{array}$ & 3 & 1129 & Mean Difference (IV, Fixed, 95\% CI) & $1.57[-0.55,3.69]$ \\
\hline
\end{tabular}

Intravenous magnesium sulfate for treating adults with acute asthma in the emergency department (Review)

Copyright @ 2014 The Cochrane Collaboration. Published by John Wiley \& Sons, Ltd. 


\section{Analysis I.I. Comparison I IV MgSO4 versus placebo, Outcome I Hospital admissions.}

Review: Intravenous magnesium sulfate for treating adults with acute asthma in the emergency department

Comparison: I IV MgSO 4 versus placebo

Outcome: I Hospital admissions

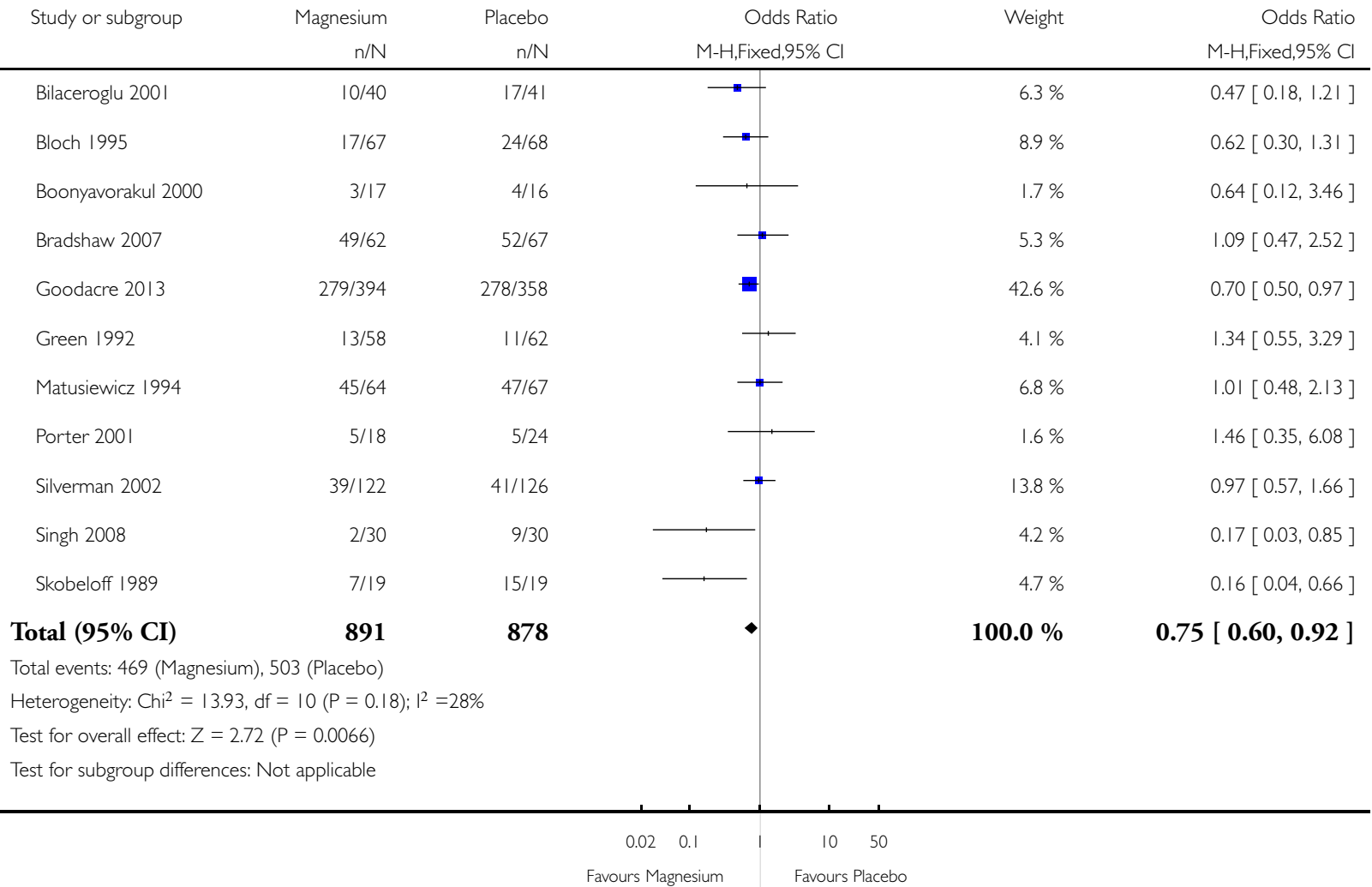




\section{Analysis I.2. Comparison I IV MgSO4 versus placebo, Outcome 2 Intensive care unit (ICU) admissions.}

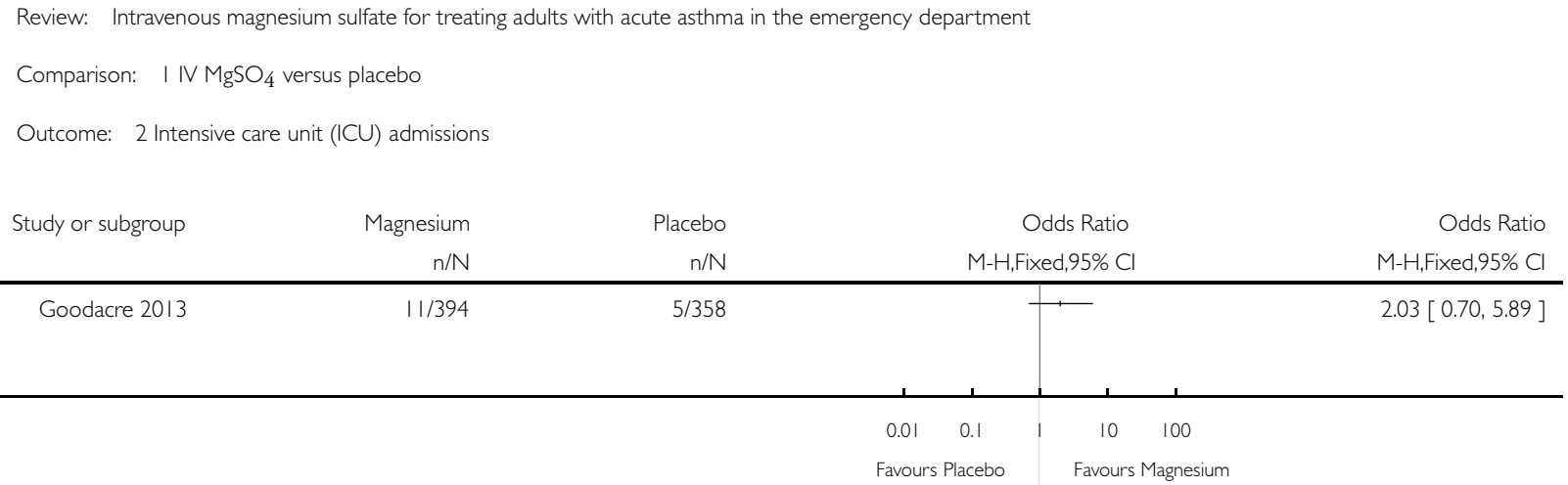

Analysis I.3. Comparison I IV MgSO4 versus placebo, Outcome 3 High dependency unit (HDU) admissions.

Review: Intravenous magnesium sulfate for treating adults with acute asthma in the emergency department

Comparison: I $\mathrm{N} \mathrm{MgSO}_{4}$ versus placebo

Outcome: 3 High dependency unit (HDU) admissions

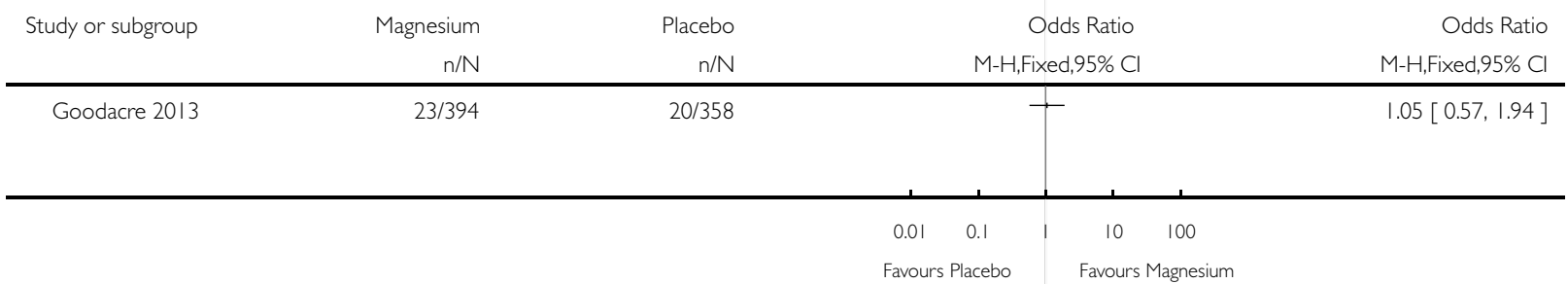




\section{Analysis I.4. Comparison I IV MgSO4 versus placebo, Outcome 4 ED treatment duration (minutes).}

Review: Intravenous magnesium sulfate for treating adults with acute asthma in the emergency department

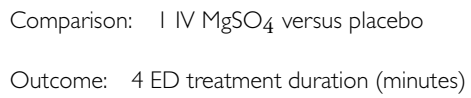

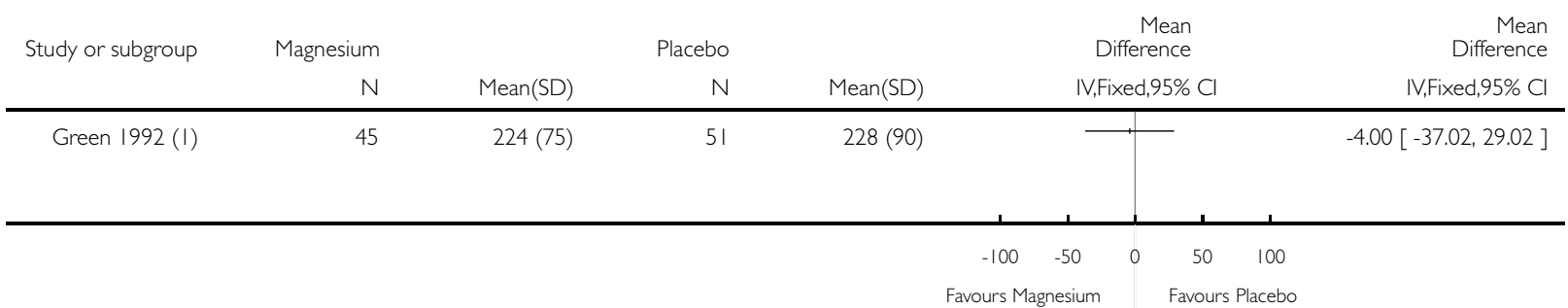

(I) Reported only for those who were discharged (i.e. those not counted in hospital admissions)

\section{Analysis I.5. Comparison I IV MgSO4 versus placebo, Outcome 5 Length of hospital stay (days).}

Review: Intravenous magnesium sulfate for treating adults with acute asthma in the emergency department

Comparison: I $\mathrm{N} \mathrm{MgSO}_{4}$ versus placebo

Outcome: 5 Length of hospital stay (days)

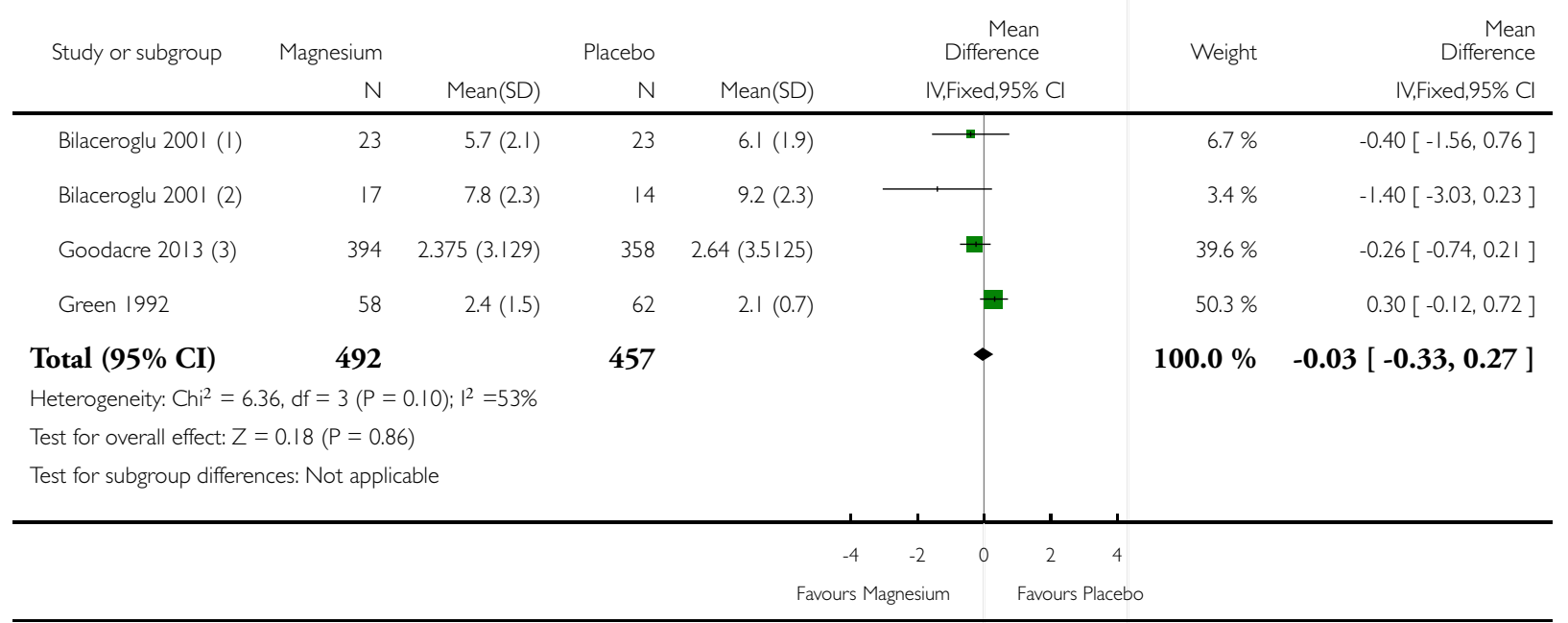

Intravenous magnesium sulfate for treating adults with acute asthma in the emergency department (Review)

Copyright @ 2014 The Cochrane Collaboration. Published by John Wiley \& Sons, Ltd. 

( I) moderate
(2) severe
(3) Converted from hours to days

\section{Analysis I.6. Comparison I IV MgSO4 versus placebo, Outcome 6 Readmission.}

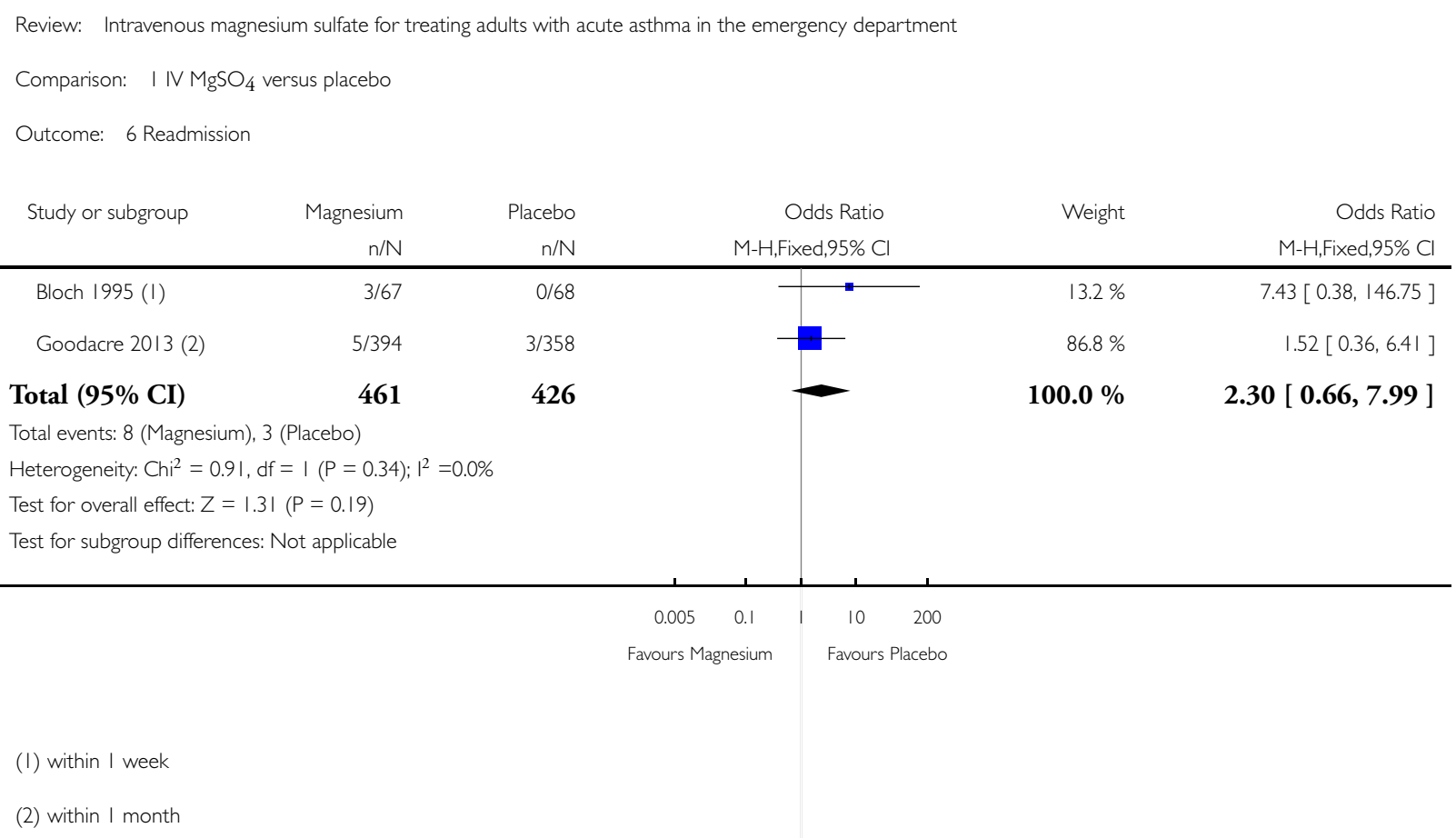




\section{Analysis I.7. Comparison I IV MgSO4 versus placebo, Outcome 7 Heart rate (bpm).}

Review: Intravenous magnesium sulfate for treating adults with acute asthma in the emergency department

Comparison: I $\mathrm{N} \mathrm{MgSO}_{4}$ versus placebo

Outcome: 7 Heart rate $(\mathrm{bpm})$

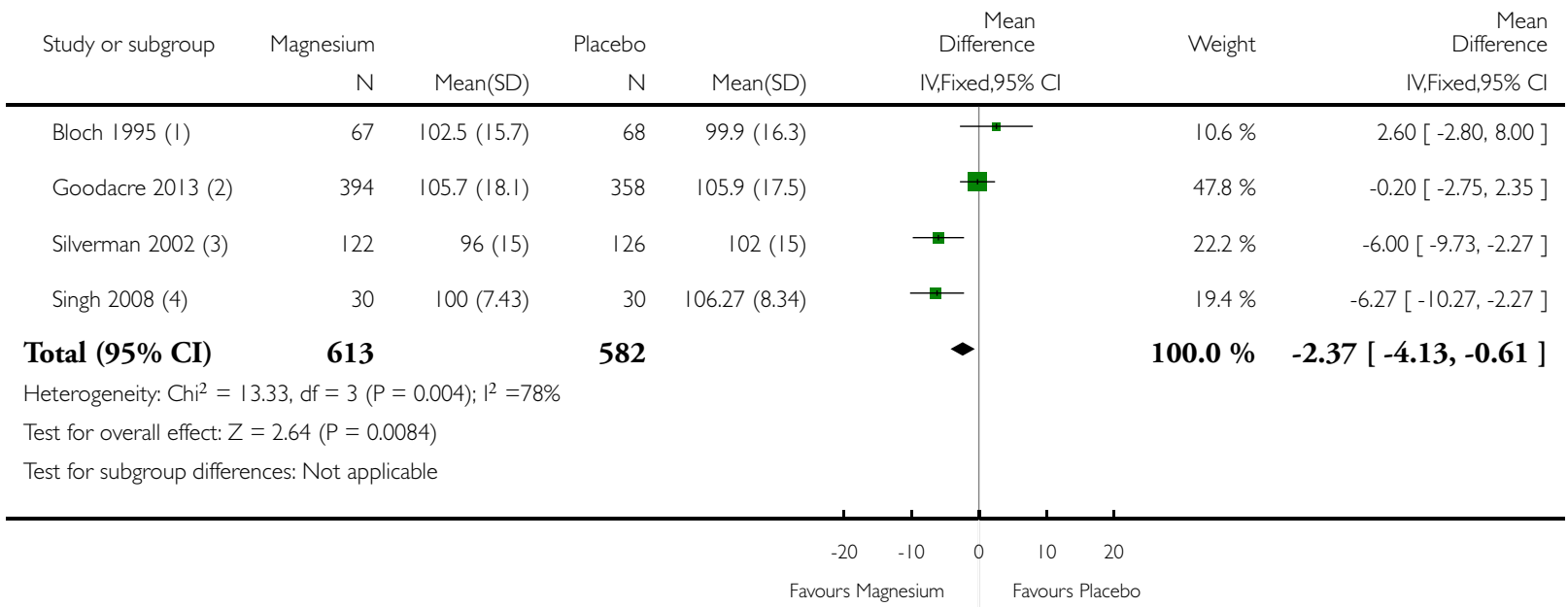
( ) All groups
(2) at 120 mins
(3) at 240 mins
(4) at 120 mins 


\section{Analysis I.8. Comparison I IV MgSO4 versus placebo, Outcome 8 Respiratory rate (breaths/min).}

Review: Intravenous magnesium sulfate for treating adults with acute asthma in the emergency department

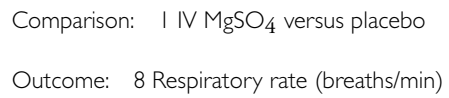

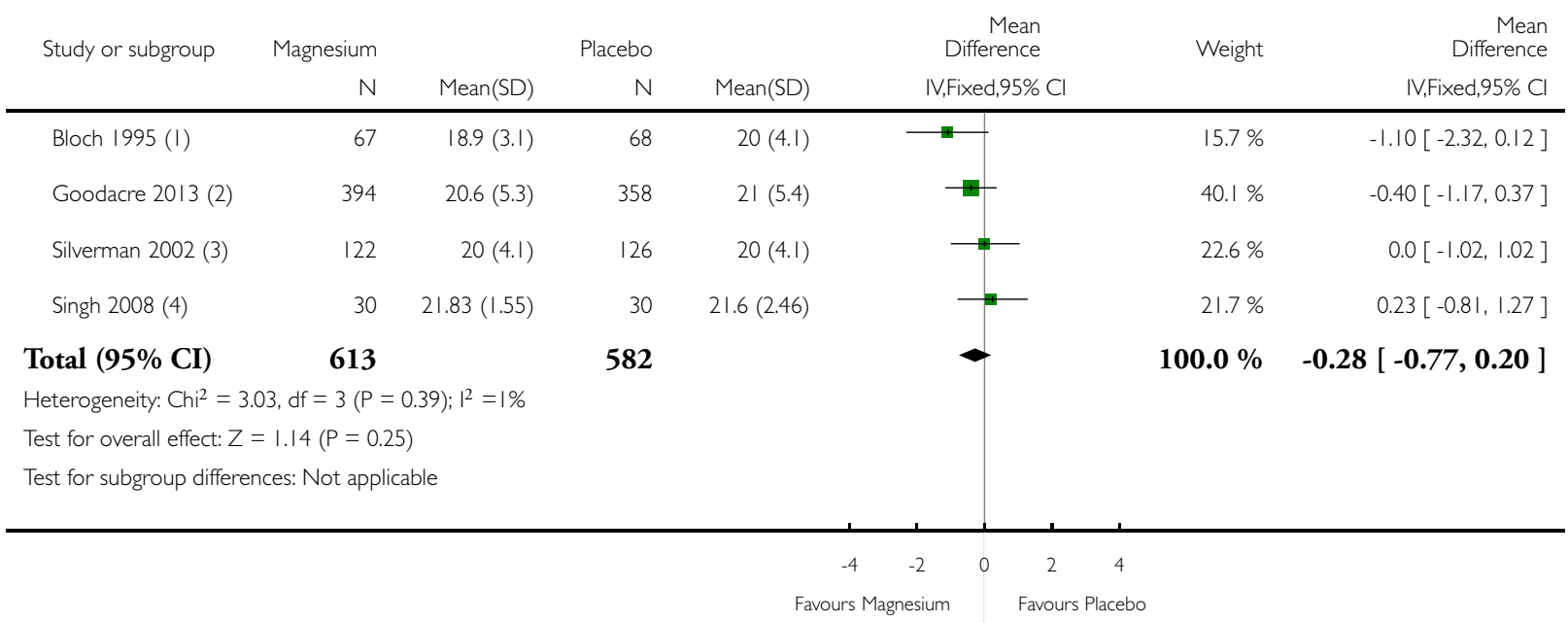
(I) All groups at 120 mins
(2) at 120 mins
(3) at 240 mins
(4) at 120 mins 


\section{Analysis I.9. Comparison I IV MgSO4 versus placebo, Outcome 9 Systolic blood pressure (mmHg).}

Review: Intravenous magnesium sulfate for treating adults with acute asthma in the emergency department

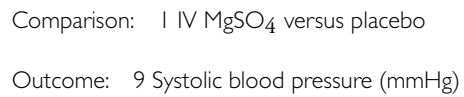

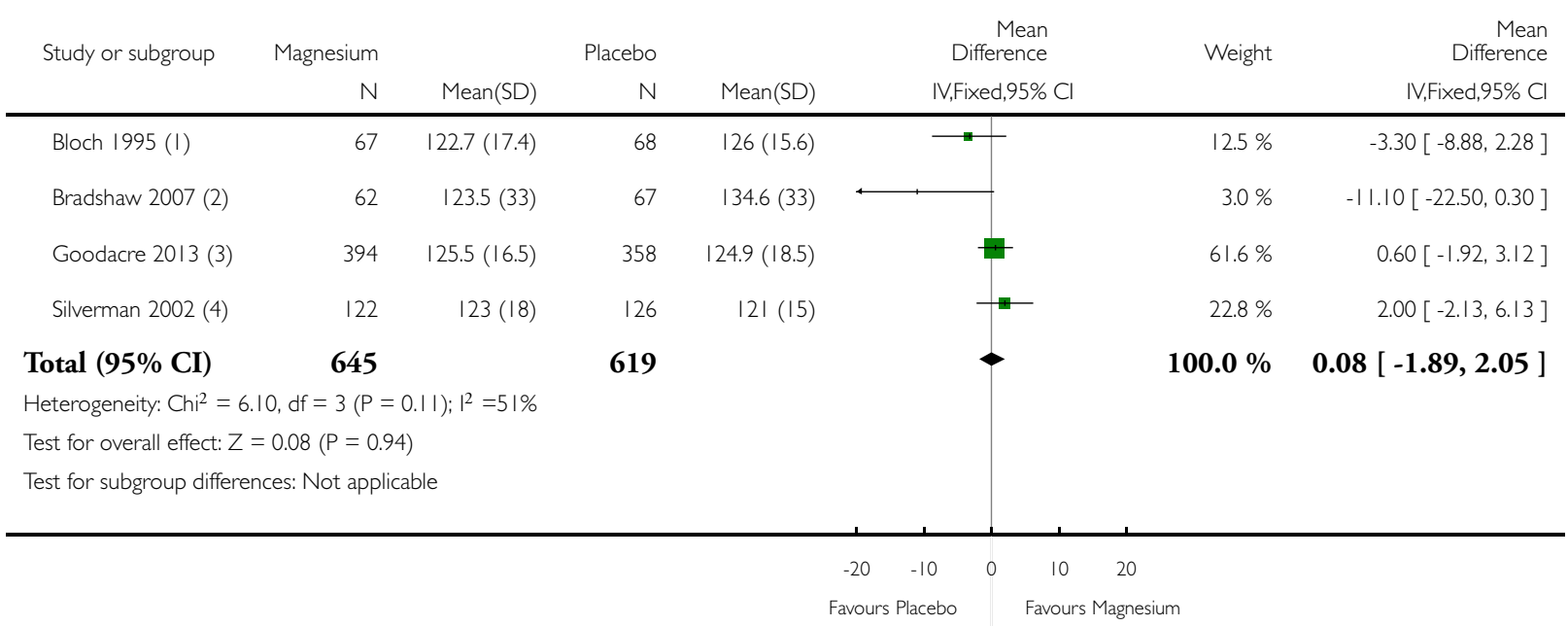
(I) All groups at 120 mins
(2) All groups at 60 mins. SD estimated from $p$ value.
(3) at 120 mins
(4) at 240 mins 


\section{Analysis I.I0. Comparison I IV MgSO4 versus placebo, Outcome 10 FEVI (\% predicted).}

Review: Intravenous magnesium sulfate for treating adults with acute asthma in the emergency department

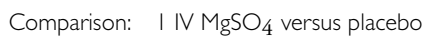

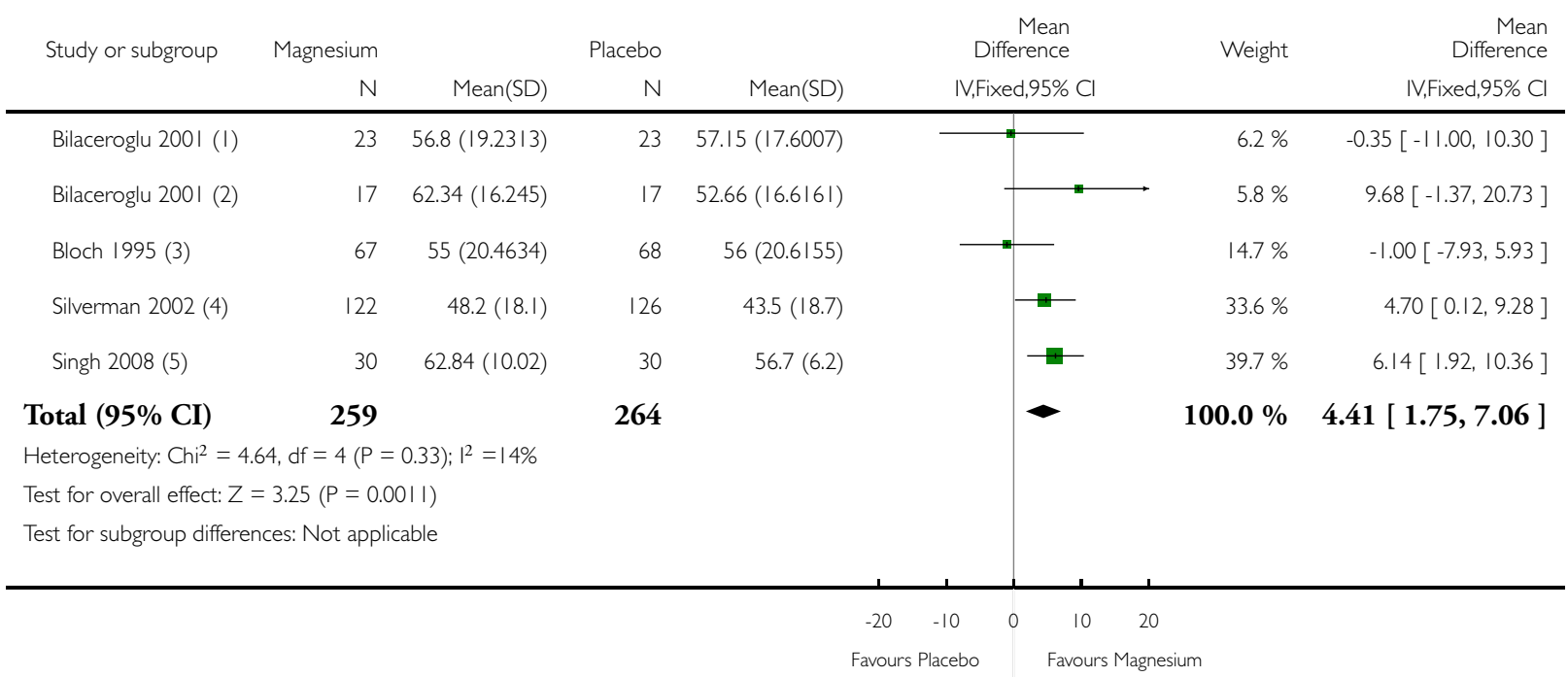
( I) Moderate at 180 mins
(2) Severe at 180 mins
(3) All groups at 120 mins. SEM calculated from graph.
(4) at 240 mins
(5) at 120 mins 


\section{Analysis I.I I. Comparison I IV MgSO4 versus placebo, Outcome I I PEF (\% predicted).}

Review: Intravenous magnesium sulfate for treating adults with acute asthma in the emergency department

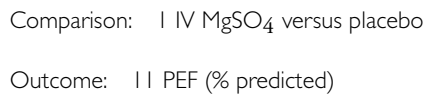

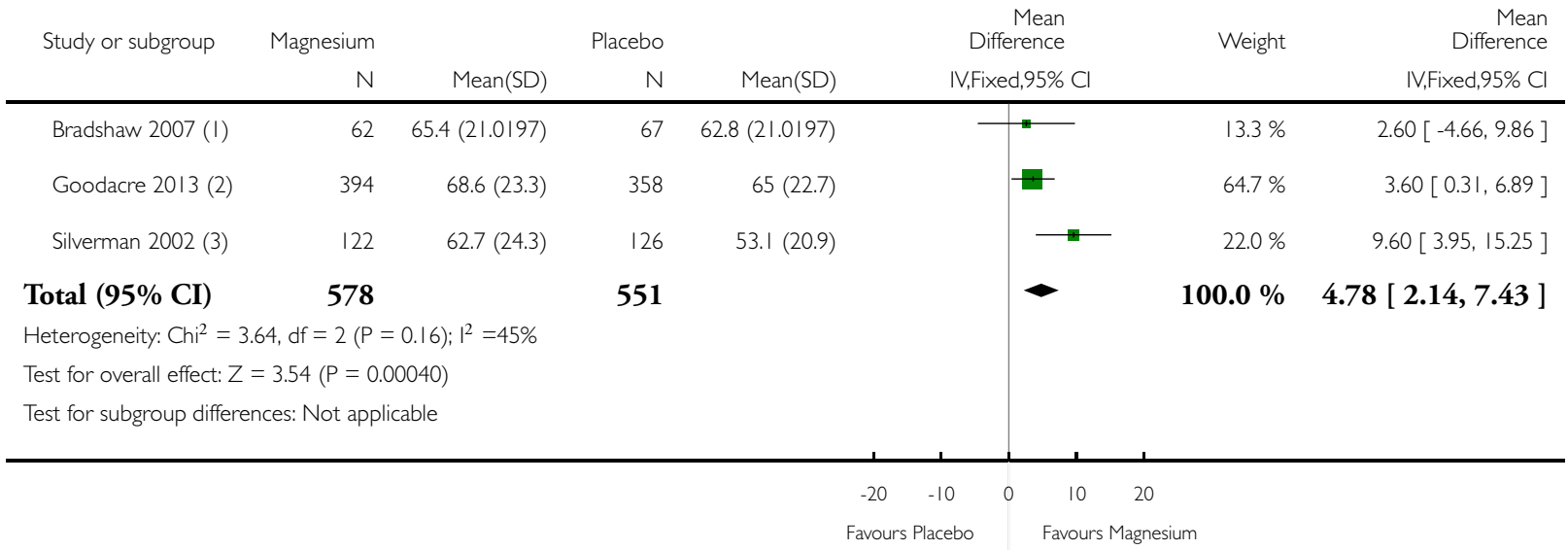
(I) All groups at 60 mins
(2) at 120 mins
(3) at 240 mins 


\section{Analysis I.I2. Comparison I IV MgSO4 versus placebo, Outcome I2 PEF (L/min).}

Review: Intravenous magnesium sulfate for treating adults with acute asthma in the emergency department

Comparison: I $\mathrm{N} \mathrm{MgSO}_{4}$ versus placebo

Outcome: $12 \mathrm{PEF}(\mathrm{L} / \mathrm{min})$

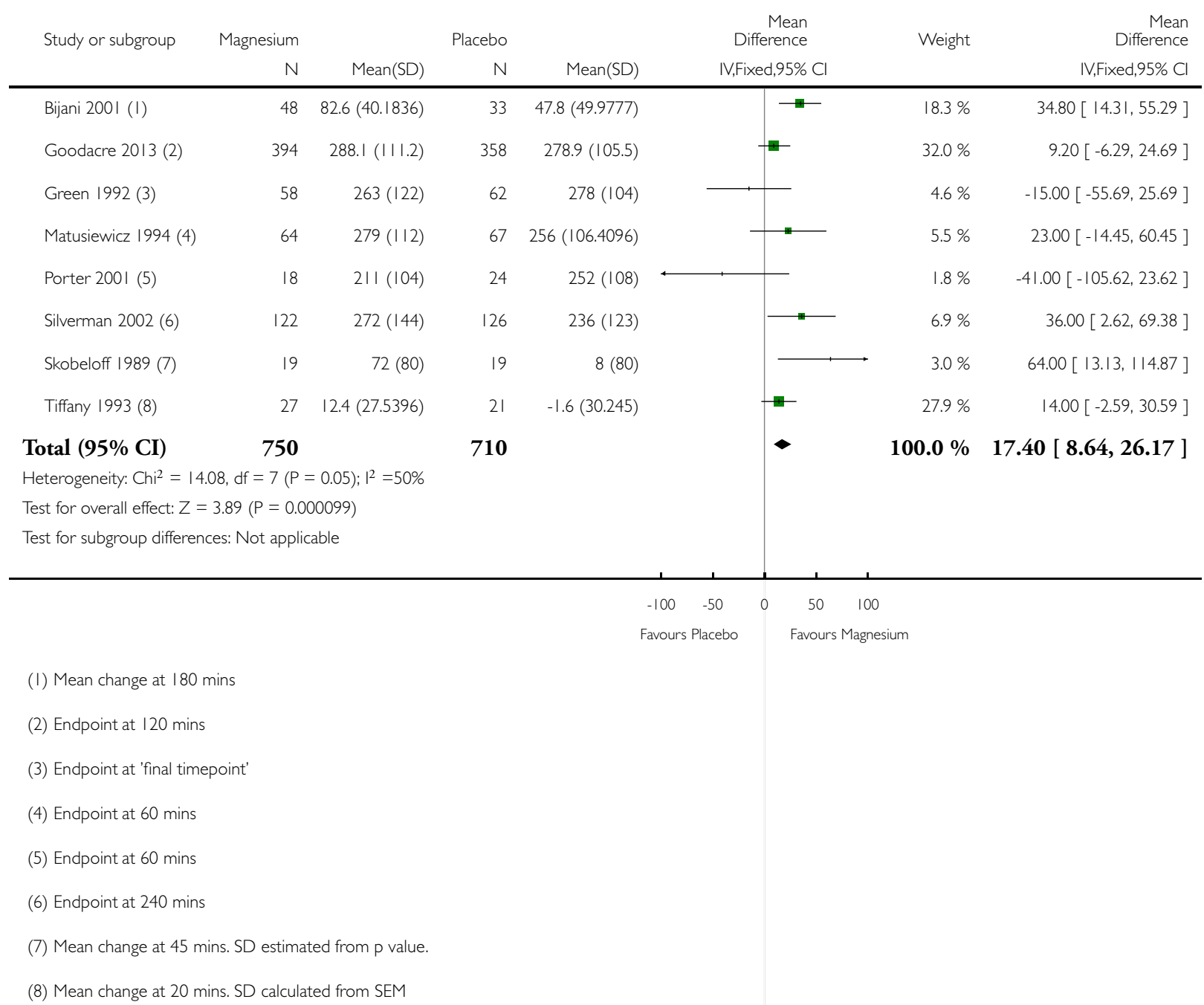




\section{Analysis I.13. Comparison I IV MgSO4 versus placebo, Outcome I3 Borg Dyspnoea Scale score.}

Review: Intravenous magnesium sulfate for treating adults with acute asthma in the emergency department

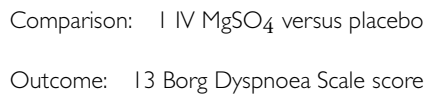

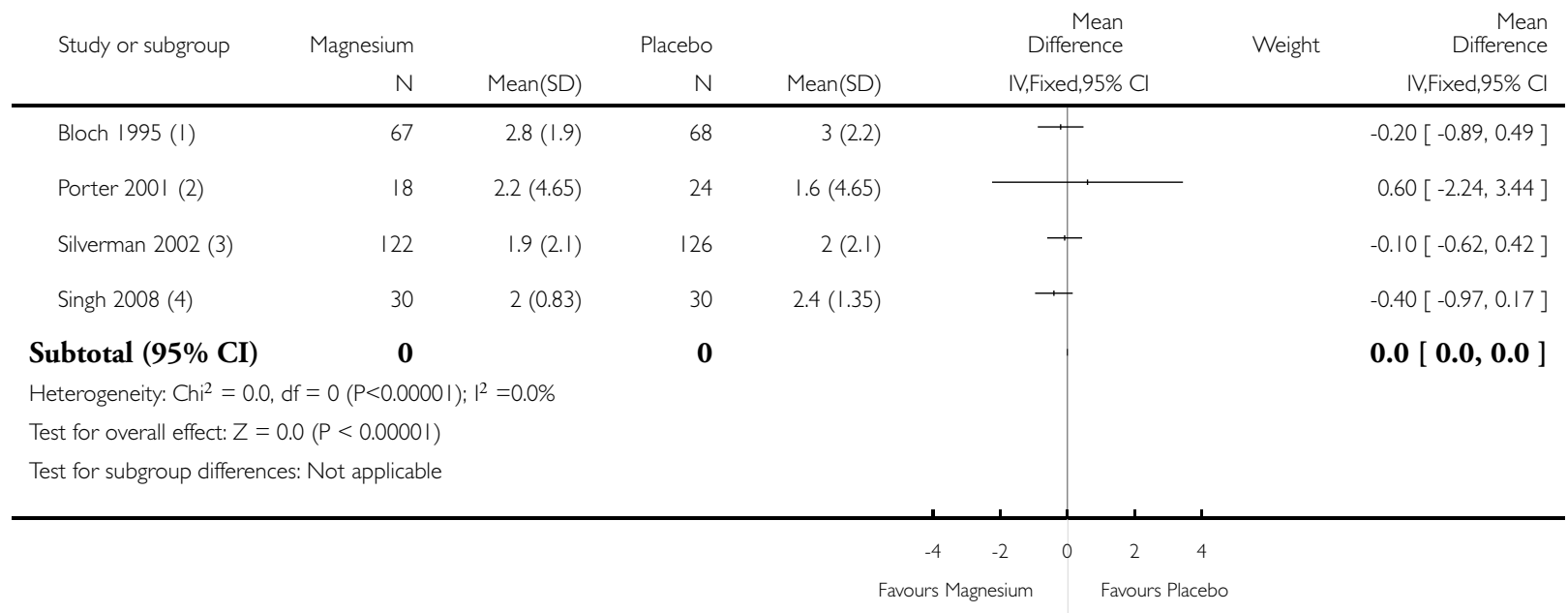

(1) Borg Dyspnoea Scale at 120 mins

(2) Borg Dyspnoea Scale at 60 mins; SDs estimated from exact p-value

(3) Borg Dyspnoea Scale at 240 mins

(4) Borg Dyspnoea Scale at 120 mins 


\section{Analysis 2.I. Comparison 2 IV MgSO4 versus placebo (subgroup and sensitivity analyses), Outcome I Hospital admissions (by severity).}

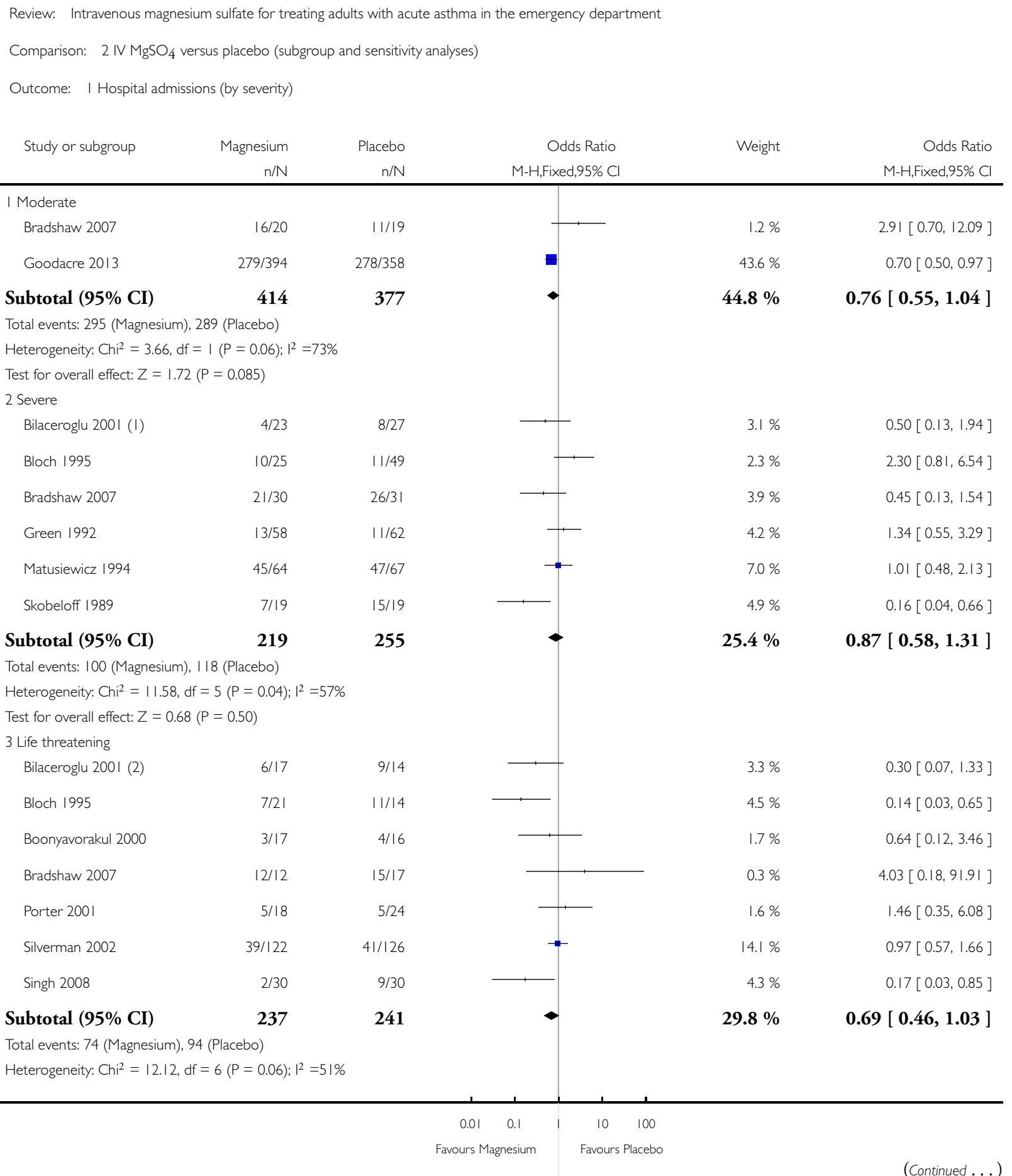




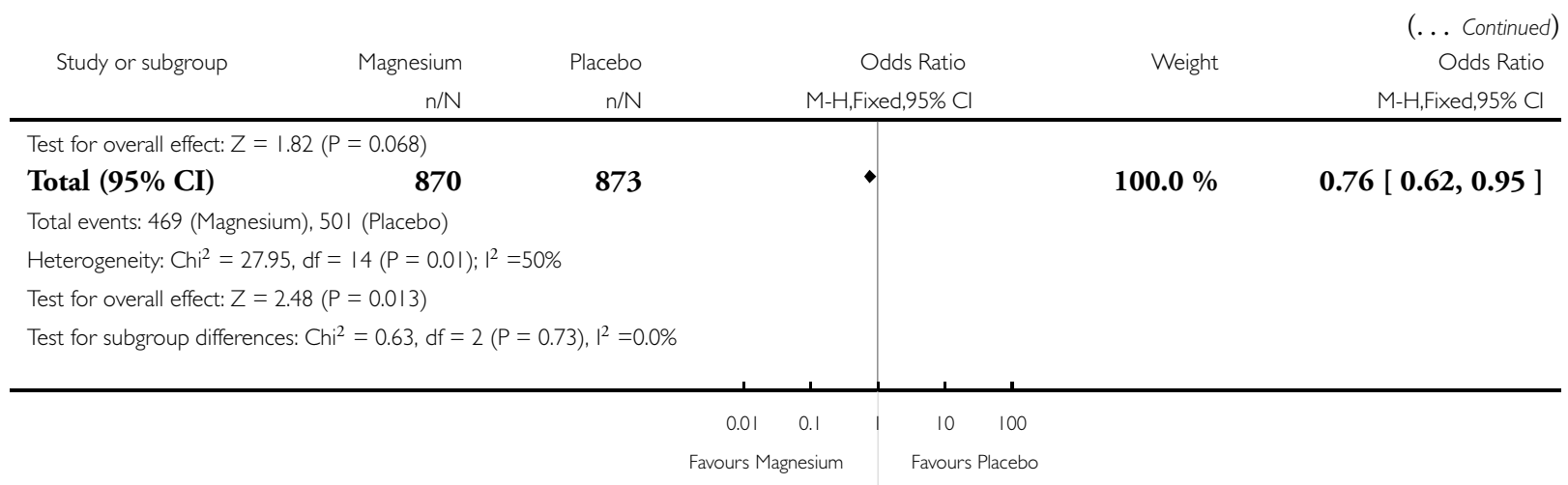

( I) Moderate

(2) Severe

\section{Analysis 2.2. Comparison 2 IV MgSO4 versus placebo (subgroup and sensitivity analyses), Outcome 2} Hospital admissions (by co-medications).

Review: Intravenous magnesium sulfate for treating adults with acute asthma in the emergency department

Comparison: $2 \mathrm{IV} \mathrm{MgSO}_{4}$ versus placebo (subgroup and sensitivity analyses)

Outcome: 2 Hospital admissions (by co-medications)

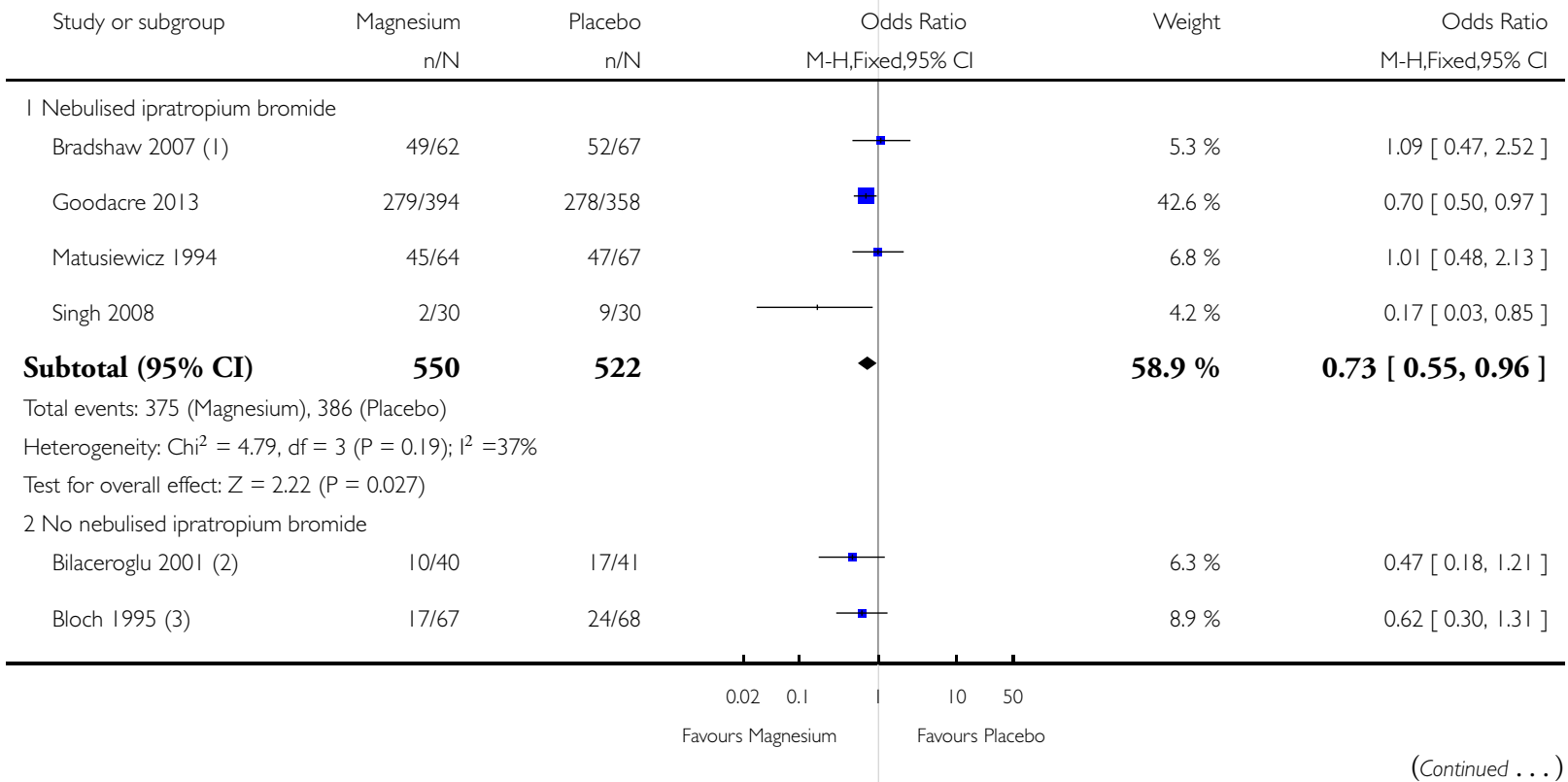




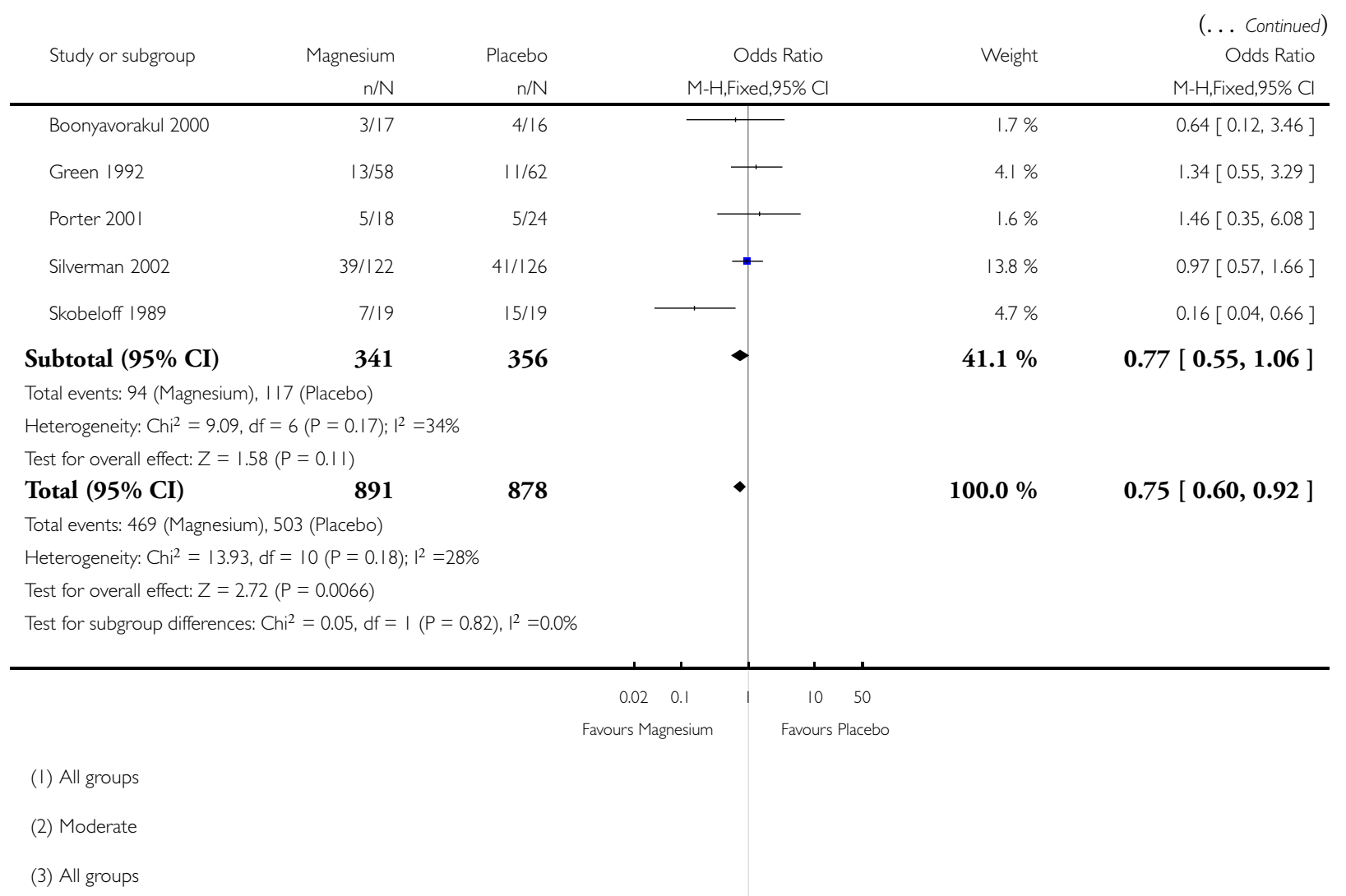


Analysis 2.3. Comparison 2 IV MgSO4 versus placebo (subgroup and sensitivity analyses), Outcome 3 Hospital admissions (risk of bias sensitivity).

Review: Intravenous magnesium sulfate for treating adults with acute asthma in the emergency department

Comparison: $2 \mathrm{IV} \mathrm{MgSO}_{4}$ versus placebo (subgroup and sensitivity analyses)

Outcome: 3 Hospital admissions (risk of bias sensitivity)

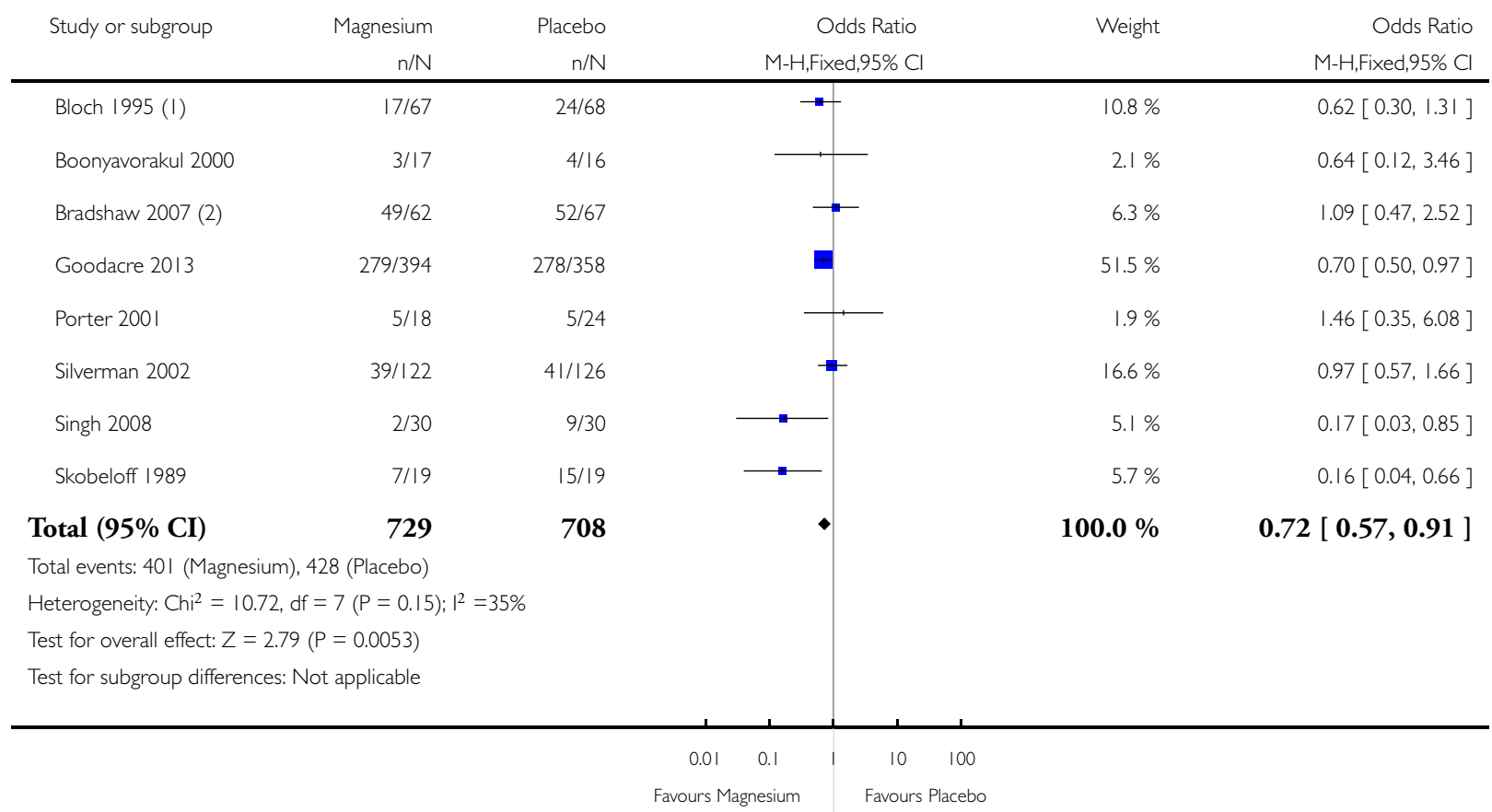

( I) All groups

(2) All groups 
Analysis 2.4. Comparison 2 IV MgSO4 versus placebo (subgroup and sensitivity analyses), Outcome 4 Hospital admissions (unpublished sensitivity).

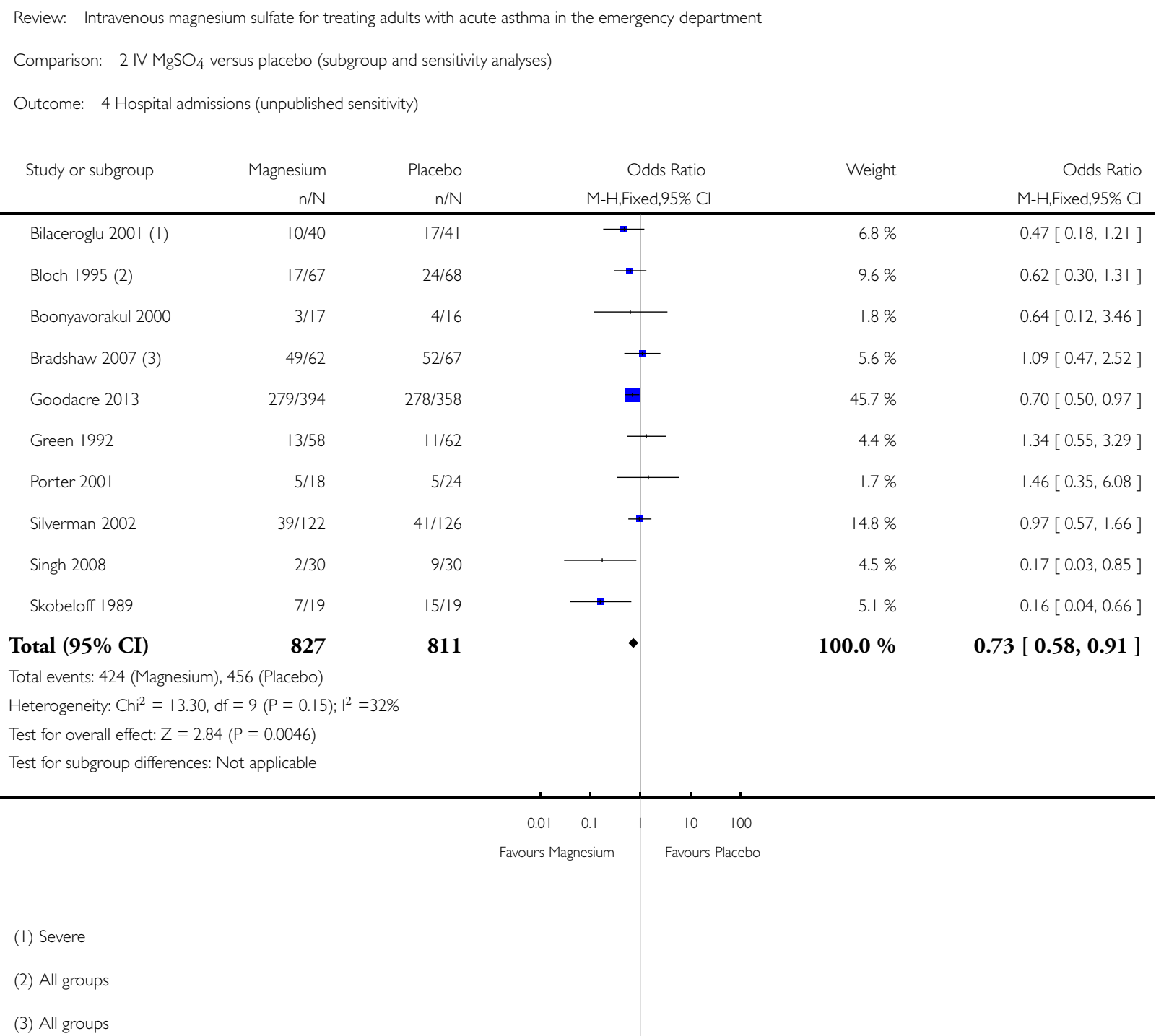




\section{Analysis 2.5. Comparison 2 IV MgSO4 versus placebo (subgroup and sensitivity analyses), Outcome 5 PEF} $\%$ predicted (Goodacre change score sensitivity).

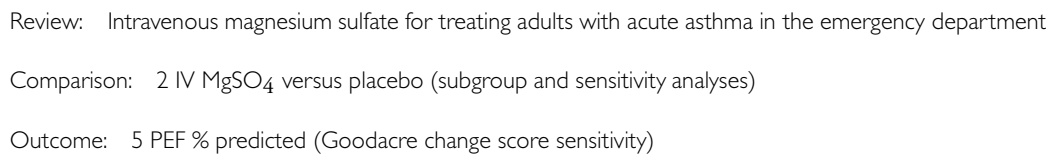

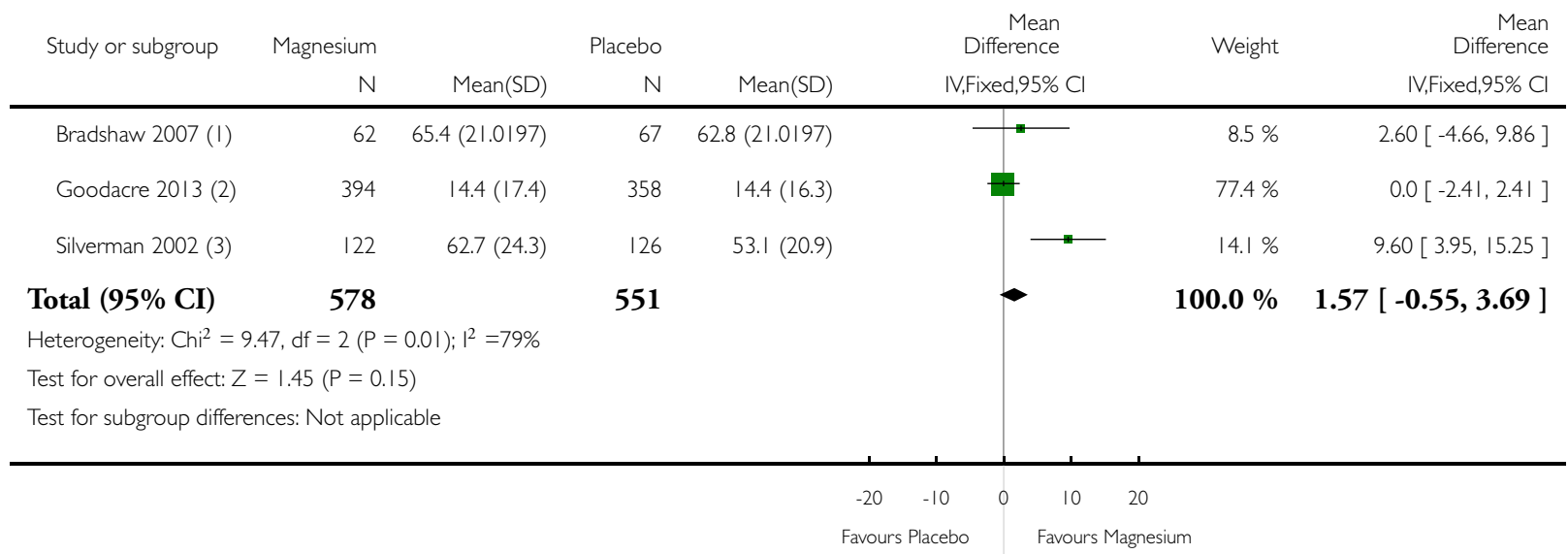
(I) All groups at 60 mins
(2) at 120 mins
(3) at 240 mins 


\section{Analysis 2.6. Comparison 2 IV MgSO4 versus placebo (subgroup and sensitivity analyses), Outcome 6 PEF L/min (Goodacre change score sensitivity).}

Review: Intravenous magnesium sulfate for treating adults with acute asthma in the emergency department

Comparison: $2 \mathrm{IV} \mathrm{MgSO}_{4}$ versus placebo (subgroup and sensitivity analyses)

Outcome: $6 \mathrm{PEF}$ L/min (Goodacre change score sensitivity)

\begin{tabular}{|c|c|c|c|c|c|c|c|c|c|}
\hline \multirow{3}{*}{ Study or subgroup } & \multirow{2}{*}{$\begin{array}{r}\text { Magnesium } \\
\mathrm{N}\end{array}$} & \multicolumn{3}{|c|}{ Placebo } & \multirow{2}{*}{\multicolumn{3}{|c|}{$\begin{array}{c}\text { Mean } \\
\text { Difference } \\
\text { IV,Fixed,95\% Cl }\end{array}$}} & \multirow[t]{2}{*}{ Weight } & \multirow{2}{*}{$\begin{array}{r}\text { Mean } \\
\text { Difference } \\
\text { IV,Fixed,95\% Cl }\end{array}$} \\
\hline & & Mean(SD) & $\mathrm{N}$ & Mean(SD) & & & & & \\
\hline & 48 & $82.6(40.1836)$ & 33 & $47.8(49.9777)$ & & & $\longrightarrow$ & $12.9 \%$ & $34.80[\mid 4.31,55.29]$ \\
\hline Goodacre 2013 (2) & 394 & $61(73.6)$ & 358 & $62.5(69.4)$ & & & + & $51.9 \%$ & $-1.50[-11.72,8.72]$ \\
\hline Green 1992 (3) & 58 & $263(122)$ & 62 & $278(104)$ & & & & $3.3 \%$ & $-15.00[-55.69,25.69]$ \\
\hline Matusiewicz I994 (4) & 64 & $279(112)$ & 67 & $256(106.4096)$ & & & & $3.9 \%$ & $23.00[-14.45,60.45]$ \\
\hline Porter 200। (5) & 18 & $211(104)$ & 24 & $252(108)$ & $\longleftarrow$ & & & $1.3 \%$ & $-41.00[-105.62,23.62]$ \\
\hline Silverman 2002 (6) & 122 & $272(144)$ & 126 & $236(123)$ & & & & $4.9 \%$ & $36.00[2.62,69.38]$ \\
\hline Skobeloff 1989 (7) & 19 & $72(80)$ & 19 & $8(80)$ & & & & $2.1 \%$ & $64.00[13.13,114.87]$ \\
\hline Tiffany $1993(8)$ & 27 & $12.4(27.5396)$ & 21 & $-1.6(30.245)$ & & & 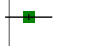 & $19.7 \%$ & $14.00[-2.59,30.59]$ \\
\hline Total (95\% CI) & 750 & & 710 & & & & $\bullet$ & $100.0 \%$ & $9.44[2.07,16.81]$ \\
\hline \multicolumn{10}{|c|}{ Heterogeneity: $\mathrm{Chi}^{2}=21.65, \mathrm{df}=7(\mathrm{P}=0.003) ; \mathrm{I}^{2}=68 \%$} \\
\hline \multicolumn{10}{|c|}{ Test for overall effect: $Z=2.5 \mathrm{I}(P=0.012)$} \\
\hline \multicolumn{10}{|c|}{ Test for subgroup differences: Not applicable } \\
\hline & & & & & -100 & -50 & 50 & 100 & \\
\hline \multicolumn{10}{|c|}{ Favours Placebo } \\
\hline
\end{tabular}
(I) Mean change at 180 mins
(2) Endpoint at 120 mins
(3) Endpoint at 'final timepoint'
(4) Endpoint at 60 mins
(5) Endpoint at 60 mins
(6) Endpoint at 240 mins
(7) Mean change at 45 mins. SD estimated from $p$ value.
(8) Mean change at 20 mins. SD calculated from SEM 
ADDITIONAL TABLES

Table 1. Summary of guideline treatment recommendations in acute asthma (adults)

\begin{tabular}{|c|c|c|c|c|}
\hline & BTS/SIGN & GINA & NACA & NAEPP \\
\hline Oxygen & $\sqrt{ }$ & $\sqrt{ }$ & $\sqrt{ }$ & $\sqrt{ }$ \\
\hline Inhaled beta 2 -agonist & $\sqrt{ }$ & $\sqrt{ }$ & $\sqrt{ }$ & $\sqrt{ }$ \\
\hline Inhaled antimuscarinic & $\sqrt{ }$ & $\sqrt{ }$ & $\sqrt{ }$ & $\sqrt{ }$ \\
\hline Sytemic corticosteroids & $\sqrt{ }$ & $\sqrt{ }$ & $\sqrt{ }$ & $\sqrt{ }$ \\
\hline IV beta 2 -agonist & $\begin{array}{l}(\sqrt{ }) \\
\text { if nebulised form cannot } \\
\text { be used } \\
\text { reliably }\end{array}$ & $\mathrm{x}$ & $\begin{array}{l}\sqrt{ } \\
\text { if no response to inhaled } \\
\text { form }\end{array}$ & $\mathrm{x}$ \\
\hline IV $\mathrm{MgSO}_{4}$ & $\sqrt{ }$ & $\sqrt{ }$ & $\begin{array}{l}\sqrt{ } \\
\text { IV or nebulised }\end{array}$ & $\sqrt{ }$ \\
\hline Heliox & $\mathrm{x}$ & $\mathrm{x}$ & $\mathrm{x}$ & $\sqrt{ }$ \\
\hline $\begin{array}{l}\text { IV aminophylline/ } \\
\text { theophylline }\end{array}$ & $\begin{array}{l}(\sqrt{ }) \\
\text { limited evidence, only } \\
\text { after senior consultation }\end{array}$ & $\begin{array}{l}(\sqrt{ }) \\
\text { if inhaled beta2-agonist } \\
\text { unavailable }\end{array}$ & $\begin{array}{l}(\sqrt{ }) \\
\text { as an alternative to IV } \\
\text { beta2-agonist }\end{array}$ & $\mathrm{x}$ \\
\hline
\end{tabular}

Table 2. Summary characteristics of included studies

\begin{tabular}{|c|c|c|c|c|c|c|}
\hline Study ID & $\begin{array}{l}\text { Country (cen- } \\
\text { tres) }\end{array}$ & Total N & Study design & Age range (years) & Dose (infusion) & Co-medications \\
\hline Bijani 2001 & Iran & 81 & $\mathrm{R}, \mathrm{DB}, \mathrm{PC}$ & $12-85$ & $\begin{array}{l}25 \mathrm{mg} / \mathrm{kg}(30 \mathrm{~min}- \\
\text { utes) }\end{array}$ & $\begin{array}{l}\text { Nebulised SABA, IV } \\
\text { xanthine, IV corti- } \\
\text { costeroid, } \mathrm{O}_{2}\end{array}$ \\
\hline Bilaceroglu 2001 & Turkey & 81 & $\mathrm{R}, \mathrm{SB}, \mathrm{PC}$ & $6-65$ & $1 \mathrm{~g}$ or $2 \mathrm{~g}$ (unclear) & $\begin{array}{l}\mathrm{O}_{2}\left(\text { if } \mathrm{PaO}_{2} \text { was }<60\right. \\
\mathrm{mmHg} \text { ) }\end{array}$ \\
\hline Bloch 1995 & USA (2) & 149 & $\mathrm{R}, \mathrm{DB}, \mathrm{PC}$ & $18-65$ & $2 \mathrm{~g}$ (20 minutes) & $\begin{array}{l}\text { Nebulised SABA, IV } \\
\text { corticosteroid }\end{array}$ \\
\hline $\begin{array}{l}\text { Boonyavorakul } \\
2000\end{array}$ & Thailand (1) & 34 & $\mathrm{R}, \mathrm{DB}, \mathrm{PC}$ & $15-65$ & $2 \mathrm{~g}$ (unclear) & $\begin{array}{l}\text { Nebulised SABA, IV } \\
\text { corticosteroid, } \mathrm{O}_{2} \text { if } \\
\text { necessary }\end{array}$ \\
\hline
\end{tabular}

Intravenous magnesium sulfate for treating adults with acute asthma in the emergency department (Review)

Copyright @ 2014 The Cochrane Collaboration. Published by John Wiley \& Sons, Ltd. 
Table 2. Summary characteristics of included studies

(Continued)

\begin{tabular}{|c|c|c|c|c|c|c|}
\hline Bradshaw 2007 & Scotland (1) & 129 & $\mathrm{R}, \mathrm{DB}, \mathrm{PC}$ & $16+$ & $1.2 \mathrm{~g}$ (15 minutes) & $\begin{array}{l}\text { Nebulised SABA, } \\
\text { nebulised LAMA, IV } \\
\text { corticosteroid, } \mathrm{O}_{2}\end{array}$ \\
\hline $\begin{array}{l}\text { Del Castillo } \\
\text { Rueda } 1991\end{array}$ & Spain (1) & 16 & $\mathrm{R}, \mathrm{DB}, \mathrm{PC}$ & ? & $1.5 \mathrm{~g}$ (15 minutes) & $\begin{array}{l}\text { Nebulised SABA, IV } \\
\text { corticosteroid }\end{array}$ \\
\hline Goodacre 2013 & UK (34) & 1109 & $\mathrm{R}, \mathrm{DB}, \mathrm{PC}$ & $16+$ & $2 \mathrm{~g}$ (20 minutes) & $\begin{array}{l}\text { Nebulised SABA and } \\
\text { LAMA, oral corticos- } \\
\text { teroid, } \mathrm{O}_{2}\end{array}$ \\
\hline Green 1992 & USA (1) & 137 & ? & $18-65$ & $2 \mathrm{~g}$ (20 minutes) & $\begin{array}{l}\text { Nebulised SABA, IV } \\
\text { corticosteroid (others } \\
\text { at physician's discre- } \\
\text { tion), } \mathrm{O}_{2}\end{array}$ \\
\hline $\begin{array}{l}\text { Matusiewicz } \\
1994\end{array}$ & UK (1) & 131 & $\mathrm{R}$ & Adults & $1.2 \mathrm{~g}$ (15 minutes) & $\begin{array}{l}\text { Nebulised SABA and } \\
\text { LAMA, } \mathrm{O}_{2} \text {, IV corti- } \\
\text { costeroid (discre- } \\
\text { tionary xanthine) }\end{array}$ \\
\hline Porter 2001 & USA (1) & 42 & $\mathrm{R}, \mathrm{DB}, \mathrm{PC}$ & $18-55$ & $2 \mathrm{~g}$ (unclear) & $\begin{array}{l}\text { Nebulised SABA, IV } \\
\text { corticosteroid, } \mathrm{O}_{2}\end{array}$ \\
\hline Silverman 2002 & USA (8) & 248 & $\mathrm{R}, \mathrm{DB}, \mathrm{PC}$ & $18-60$ & $2 \mathrm{~g}$ (15 minutes) & $\begin{array}{l}\text { Nebulised SABA, IV } \\
\text { corticosteroid, } \mathrm{O}_{2}\end{array}$ \\
\hline Singh 2008 & India (1) & 70 & $\mathrm{R}, \mathrm{SB}, \mathrm{PC}$ & $18-60$ & $2 \mathrm{~g}$ (20 minutes) & $\begin{array}{l}\text { Nebulised SABA, } \\
\text { nebulised LAMA, IV } \\
\text { corticosteroid, } \mathrm{O}_{2}\end{array}$ \\
\hline Skobeloff 1989 & USA (1) & 38 & $\mathrm{R}, \mathrm{DB}, \mathrm{PC}$ & $18-70$ & $1.2 \mathrm{~g}$ (20 minutes) & $\begin{array}{l}\text { Nebulised SABA, IV } \\
\text { metaproterenol, IV } \\
\text { xanthine }\end{array}$ \\
\hline Tiffany 1993 & USA (1) & 48 & $\mathrm{R}, \mathrm{DB}, \mathrm{PC}$ & $18-60$ & $2 \mathrm{~g}$ (20 minutes) & $\begin{array}{l}\text { Nebulised SABA, IV } \\
\text { corticosteroid, SABA } \\
\text { aerosol, IV xanthine }\end{array}$ \\
\hline
\end{tabular}

DB: Double-blind; IV: Intravenous; LAMA: Long-acting muscarinic antagonist; $\mathrm{O}_{2}$ : Oxygen; $\mathrm{PaO}_{2}$ : Partial pressure of oxygen in arterial blood; PC: Placebo-controlled; R: Randomised; SABA: Short-acting beta 2 -agonist; SB: Single-blind.

Bilaceroglu 2001 included adults and children, but only 10 participants were younger than 18 years of age; mean age was 36 ( \pm 13.4 ) years. 
Table 3. Baseline severity criteria

\begin{tabular}{|c|c|c|c|c|c|c|}
\hline Study ID & Inclusion & $\begin{array}{l}\text { Category } \\
\text { within trial }\end{array}$ & PEF & $\mathbf{F E V}_{1}$ & Other & Classification* \\
\hline Bijani 2001 & $\begin{array}{l}\mathrm{PEF}<200 \text { af- } \\
\text { ter bronchodila- } \\
\text { tor and corticos- } \\
\text { teroids }\end{array}$ & All participants & $31 \%$ predicted & - & $\mathrm{RR}=35 \mathrm{rpm}$ & Life threatening \\
\hline \multirow[t]{2}{*}{ Bilaceroglu 2001} & \multirow{2}{*}{$\begin{array}{l}\text { PEF increasing < } \\
50 \% \text { or } \\
\mathrm{FEV}_{1} \\
<75 \% \text { predicted } \\
\text { after single } \\
\text { salbutamol }\end{array}$} & Moderate & $57 \%$ predicted & $43 \%$ predicted & $\begin{array}{l}\mathrm{PaO}_{2}=69 \\
\mathrm{mmHg}\end{array}$ & Severe \\
\hline & & Severe & $32 \%$ predicted & $32 \%$ predicted & $\begin{array}{l}\mathrm{PaO}_{2}=64 \\
\mathrm{mmHg}\end{array}$ & Life threatening \\
\hline \multirow[t]{2}{*}{ Bloch 1995} & \multirow{2}{*}{$\begin{array}{l}\mathrm{FEV}_{1} \\
<75 \% \text { predicted } \\
\text { after single } \\
\text { salbutamol }\end{array}$} & Moderate & - & $40 \%$ predicted & - & Severe \\
\hline & & Severe & - & $20 \%$ predicted & - & Life threatening \\
\hline $\begin{array}{l}\text { Boonyavorakul } \\
2000\end{array}$ & $\begin{array}{l}\text { Composite } \\
\text { severity score }\end{array}$ & All participants & - & - & $\begin{array}{l}\mathrm{RR}=33 \mathrm{rpm} \\
\mathrm{HR}=125 \mathrm{bpm}\end{array}$ & Life threatening \\
\hline \multirow[t]{3}{*}{ Bradshaw 2007} & \multirow[t]{3}{*}{$\begin{array}{l}\mathrm{PEF}<75 \% \text { pre- } \\
\text { dicted }\end{array}$} & Moderate & $\begin{array}{l}60 \% \text { predicted } \\
248 \mathrm{~L} / \mathrm{min}\end{array}$ & - & $\mathrm{HR}=102 \mathrm{bpm}$ & Moderate \\
\hline & & Severe & $\begin{array}{l}41 \% \text { predicted } \\
170 \mathrm{~L} / \mathrm{min}\end{array}$ & - & $\mathrm{HR}=109 \mathrm{bpm}$ & Severe \\
\hline & & Life threatening & $\begin{array}{l}23 \% \text { predicted } \\
96 \mathrm{~L} / \mathrm{min}\end{array}$ & - & $\mathrm{HR}=116 \mathrm{bpm}$ & Life threatening \\
\hline $\begin{array}{l}\text { Del Castillo } \\
\text { Rueda } 1991\end{array}$ & - & All participants & - & - & - & $\begin{array}{l}\text { Unknown (not in } \\
\text { analysis) }\end{array}$ \\
\hline Goodacre 2013 & $\begin{array}{l}\text { One or more } \\
\text { of the following: } \\
\mathrm{PEF}<50 \% \text { pre- } \\
\text { dicted; } \mathrm{RR}>25 \text {, } \\
\mathrm{HR}>110 \\
\text { or cannot com- } \\
\text { plete sen- } \\
\text { tences, but not } \\
\text { life threatening }\end{array}$ & All participants & $\begin{array}{l}52 \% \text { predicted } \\
433 \mathrm{~L} / \mathrm{min}\end{array}$ & - & - & Moderate \\
\hline Green 1992 & - & All participants & $143 \mathrm{~L} / \mathrm{min}$ & - & $\begin{array}{l}\mathrm{RR}=29 \mathrm{rpm} \\
\mathrm{HR}=108 \mathrm{bpm}\end{array}$ & Severe \\
\hline
\end{tabular}


Table 3. Baseline severity criteria

(Continued)

\begin{tabular}{|c|c|c|c|c|c|c|}
\hline $\begin{array}{l}\text { Matusiewicz } \\
1994\end{array}$ & $\begin{array}{l}\mathrm{PEF}<250 \mathrm{~L} / \\
\text { min or }<50 \% \\
\text { predicted }\end{array}$ & All participants & - & - & - & Severe \\
\hline Porter 2001 & $\begin{array}{l}\mathrm{PEF}<100 \mathrm{~L} / \\
\text { min or }<25 \% \\
\text { predicted }\end{array}$ & All participants & $88.5 \mathrm{~L} / \mathrm{min}$ & - & $\begin{array}{l}\mathrm{RR}=31 \mathrm{rpm} \\
\mathrm{HR}=110 \mathrm{bpm}\end{array}$ & Life threatening \\
\hline Silverman 2002 & $\begin{array}{l}\mathrm{FEV}_{1}<30 \% \\
\text { predicted }\end{array}$ & All participants & $\begin{array}{l}27 \% \text { predicted } \\
143 \mathrm{~L} / \mathrm{min}\end{array}$ & $23 \%$ predicted & $\mathrm{HR}=102 \mathrm{bpm}$ & Life threatening \\
\hline Singh 2008 & $\begin{array}{l}\mathrm{FEV}_{1}<30 \% \\
\text { predicted }\end{array}$ & All participants & $22 \%$ predicted & $38 \%$ predicted & $\mathrm{HR}=127 \mathrm{bpm}$ & Life threatening \\
\hline Skobeloff 1989 & $\begin{array}{l}\mathrm{PEF}<200 \mathrm{~L} / \\
\text { min, not dou- } \\
\text { bled after beta- } \\
\text { agonist, IV cor- } \\
\text { ticosteroid, theo- } \\
\text { phylline }\end{array}$ & All participants & $\begin{array}{l}-150 \mathrm{~L} / \mathrm{min} \\
\text { (from graph) }\end{array}$ & - & $\begin{array}{l}\mathrm{HR}=-100 \mathrm{bpm} \\
\text { from graph } \\
\mathrm{RR}=-28\end{array}$ & Severe \\
\hline Tiffany 1993 & $\begin{array}{l}\mathrm{PEF} \\
<200 \mathrm{~L} / \mathrm{min}, \text { not } \\
\text { doubled after al- } \\
\text { buterol } \times 2\end{array}$ & All participants & $115 \mathrm{~L} / \mathrm{min}$ & $0.95 \mathrm{~L}$ & - & Life threatening \\
\hline
\end{tabular}

bpm: Beats per minute; $\mathrm{FEV}_{1}$ : Forced expiratory volume in 1 second; HR: Heart rate; $\mathrm{PaO}_{2}$ : Partial pressure of oxygen in arterial blood; PEF: Peak expiratory flow; rpm: Respirations per minute;RR: Respiration rate..

Classification for the severity subgroup analysis was assigned by an independent clinician and was cross-checked with study authors' own judgements. Discrepancies were resolved through discussion. 
A P PENDICES

\section{Appendix I. Sources and search methods for the Cochrane Airways Group Specialised Register (CAGR)}

\section{Electronic searches: core databases}

\begin{tabular}{ll}
\hline Database & Frequency of search \\
\hline CENTRAL (The Cochrane Library) & Monthly \\
\hline MEDLINE (Ovid) & Weekly \\
\hline EMBASE (Ovid) & Weekly \\
\hline PsycINFO (Ovid) & Monthly \\
\hline CINAHL (EBSCO) & Monthly \\
\hline AMED (EBSCO) & Monthly \\
\hline
\end{tabular}

Handsearches: core respiratory conference abstracts

\begin{tabular}{l|l}
\hline Conference & Years searched \\
\hline American Academy of Allergy, Asthma and Immunology (AAAAI) & 2001 onwards \\
\hline American Thoracic Society (ATS) & 2001 onwards \\
\hline Asia Pacific Society of Respirology (APSR) & 2004 onwards \\
\hline British Thoracic Society Winter Meeting (BTS) & 2000 onwards \\
\hline Chest Meeting & 2003 onwards \\
\hline European Respiratory Society (ERS) & $1992,1994,2000$ onwards \\
\hline International Primary Care Respiratory Group Congress (IPCRG) & 2002 onwards \\
\hline Thoracic Society of Australia and New Zealand (TSANZ) & 1999 onwards \\
\hline
\end{tabular}




\section{Asthma search}

1. exp Asthma/

2. asthma\$.mp.

3. (antiasthma $\$$ or anti-asthma $\$$ ).mp.

4. Respiratory Sounds/

5. wheez\$.mp.

6. Bronchial Spasm/

7. bronchospas $\$ . m p$.

8. (bronch $\$$ adj3 spasm\$).mp.

9. bronchoconstrict $\$$.mp.

10. exp Bronchoconstriction/

11. (bronch\$ adj3 constrict\$).mp.

12. Bronchial Hyperreactivity/

13. Respiratory Hypersensitivity/

14. ((bronchial $\$$ or respiratory or airway $\$$ or lung $\$$ ) adj3 (hypersensitiv $\$$ or hyperreactiv $\$$ or allerg $\$$ or insufficiency)).mp.

15. ((dust or mite\$) adj3 (allerg\$ or hypersensitiv\$)).mp.

16. or/1-15

\section{Filter to identify RCTs}

1. exp "clinical trial [publication type]"/

2. (randomised or randomised).ab,ti.

3. placebo.ab,ti.

4. dt.fs.

5. randomly.ab,ti.

6. trial.ab,ti.

7. groups.ab,ti.

8. or/1-7

9. Animals/

10. Humans/

11. 9 not (9 and 10)

12. 8 not 11

The MEDLINE strategy and RCT filter are adapted to identify trials in other electronic databases.

\section{Appendix 2. Search strategy to identify relevant trials from the CAGR}

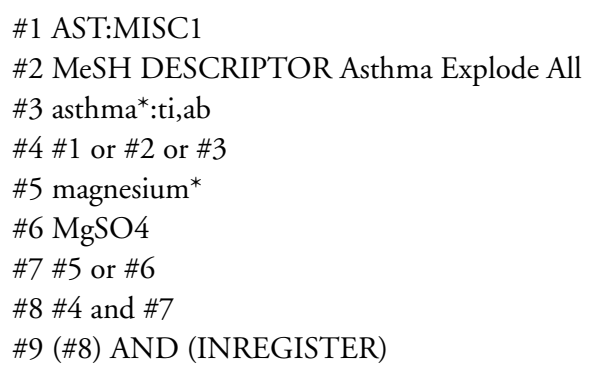


CONTRIBUTIONSOFAUTHORS

All review authors contributed to all aspects of the review.

\section{DECLARATIONSOF INTEREST}

None known.

\section{SOURCES OF SUPPORT}

\section{Internal sources}

- No sources of support supplied

\section{External sources}

- KK, UK

National Institute for Health Research (NIHR). Programme grant funding

\section{DIFFERENCES BETWEEN PROTOCOLANDREVIEW}

We could not carry out the prespecified subgroup analysis based on age, as no studies had a mean participant age above 65 years. For the severity subgroup analysis, we renamed the categories from mild, moderate and severe to moderate, severe and life threatening to fit with BTS/SIGN 2012 classifications. For the co-medications subgroup analysis, we changed the labelling from 'maximal and minimal' to 'with and without ipratropium bromide' so as not to imply preference of one strategy over the other (definitions remained the same). We considered a meta-analysis of $\mathrm{O}_{2}$ saturations to be not viable. We added a post-hoc sensitivity analysis using change from baseline instead of endpoint means from Goodacre 2013, as baseline imbalances were noted in this study. 